University of Rhode Island

DigitalCommons@URI

Open Access Master's Theses

1992

\title{
Handling Missing Data in Time Series Analysis
}

Suzanne M. Colby

University of Rhode Island

Follow this and additional works at: https://digitalcommons.uri.edu/theses

\section{Recommended Citation}

Colby, Suzanne M., "Handling Missing Data in Time Series Analysis" (1992). Open Access Master's Theses. Paper 1571.

https://digitalcommons.uri.edu/theses/1571

This Thesis is brought to you for free and open access by DigitalCommons@URI. It has been accepted for inclusion in Open Access Master's Theses by an authorized administrator of DigitalCommons@URI. For more information, please contact digitalcommons-group@uri.edu. 


\section{HANDLING MISSING DATA IN}

TIME SERIES ANALYSIS

BY

SUZANNE M. COLBY

A THESIS SUBMITTED IN PARTIAL FULFILLMENT OF THE REQUIREMENTS FOR THE DEGREE OF MASTER OF ARTS

IN

PSYCHOLOGY

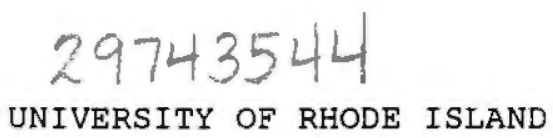

1992 


\section{ABSTRACT}

The nature of time series designs often leads to missing data, due to its requirement of taking a large number of repeated observations on a single experimental unit. There are many methods available for estimating missing observations; some have been borrowed or adapted from univariate methods, while others have been developed specifically for the time series problem. This study compares the effects of four different methodg of data estimation on time series analysis. These methods include: (1) deletion of the missing data points; (2) substitution of the mean of the series; (3) substitution of the mean of the observations adjacent to each missing data point; and (4) the use of a maximum likelihood algorithm to estimate the missing data points. Time series data were simulated for 50 different combinations of autocorrelation, slope, and proportion of data missing. Original series were 100 data points in length. Methods of data point estimation were compared in terms of the resulting time series analysis estimates of level, error variance, degree of autocorrelation, and slope in the series.

Major findings include: (1) the maximum likelihood approach is consistently accurate under all conditions tested; (2) the mean of the series is the least accurate approach overall; and (3) using the mean of the adjacent observations also has significant limitations. Results also indicate that conditions of severe negative autocorrelation in the time series lead to worse estimates of error variance, when using deletion or mean of the adjacent observations. Finally, series that have a non-zero slope result in less accurate parameter estimation. 


\section{ACKNOWLEDGMENTS}

I would like to thank the members of my thesis committee, Jim Prochaska and Jim Heltshe, and especially wayne Velicer, whose high standards, dedication, and wisdom are an inspiration. I am truly fortunate to work with a major professor of his caliber.

I would also like to thank John Harrop, who provided invaluable assistance in figuring out the data generation program and the nuances of getting SAS/ETs to estimate slope. John's help easily saved me months of work on this project. I am also indebted to the staff at the Academic Computer Center at the University of Rhode Island, who were all extremely helpful and efficient.

Finally, I want to thank my husband, Jack, for his encouragement and his sense of perspective throughout. 


\section{TABLE OF CONTENTS}

page

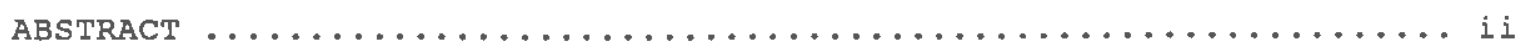

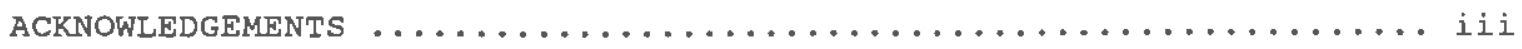

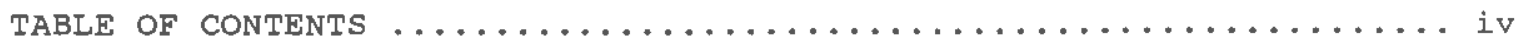

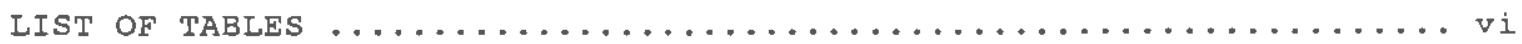

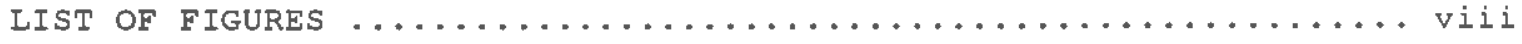

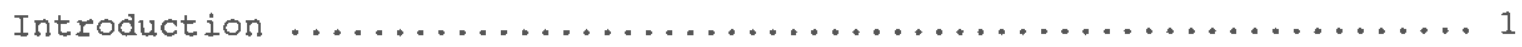

Time Series Analysis: General ...................... 3

Time series Analysis: ARIMA $(1,0,0) \ldots \ldots \ldots \ldots \ldots \ldots \ldots \ldots$

Classification of Missing Data Mechanism ................ 7

Methods of Handling Missing Data: Time Series Analysis ....... 8

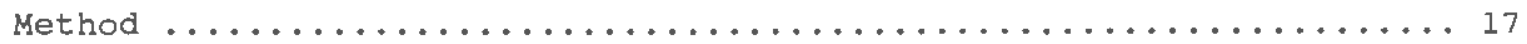

Data Generation ............................ 17

Independent variables $\ldots \ldots \ldots \ldots \ldots \ldots \ldots \ldots \ldots \ldots \ldots \ldots \ldots \ldots$

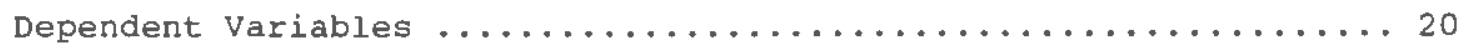

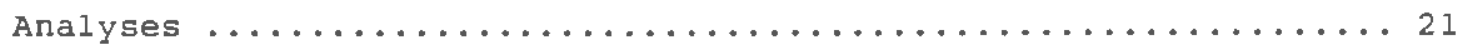

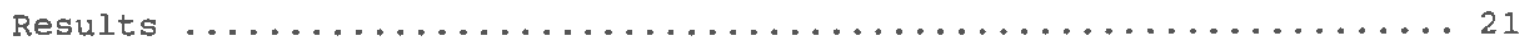

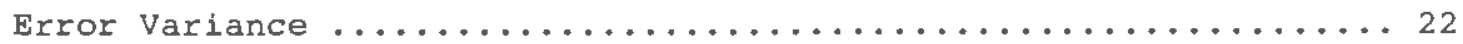

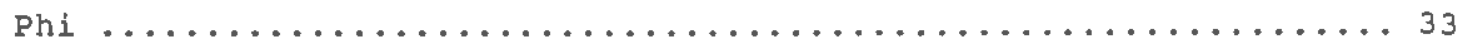

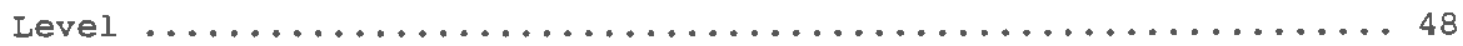

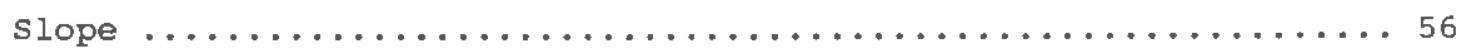

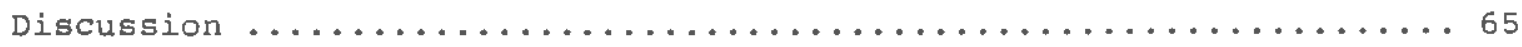

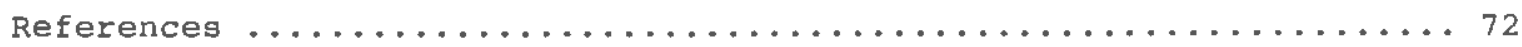

Appendix A: ANOVA Summary Table for Error variance...........76

Appendix B: ANOVA summary Table for Phi (Phi $=-.80) \ldots \ldots \ldots \ldots . .77$ 


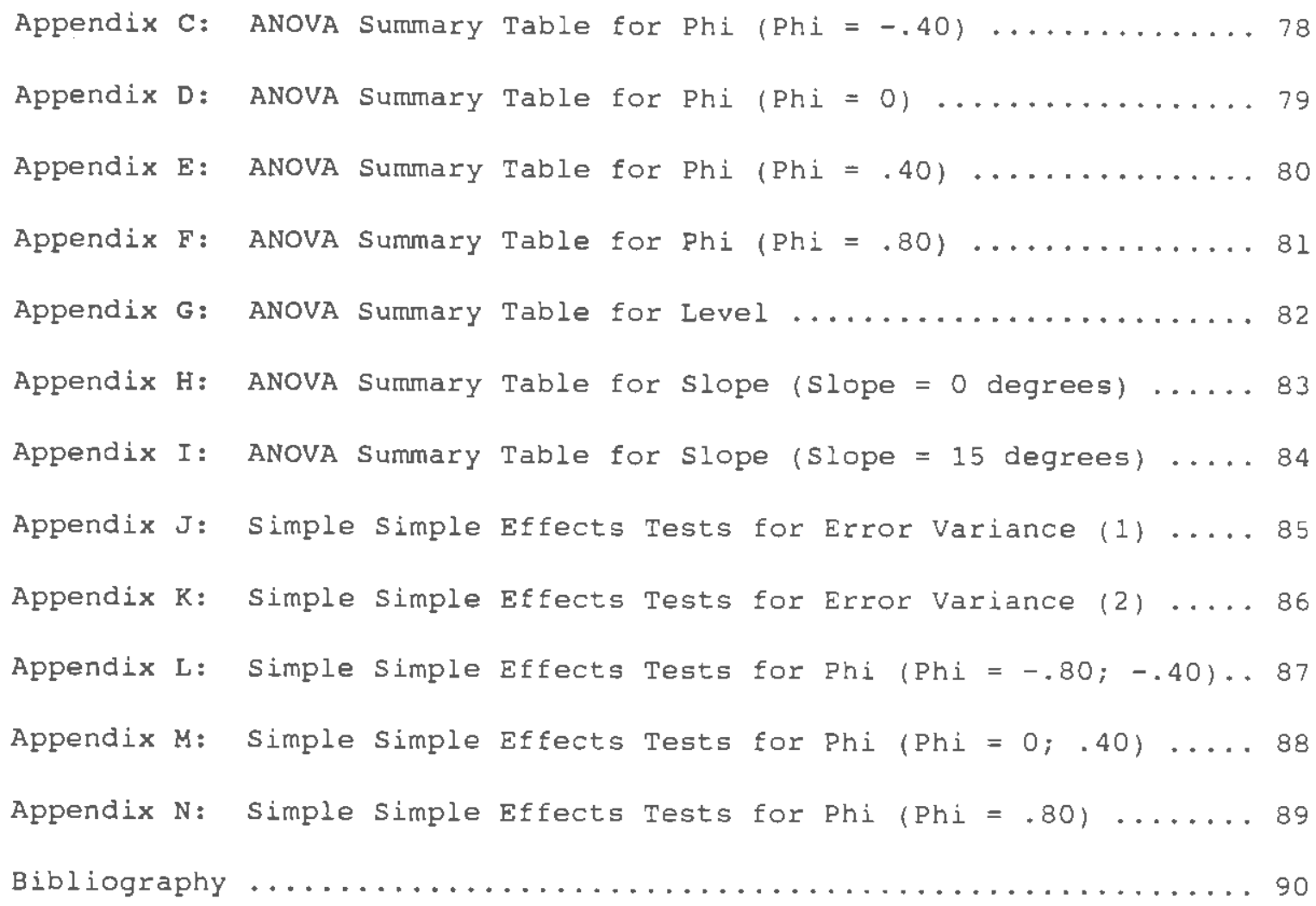


Table 1

Means and Standard Deviations of Estimates of Error Variance for

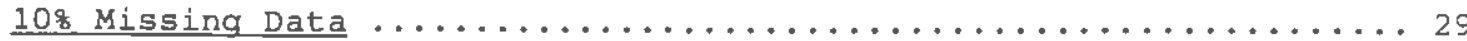

Table 2

Means and Standard Deviations of Estimates of Error Variance for

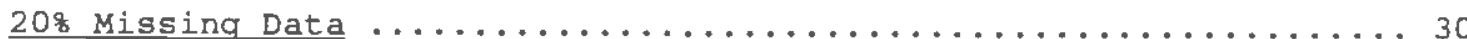

Table 3

Means and Standard Deviations of Estimates of Error Variance for

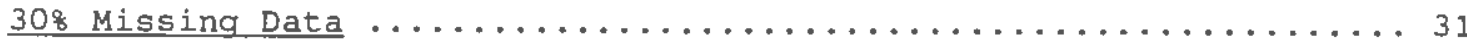
Table 4

Means and Standard Deviations of Estimates of Error Variance for

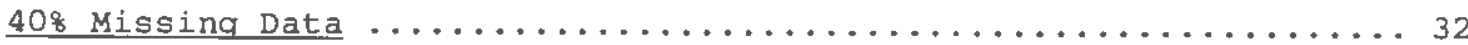
Table 5

Means and Standard Deviations of Estimates of Phi (Phi $=-.80$

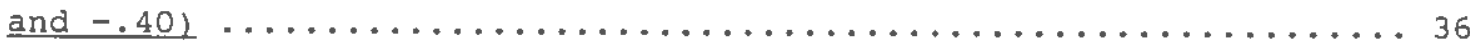

Table 6

Means and Standard Deviations of Estimates of Phi (Phi $=-.40$

and 0$)$

Table 7

Means and Standard Deviations of Estimates of Phi (Phi 0 and .401

Table 8

Means and Standard Deviations of Estimates of Phi (Phi $=.80$ ) ... 49 
Table 9

Means and Standard Deviations of Estimates of Level at $10 \%$ Missing

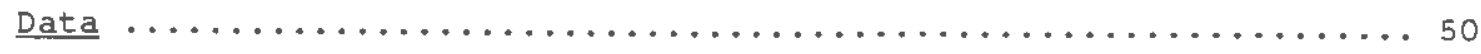

Table 10

Means and Standard Deviations of Estimates of Level at $20 \%$ Missing

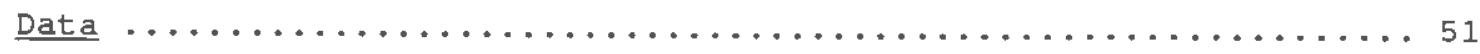

Table 11

Means and Standard Deviations of Estimates of Level at $30 \%$ Missing

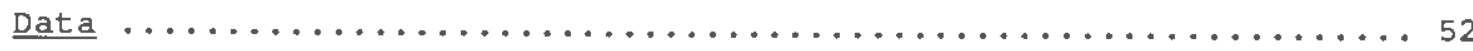

Table 12

Means and Standard Deviations of Estimates of Level at 408 Missing

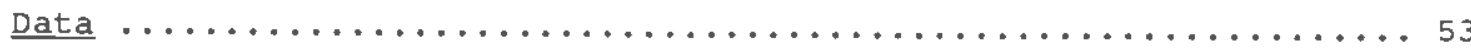

Table 13

Means and Standard Deviations of Estimates of Tangent of Slope

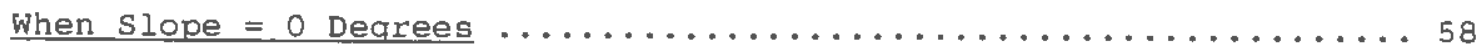

Table 14

Means and Standard Deviations of Estimates of Tangent of Slope

When Slope $=0$ Deqrees (Continued) $\ldots \ldots \ldots \ldots \ldots \ldots \ldots \ldots \ldots$

Table 15

Means and Standard Deviations of Estimates of Tangent of slope

When slope $=15$ Deqrees $\ldots \ldots \ldots \ldots \ldots \ldots \ldots \ldots \ldots \ldots \ldots \ldots \ldots \ldots$

Table 16

Means and Standard Deviations of Estimates of Tangent of Slope

when Slope $=15$ Degrees (Continued) $\ldots \ldots \ldots \ldots \ldots \ldots \ldots \ldots$ 


\section{LIST OF FIGURES}

page

\section{Figure 1.}

Mean error variance as a function of missing data technique, percent data missing, and slope of series $\ldots \ldots \ldots \ldots \ldots \ldots \ldots \ldots \ldots$

\section{Fiqure 2.}

Mean error variance as a function of missing data technique and

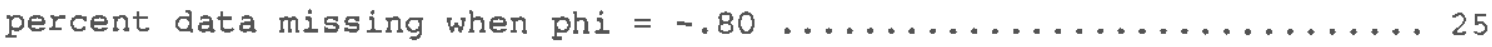

\section{Figure 3 .}

Mean error variance as a function of missing data technique and percent data missing, collapsing across all levels of phi except

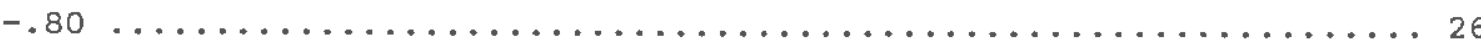

\section{Fiqure 4.}

Mean estimates of phi as a function of missing data technique, percent data missing, and slope of series. (Criterion $=-.80$ ) $\ldots . .34$ Figure 5.

Mean estimates of phi as a function of missing data technique, percent data missing, and slope of series. (Criterion $=-.40$ ) $\ldots .38$ Figure 6.

Mean estimates of phi as a function of missing data technique, percent data missing, and slope of series. (Criterion $=0$ ) $\ldots . .44$ Figure 7.

Mean estimates of phi as a function of missing data technique, percent data missing, and slope of series. (Criterion $=.40$ ) $\ldots .45$ Figure $\underline{8}$.

Mean estimates of phi as a function of missing data technique, percent data missing, and slope of series. (Criterion $=.80$ ) $\ldots .44$ 
Figure 9.

Mean estimates of level as a function of missing data technique,

percent data missing, and slope of series. (Criterion $=0$ ) $\ldots \ldots 55$

Figure 10.

Mean estimates of tangent of slope as a function of missing data

technique and phi. (Criterion value $=.27$ ) $\ldots \ldots \ldots \ldots \ldots \ldots \ldots$

Figure 11.

Mean estimates of tangent of slope as a function of missing data

technique and percent data missing. (Criterion value $=.27$ ) $\ldots .661$ 
Handling Missing Data in Time Series Analysis

The use of time series analysis for analyzing small n or single case behavioral data is becoming increasingly recognized as an appropriate tool for research in the behavioral sciences. Time series analysis is used for experimental designs that consist of repeated observations on a single experimental unit. This design may be conceptualized as the reverse of an Analysis of Variance (ANovA) design: rather than taking one observation each of many individual subjects, one takes many observations of a single subject. ANova deals with group means, while time series analysis examines behavior over time within a single subject.

One major advantage of using time series analygis is that it allows the researcher to look at a pattern of change in behavior over time, rather than look at behavior at a single discrete point in time. However, the time series approach often results in the presence of dependency in the data. Dependency is the extent to which a subject's (or any experimental unit's) behavior at time $t$ is predicted by that subject's behavior at time t-1. The terms "dependency" and "autocorrelation" are used interchangeably.

Missing data is a common problem in studies that are characterized by repeated observations on the same experimental unit, particularly when the experimental unit is a person (Laird, 1988). The number of observations required for baseline time series ranges between 30 and 50. obtaining complete data on a person at regular intervals for 30 to 50 observations is difficult, and the causes of the missing data are often 
beyond the control of the experimenter. For example, if the study requires that the participant come to the research site for every observation, missing data may result on weekends if appointments cannot be scheduled, or on any days when unforeseen events (e.g., illness; lack of transportation) preclude attendance. Alternatively, self-report data may be used (e.g., self-monitoring at regular intervals, or retrospective reports), which rely upon the study participants' compliance and memory.

It is reasonable to assume that the greater the number of observations required on a single experimental unit, the more likely it is that some observations will be missing. Thus, time series designs are particularly susceptible to missing data problems. Since implementation of time series analysis requires complete data, it is necessary to correct for missing data prior to analysis.

This study examines the effects of using different techniques for handling missing data on time series analysig. Available techniques vary widely in terms of ease of implementation and theoretical appropriateness. Most of the development and application of the more sophisticated approaches (e.g., maximum likelihood estimation for statespace models, have been developed within the field of econometrics, leading some to question their applicability to clinical research (Rankin \& Marsh, 1985). This comparison of missing data techniques is an attempt to provide an empirical basis for researchers to choose the most appropriate and practical method available to them. 
A comparison of missing data techniques could have been done using well-known data sets or simulated data. The decision to simulate data was made so that factors that may affect the comparability of these techniques (e.g., degree of slope and dependency) could be systematically manipulated. In addition, the use of simulated data provided population parameter values (criterion values) against which estimates could be compared.

Fifty different types of series (10 samples of each) representing different degrees of dependency (phi), a slope of zero versus a positive slope of 15 degrees, and different proportions of randomly eliminated data points were generated. Four different techniques for handing missing data were then employed in each series, and results were compared for each technique.

Time Series Analysis: General

The major advantage of time series analysis over analysis of variance is that it takes dependency into account, and therefore yields more accurate parameter estimates and significance tests. Consider the effect of dependency in the data on significance tests when ANOVA is used rather than time series analysis. If the dependency is positive, variability in the data is decreased, and the probability of a Type I error increases. If the dependency is negative, there is more variability in the data, thus increasing the likelihood of a Type II error.

Box and Jenkins (1970) developed the procedures for analyzing time series models. These Autoregressive Integrated Moving Averages (ARIMA) 
models mathematically represent the dependence in the data. For a more thorough description of time series analysis for the social sciences, see Glags, Willson, and Gottman (1975), Gottman (1981), or McCleary and Hay $(1980)$.

ARIMA models have three parameters ( $P, d$, and $q$ ). $P$ represents the order of the autoregressive component; d represents the amount of differencing necessary to remove any cyclicity present in the series; and $q$ represents the order of the moving averages component. The numeric values of these three parameters specify the type of ARIMA model that best fits the serieg. Among the many methods available for model identification, the most common method (Glass, Willson, \& Gottman, 1975) consists of examining the patterns of autocorrelations and partial autocorrelations in the data. Once the ARIMA model that best describes the process underlying the series has been identified, the data are transformed to meet the assumptions of the general linear model.

For the purposes of this study, the type of ARIMA model was held constant while degree of dependency, slope, and proportion of missing data in the series were manipulated. Even though model identification may be considered by some to be a central issue in time series analysis, it is not essential to time series analysis. Because methods of model identification (e.g., Glass, Willson, \& Gottman, 1975) are subjective and have been shown to be unreliable (Velicer \& Harrop, 1983), several methods of time series analysis without model identification have been proposed. All of these methods employ an estimated or generalized transformation matrix, rather than a transformation specific to the 
ARIMA model that underlies the series. Velicer and McDonald (1984) suggest analyzing a higher order $(5,0,0)$ autoregressive model for all series. Simonton (1977) assumes that a simple (1, 0, 0) autoregressive model is appropriate for all cases. Algina and Swaminathan (1979) use a sample estimation of the transformation matrix. This approach is limited in its applicability, since it requires that the number of subjects be greater than the number of observations. For a discussion of these approaches' respective merits, see velicer and McDonald (1984). Time series Analysis: ARIMA $(1,0,0)$

A first order autoregressive ARIMA model was selected because it is the most commonly encountered model in the behavioral sciences. Glass, Willson, and Gottman (1975) state that higher-order models are unusual in the behavioral sciences. In a study of couple interaction during marital counseling, all of the 98 series could be represented by either $(0,0,0)$ or $(1,0,0)$ models (Revenstorf et al., 1980). Also, in a reanalysis of 70 clinical series published in journal articles over a four year period, Marsh and Shibano (1984) found that 40 percent of the series could be described as $(0,0,0)$ models, and 48 percent could be described as autoregressive models with one or two terms. More relevant is the fact that the use of a $(1,0,0)$ model proved satisfactory with 80 percent of the series tested. In order to determine characteristics of time series data for a simulation study, Rankin and Marsh (1985) examined baseline data obtained from the Elderly Support Project at the school of Social service Administration at the University of Chicago. Of the 16 series that met their criteria 
(complete data and a minimum of 30 data points), 11 were identified as $(0,0,0)$ models, 4 as $(1,0,0)$, and 1 as a $(0,0,1)$ model. As a result, data for the Rankin and Marsh (1985) simulation study were generated to fit a first order autoregressive model.

There are four parameters that describe first order autoregressive ARIMA models: level (L), slope (S), error variance, and autocorrelation (phi). I is the level of a series at time $=0$. This value is the intercept of the best-fitting straight line through the plotted observations of a series. When the series is level (i.e., the slope of this line is equal to zero), $L=$ the mean of the series. If the series is not level, then the mean of the series is determined in part by the number of observations (N) in the series. Therefore, the intercept of the series (L) is used, because it is independent of the length of the series.

Error variance is a measure of the chance variation that remaing in the time series, once the series has been transformed to remove the dependency from the data. The residual error variance must be uncorrelated (i.e., not significantly different from a series of random errors) with a mean of zero. It is calculated by dividing the error sum of squares by the number of observations in the series.

Phi represents the degree of dependency in the data. In an adequate ( $1,0,0)$ model, the value of phi must lie within the "bounds of stationarity" (Dixon, 1988), from -1.00 to 1.00 . In this case, phi is analogous to a correlation coefficient. When phi is equal to zero, there is no dependency in the data, and the time series analysis is 
equivalent to an ANOVA. (ANOVA is a special case of time series analysis). When phi is equal to 1.00 or -1.00 , behavior is considered to be perfectly predictable (e.g., what a subject does at time $t-1$ completely determines what that subject does at time $t$ ).

Negative and positive autocorrelation are distinguished by the direction in which a subject's behavior deviates from one time point to the next. For example, phi is positive when a subject's behavior deviates in the same direction at time $t$ as it did at time $t-1$. Likewise, phi is negative when a subject's behavior deviates in the opposite direction at time $t$ than it did at time $t-1$.

\section{Missing Data}

\section{Classification of the Missing Data Mechanism}

The choice of an appropriate method for handing missing data depends in part on the reason why the data are missing, or the missing data mechanism. The following classifications were developed by Rubin (1976).

Data are Missing Completely at Random (MCAR) if the observations with any missing values are a random subsample of the full sample. In this case, the missing data mechanism is unrelated to the model and is therefore ignorable.

Data are Missing at Random (MAR) if the pattern of missingness for a variable is not a function of its observed values, but it may be a function of other values in the model. For example, a response for annual household income on a survey may be missing for several reasons. One reason is that the respondent may not know his/her household income. 
The missing data mechanism may be a function of the respondent's age (e.g., very young respondents often don't know their family's income) but not a function of the respondent's household income. MAR is a less stringent assumption than MCAR.

Values are classified as "not MAR" when they are systematically missing from the data set. In other words, the missingness is a function of the values that are missing. For example, a survey which inquires about the respondent's participation in illicit activity is likely to have some missing values for respondents who have broken the law, and complete data for respondents who have not.

In this study, methods of handling missing data were compared in simulated time series data where the eliminated observations are MCAR. Data that are missing at random (MAR) or systematically missing from a data set may be more typical of most missing data problems. However, the MCAR condition is the most basic missing data condition, and therefore is a logical starting point for research of this nature. Also, findings based on replacing data that are MCAR may be generalizable to other missing data conditions. Methods of Handling Missing Data: Time Series Analysis Missing data may be handled using any one of three general strategies: complete case analysis; imputation of an estimate of the missing value; or direct analysis of the incomplete data set, either by available case analysis or a maximum likelihood analysis (Little \& Rubin, 1990). 
A commonly used approach to handling missing data in time series analysis is to eliminate the observations that are missing from the series, and then analyze the condensed series as if it were the same as an original shorter series. This procedure is analogous to complete case analysis (also known as listwise deletion), which is often used to handle missing data in other types of univariate and multivariate analyses. When using listwise deletion, all cases that have missing data on any variable are eliminated from the sample. Statistical analyses are then performed on the set of cases with complete data on every variable.

The costs associated with using listwise deletion to hande missing data are: (1) this method will always decrease the sample size (sometimes dramatically) if there are any missing values at all, and (2) the non-missing values for the dropped cases aren't utilized, which leads to inefficient estimators (Bollen, 1989). In univariate time series analysis (i.e., time series analysis in which only one measure is taken at each timepoint), these problems are not as severe as for other multivariate analyses. Since the sample size (N) in time series is the number of observations rather than the number of subjects, and since typically one observation is taken at each time point, there aren't any non-missing data that are excluded from the analysis.

The problem that may arise when using the deletion approach for time series analysis is unique to repeated measures types of analyses. When time points with missing data are eliminated from the series, the result is equivalent to a series with irregular time intervals. This is 
a problem because when data are collected at irregular time intervals, but treated as though they were collected at regular intervals, autocorrelation becomes more difficult to detect.

Time series statistical models assume that the data are gathered at regular time intervals. However, typical time series data is often collected at irregular time intervals, due to pragmatic considerations such as difficulty in scheduling repeated appointments (e.g., observations may occur five days per week, with no observations taking place on weekends). A related problem occurs when observations are taken at regular intervals, but occur too far apart to detect the pattern of autocorrelation accurately. Both of these approaches result in missing data problems, although they are usually not conceptualized as such.

The result is a biased sample of the behavior of interest (Busk \& Marascuilo, 1988; Suen, 1987). To handle missing data by eliminating observations and analyzing a condensed series should add more irregularity and further distort the pattern of autocorrelation in the series. This point has been supported by Rankin and Marsh (1985), based on the results of their simulation study which examined the effects of missing data on time series analysis. The authors concluded that once more than $20 \%$ of the data were missing, the higher the percentage of data were missing from the series, the more the series deviates from the complete data pattern. They in turn cautioned against graphing techniques that condense intervals with missing data. 
Clearly, deletion is not an ideal technique for handling missing data, but its simplicity is appealing to many researchers. Also, since there is some evidence that this approach isn't detrimental when less than 20 of a series is missing, it was included in this study as one viable method for comparison with other missing data techniques.

Rankin and Marsh (1985) also cautioned against graphing all of the observed data points, then extrapolating the missing values by connecting successive points. This technique is the equivalent of taking the mean of the adjacent observations. In other types of multivariate analyses, it is common to impute the mean of a given variable for missing values of that variable. Under certain conditions, taking the mean of the adjacent observations is likely to be more accurate for time series analysis than imputing the mean of the entire series. For example, the mean of the adjacent observations should be more accurate when the slope of a series is not zero. In this case, imputing the mean of the entire series could lead to inaccurate estimates, especially at the beginning or the end of a series. Imputing the mean of the adjacent observations may also be more accurate than the mean of the entire series when phi (autocorrelation) is positive. However, when phi is negative, using the mean of the adjacent observations may artificially smooth the series, and mask the amount of autocorrelation actually present in the behavior of interest. Substituting the mean of the entire series is more comparable to the typical mean imputation used in other multivariate analyses. In this case, the mean would be obtained from all of the non-missing 
observations in a series, and that value would be imputed for each missing observation. In regard to time series parameter estimation, imputing the mean of the series may have the same negative consequence as taking the mean of the adjacent observations. That is, imputing mean values may inappropriately smooth a series with negative autocorrelation. An additional problem occurs when the proportion of the missing data increases, and the mean of the series is subsequently imputed for each missing data point. The true variability of the series could be underestimated as many of the observations in a given series take on an equal value.

Regression estimateg are obtained by using the most highly correlated variables in the data set as predictors. This procedure yields the most accurate estimates of the missing values (Tabachnick \& Fidell, 1989). However, regression estimates tend to "over-fit" data sets, and therefore make results less generalizable. Specifically, variables in a data set will appear to correlate more highly than they actually do. Bias in regression estimates can be minimized by restricting the predictors to one variable at a time for missing values in another variable.

This approach is impractical to extend to time series analysis. Theoretically, if 10 subjects were run in a time series design, and these subjects had missing data for different observations, regression estimates could be predicted for missing obgervations by using the relationship between the missing timepoint and the preceding timepoint for the other nine subjects. However, in time series analysis, separate 
subjects are treated as replications, and therefore should be kept independent of each other. Another problem with using regression estimates for time series analysis is that missing values will be estimated from a preceding observation, and then used in turn to predict later observations, thus compounding the error in estimation. In typical uses of regression estimation, estimates of missing values would never be put in a regression equation in order to estimate another missing value. For these reasons that are specific to time series analysis, regression estimates were considered too problematic to test against the other techniques for handing missing data.

BMDP $2 \mathrm{~T}$ (Dixon, 1990) uses "blocks" of contiguous data to forecast estimates of missing values. The program will identify a time series from the first non-missing value until the first missing value (i.e., complete block of data). To estimate the missing value, $2 \mathrm{~T}$ determines which type of ARIMA model the block of complete data is from. The forecast of the missing data point is based on this model. This approach seems acceptable for a few missing observations, but when several data points are missing throughout the data set, forecasting ends up being based on too few data points. Also, the forecasting procedure would have to be repeated for each missing observation. Perhapg the least theoretically flawed method for handing missing data is a direct analysis of the incomplete data set using maximum likelihood estimation. One algorithm that has been used for this purpose is the EM (expectation maximization) algorithm. The EM algorithm is a general iterative algorithm for maximum likelihood 
estimation in missing data problems. For years, the algorithm had been applied to a limited and distinct set of problems. With each new application, the generality of the algorithm's underlying principle became more apparent (Baum et al., 1970; Beale \& Little, 1975; Hartley, 1958). In 1977, Dempster, Laird, and Rubin demonstrated the generality of what they named the "EM" algorithm, and provided a broad range of examples of its applications. For a detailed description of the background of the EM algorithm, see Little and Rubin (1987).

The $E M$ algorithm is implemented in a two-step procedure. The $M$ step estimates parameters of the model based on all of the observed values. The E step finds the conditional expectation of the missing values, given the observed values and the current estimates of the parameters. These expectations are then substituted for the missing values, and the parameters are re-estimated. Each iteration decreases the residual sum of squares. Iteration continues until convergence. Disadvantages to using the $\mathrm{EM}$ algorithm include the fact that it is more difficult to implement than the other missing data techniques discussed, and that it can be very slow to converge when there is a lot of missing data. Also, since this is a direct analysis approach, estimates of individual data points are not obtained, therefore precluding graphic presentation of the time series data.

An algorithm that is very similar to the EM algorithm has been incorporated into the most recent version of SPSS-X Trends ARIMA (SPSS, Inc., 1988). Use of this algorithm allows direct analysis of a data series with embedded missing values, using a technique known as Kalman 
filtering. This approach was actually developed for general state-space models (Kalman, 1960) and had been applied to Box-Jenkins ARIMA models with moving averages components, but were considered more difficult to implement with autoregressive models than the EM algorithm (Little \& Rubin, 1987).

Now that this technique is available in commercial software, the procedure is much easier to use. The greatest drawback in the use of this technique is that the Kalman filtering algorithm takes much longer to reach its solution. Even a single imbedded missing value increases ARIMA processing time substantially; in extreme cases, by a factor of 10. Because Kalman filtering can take so long, spss-X suggests a 3-step process to handle missing data. First, the RMV procedure would be used to make a copy of the data set with data interpolated in place of the missing data. Next, ACF and ARIMA would identify the type of ARIMA model and estimate the coefficients for the series without the missing data. Using the model identified during this step, ARIMA would be run again, this time on the original data set with the missing values using the kalman filter to handle missing data. APPLY INITIAL should be used so that the iteration will start with the final estimates from the previous ARIMA procedure. This process supplies the Kalman filter with good initial estimates, and therefore reduces the number of iterations needed for convergence. Like the EM algorithm, this technique does not result in estimates of the individual missing values.

Another maximum likelihood algorithm was suggested by Jones (1980). This approach has the same limitation as the EM algorithm and 
the Kalman filter (in terms of not providing estimates of the missing observations), however, it is equally appropriate mathematically, and it has also been made available in commercial software. SAS/ETS (SAS Institute, 1988) has incorporated this iterative algorithm into Proc ARIMA in its version 6 release. If a data set with missing values is input to SAS Proc ARIMA, this algorithm is automatically used to estimate the datapoints, and perform the time series analysis. This technique may be too easy to use--researchers who do not read the manual carefully will not know that this method has been employed. This is in contrast to SPSS-X Trends ARIMA, which identifies the number of missing values in the series, and clearly states on the printout that a Kalman filter has been used to estimate the missing data. Using the Jones (1980) algorithm, missing values are forecasted using the initial parameter estimates, which are based on the available data. The conditional least squares algorithm then fills in the missing values; estimates of the parameters and missing values are updated at each iteration until convergence. Although this technique works basically the same way as the Kalman filter, processing time is quite fast.

The Jones algorithm, available through SAS/ETS, was tested in this study. Of the three maximum likelihood approaches discussed, it is the fastest and easiest to implement. It was fully expected that this maximum likelihood technique would be the most accurate approach to handing missing data. However, some researchers may not use maximum likelihood estimation because they prefer to use other time series 
computer programs (e.g., BMDP 2T), or because they continue to handle missing observations at the raw data level, prior to analysis. Since some may continue to rely on less appropriate but well-known methods, it was considered important to find out the conditions under which this maximum likelihood approach distinguishes itself from the other methods. Although there are many techniques available for handling missing data for other types of experimental designs, the special complications presented by autocorrelation in time series analysis have received limited attention in the domain of applied behavioral research. To date, only one simulation study has been published which examined the effect of missing data on behavioral time series analysis (Rankin \& Marsh, 1985). This study used the deletion approach to handling the missing data. The fields of econometrics and engineering have produced more in-depth treatment of this topic (Harvey \& Pierse, 1984; Kohn \& Ansley, 1986). This research is based on general statespace models developed by Kalman (1960) rather than the Box-Jenkins ARIMA models.

\section{Method}

\section{Data Generation}

Time series data were generated using a FORTRAN computer program. The program used was adapted from a program that was developed by Padia (1975) and revised by Harrop and Velicer (1985). Initially, 10 series were generated, representing all possible combinations of 5 levels of dependency (phi) and 2 levels of slope (s). Ten replications (samples) of each of the 10 series were then generated. Ten replications were 
chosen based on Harrop and Velicer (1990). In a simulation study which evaluated computer programs for analyzing interrupted time series data, some preliminary runs were done to decide between 5, 10, and 20 replications. They found that 10 and 20 replications yielded estimates that were more accurate and stable than estimates from 5 replications. In addition, there was little or no improvement in the estimates when using 20 replications as opposed to 10 .

These 100 complete data sets (i.e., 10 replications of each of the 10 series) served as comparisons for the missing data estimation conditions. All series fit an ARIMA first order autoregressive (1, 0 , 0) model and were originally 100 data points in length (i.e., prior to any data elimination). The mean of the random component of all series is zero, and the variance is 1 .

Independent Variables Manipulated

Slope. (S). Half of the series generated had a slope of zero; the other half had a positive slope of 15 degrees. Because the series consist of 100 data points, a slope of 15 degrees is sufficient to test the effects of slope on the effectiveness of the missing data methods. Also, there was no reason to expect that the effects of a negative slope would be any different than the effects of a positive slope, so negative slopes were not investigated in this study.

Degree of Dependency (Phi). Series were generated with five different levels of autocorrelation. Four values of phi $(-.8,-.4, .4$ and .8) were chosen because they represent moderate and severe levels of autocorrelation that may be encountered in time series designs. It was 
considered necessary to include negative and positive values of phi, since most techniques should affect these series differently. The fifth level of phi chosen was the white noise model, in which phi equals zero. (When phi $=0$, the time series model defaults to an ANOvA model, and techniques appropriate for ANOVA may be used). This model provides a baseline for comparison.

Proportion of Missing Data. In Rankin and Marsh's (1985) investigation of the effects of missing data (with no replacement), six different percentages were deleted: 10\%, 20\%, 30\%, 40\%, 50\%, and 60\%. The authors concluded that the higher the percentage of missing data, the poorer the model's overall fit, with poor fit beginning to occur when the percentage was more than $20 \%$. Because a negative impact began to occur at $20 \%$ missing data, this study limited the percentages to $10 \%$, 208,308 , and 408 .

Data were randomly eliminated from each of the 100 original series in the four different proportions. This resulted in a total of 50 conditions, or 500 series (10 replications each of : the original 10 complete data sets; the same 10 data sets with $10 \%$ of observations randomly eliminated; the same 10 data sets with $20 \%, 30 \%$, and $40 \%$ of observations randomly eliminated).

Techniques for Handling Missing Data. Four different missing data techniques were employed:

a. No estimate of the missing data; the series were condensed and analyzed as a shorter series. (Deletion) 
b. Mean of each series was imputed in place of the missing observations.

c. Mean of the adjacent observations was imputed in place of the missing observations.

d. Maximum-likelihood algorithm was used to directly analyze the data set and estimate the parameters of the series.

All four techniques were employed for each of the 40 conditions (400 series) with missing data. This resulted in a total of 170 conditions: 5 levels of phi $\times 2$ levels of slope $\times 4$ proportions of missing data $\times 4$ methods of handling missing data, plus the 10 original. and complete series. Finally, 1700 time series analyses were performed: 10 replications of each of the 170 conditions.

\section{Dependent Variables}

Four dependent variables were obtained from each time series analysis, which correspond to the four parameters of the model.

Error Variance. Minimum residual error variance was obtained by dividing the sum of squares error at the last iteration by the number of data points in the series (usually 100). The number of data points had to be adjusted by the missing data technique employed. For example, when deletion was used, and $40 \%$ of the data were missing, the number of data points in the series was 60 . Error variance was used as a dependent variable because it is critical in the calculation of significance tests, when testing intervention effects $(e+g .$, in an interrupted time series design). The population value for error variance was 1. 
Autocorrelation parameter (phi). An estimate of phi was obtained for each series to see how missing data techniques affect this parameter.

Level (L). Estimates of level were also obtained for each series, to assess the effects of missing data techniques on this parameter. This parameter is crucial for interrupted time series analysis, where change in level is one of the two parameters which measures intervention effects. For this reason, it is important to have an accurate measure of baseline level. The population value of $L$ was 0 .

slope (S). Change in slope is the other parameter which measures intervention effects in time series analysis. Estimates of slope were obtained for each series to test whether missing data methods affect the accuracy of estimating this parameter.

\section{Analyses}

Time series analyses were performed using SAS/ETS Version 6, Proc ARIMA (SAS Institute, 1988) on an IBM 4381 mainframe computer. SAS uses a nonlinear algorithm for its solution. Analyses used the true model identification, and default values for starting estimates and stopping criterion. The maximum number of iterations was set at 50 . The conditional least squares (CLS) method of estimation was used.

\section{Results}

Separate repeated measures analyses of variance were used for each of the four dependent variables: error variance, phi, level, and slope. In the cases of phi and slope, which are independent as well as dependent variables, separate analyses of variance were performed for 
each level of the independent variable. Summary tables for these ANOVA's are presented in Appendices A through I.

\section{Error Variance.}

A $2 \times 5 \times 5 \times 4$ (slope $\times$ phi $\times$ percent missing $\times$ technique) analysis of variance was used to examine differences in estimation of variance in the series. The percentage of data missing from the series and the technique for handling missing data were within-groups (i.e., repeated measures) factors; phi and slope were between-groups factors.

Siqnificant overall effects. In this analysis, all four main effects were significant: slope $(\underline{F}(1,90)=2623.51, \underline{p}<.001)$; phi ( $\underline{F}$ $(4,90)=35.47, \mathrm{p}<.001)$; percent missing $(\underline{\mathrm{F}}(4,360)=1721.68, \underline{\mathrm{p}}<$ $.001)$; and technique $(\underline{F}(3,270)=6062.99, \underline{p}<.001)$. There were five significant 2-way interactions: percent missing by slope $(\underline{\underline{F}}(4,360)=$ $1327.76, \mathrm{p}<.001)$; percent missing by phi $(\underline{F}(16,360)=10.95, \mathrm{p}<$ $.001)$; technique by slope $(\underline{\underline{F}}(3,270)=5944.72, \underline{\mathrm{p}}<.001)$; technique by phi $(\underline{E}(12,270)=11.03, \underline{\mathrm{e}}<.001)$; and percent missing by technique ( $\underline{F}$ $(12,1080)=1854.24, \underline{\mathrm{p}}<.001)$. The interaction between phi and slope was not significant. There were two significant 3-way interactions: technique by percent missing by slope $(\underline{\underline{F}}(12,1080)=1797.54, \underline{p}<.001)$ and technique by percent missing by phi $(\underline{F}(12,1080)=2.58$, 루 $<.001)$. The remaining two 3-way interactions (percent missing by slope by phi, and technique by slope by phi) and the 4-way interaction were not significant.

In Figure 1, the technique by percent missing by slope interaction is demonstrated. Simple effects tests showed that this interaction was 


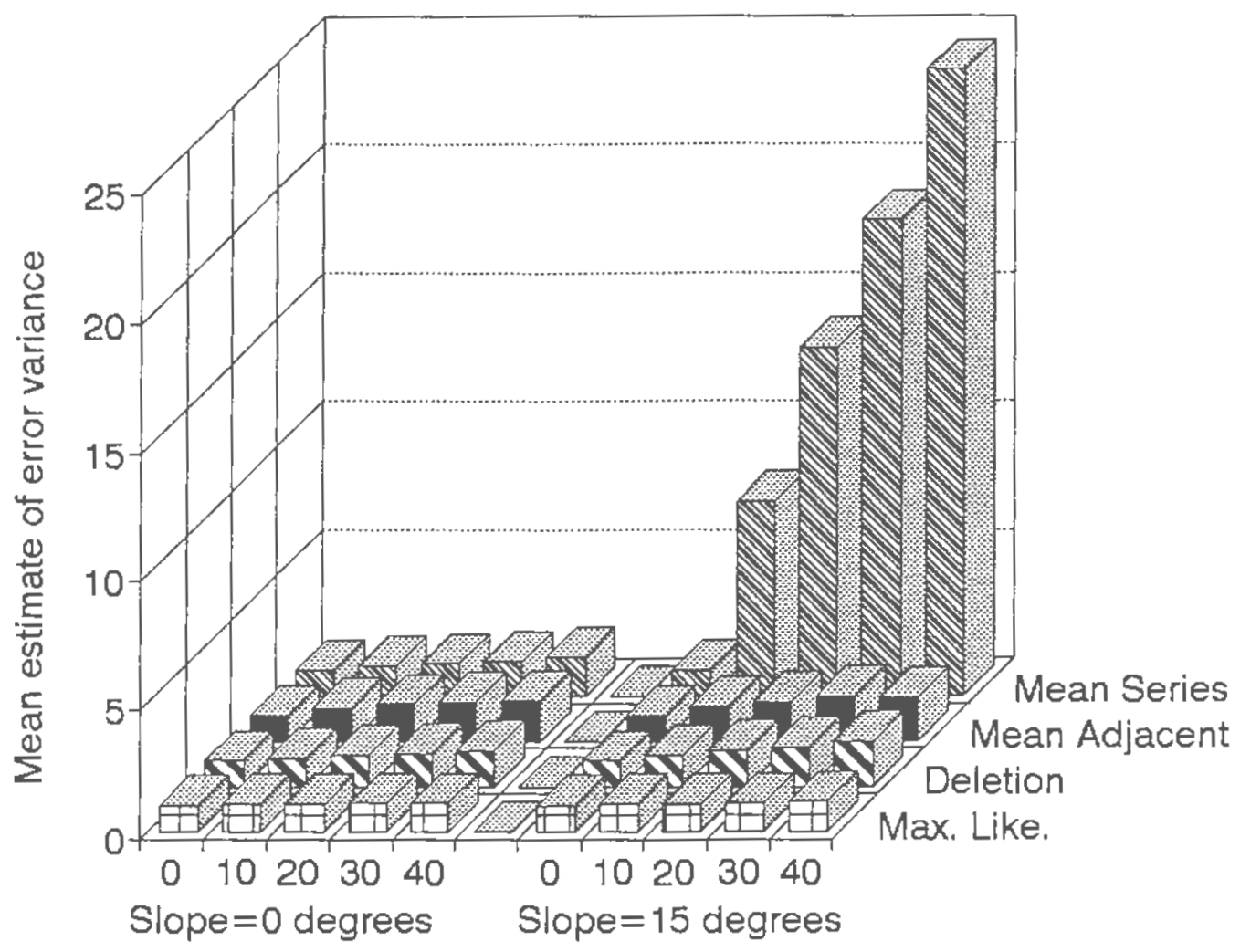

Percentage of data points missing

Figure 1. Mean ertor variance as a function of missing data technique, percent data missing, and slope of series. Criterion $=1$. 
significant when slope $=15$ degrees $(\underline{\underline{F}}(12,1080)=3683.93$, $<.001)$, but not when slope $=0$ degrees. However, when simple simple effects tests were performed to determine at which levels of percent missing the mean estimates of error variance were different by technique, every level of missing data (i.e., 10\%, 20\%, 30\%, 40\%) was significant at both slope $=0$ degrees and slope $=15$ degrees. The magnitude of these simple simple effects and their associated E-values are presented in Appendix J .

The technique by percent missing by phi interaction is demonstrated in Figures 2 and 3 . Simple effects tests showed that this interaction was significant at every level of phi: $-.80(\underline{F}(12,1080)=$ $4456.52, \underline{\mathrm{p}}<.001) ;-.40(\underline{\mathrm{F}}(12,1080)=4349.56, \underline{\mathrm{p}}<.001) ; 0(\underline{\mathrm{F}}(12$, $1080)=4499.15, \mathrm{p}<.001) ; .40(\underline{\mathrm{F}}(12,1080)=4467.04, \mathrm{p}<.001) ;$ and $.80(\underline{\underline{F}}(12,1080)=4754.63, \underline{\mathrm{p}}<.001)$. Simple simple effects tests were significant for technique at every combination of percent data missing and level of phi. Results of these tests are presented in Appendix $K$.

Follow up tests of siqnificance: Technique by percent missing by slope interaction. Tukey tests were done to determine the significant mean differences in variance estimation among the techniques, under different combinations of percent missing data and degree of slope. With the alpha level set at .05 , mean differences had to exceed .328 to be significant.

Major findings. As can be seen in Figure 1, the major finding concerning the error variance dependent variable involves the mean of 


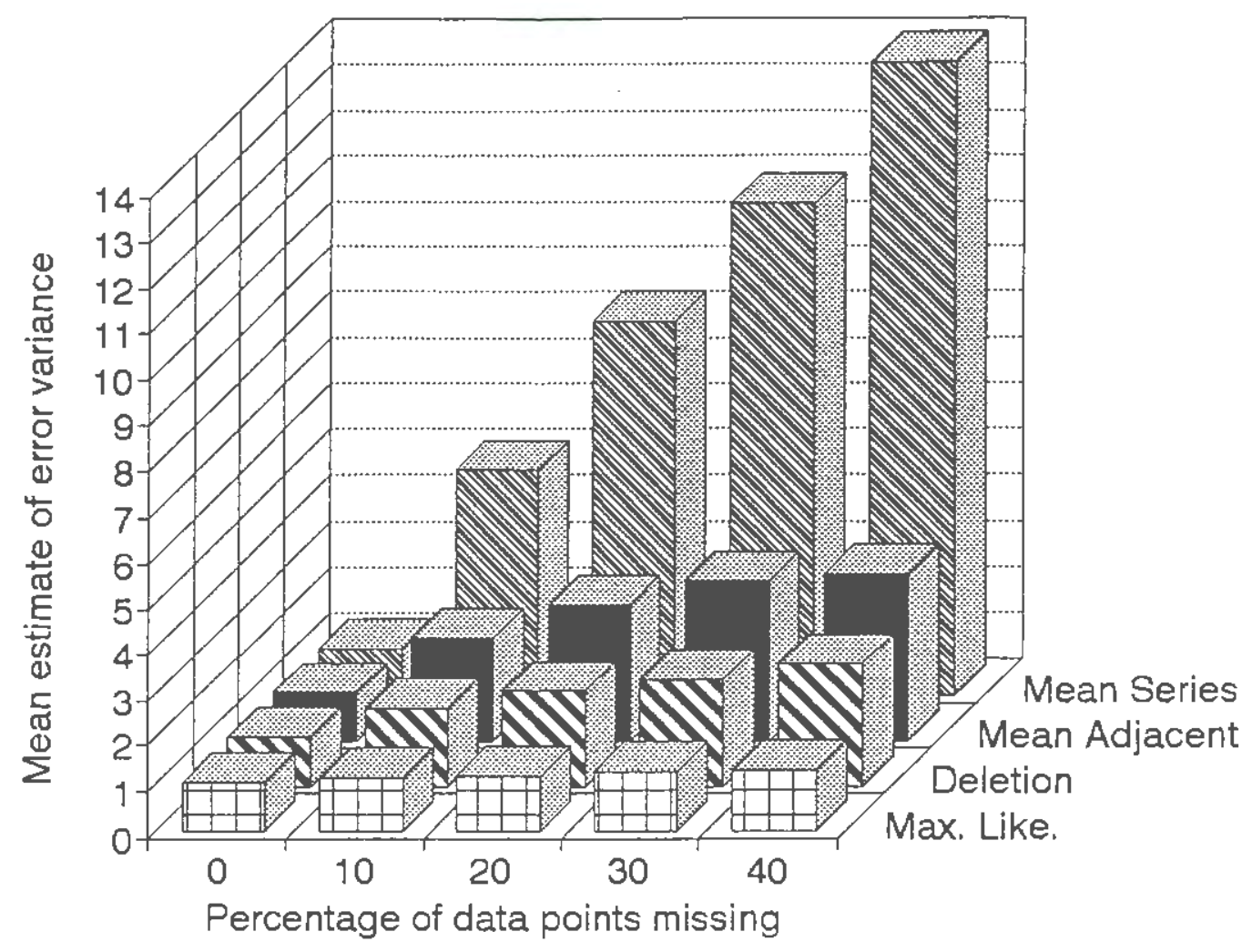

Figure 2. Mean error variance as a function of missing data technique, percent data missing, when phi $=-.80$. Criterion $=1$. 


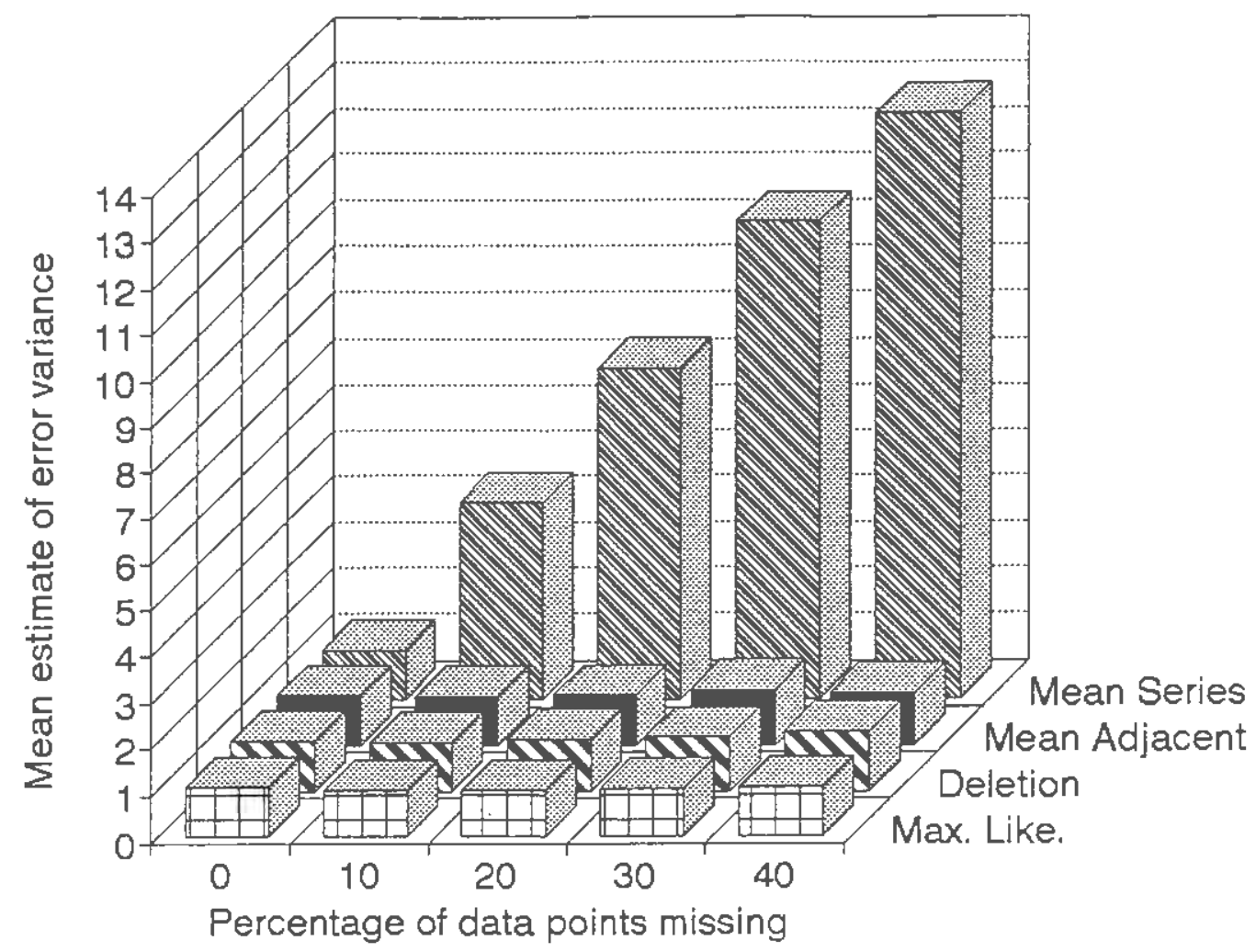

Figure 3. Mean error variance as a function of missing data technique, percent data missing, collapsing across all levels of phi except -.80 . Criterion $=1$. 
the series approach when the time series has a 15-degree slope.

Resulting estimates of variance are extremely high, ranging from 7.6 when 10 of the data were missing to 24.4 when 408 of the data were missing (the criterion value was 1). By way of contrast, the maximum likelihood approach yielded accurate variance estimates at all levels of missing data (i.e., the means were not significantly different from those in the complete data condition).

Minor findings. Other findings when slope $=15$ degrees, while statistically significant, are less dramatic. Beginning at 208 missing data, use of deletion and mean of the adjacent observations both led to estimates of variance that were significantly higher than those from the complete data set. Both approaches' overestimates were fairly modest, ranging from about 1.3 when $20 \%$ of the data were missing to about 1.6 at 40 o missing. The deletion approach was consistently more accurate than the mean of the adjacent observations, but this difference was not statistically significant.

$$
\text { When slope }=0 \text { degrees, there were similar minor findings. }
$$

Maximum likelihood was the most accurate approach, followed by deletion and mean of the series; mean of the adjacent observations was least accurate. Beginning at $20 \%$ missing data, mean of the adjacent observations resulted in variance estimates that were significantly higher than those estimates when the data set was complete. At 30 o missing data, mean of the series also resulted in a significantly higher variance estimate than that of the complete data set, but was not significantly higher than any of the other mean estimates. At $40 \%$ 
missing data, deletion also led to overestimates of variance, but this approach was still significantly more accurate than either mean of the series or mean of the adjacent observations. See Tables 1 through 4 for the means and standard deviations of these conditions.

Follow up tests of significance: Technigue by percent missing by phi interaction. Separate Tukey tests were done at each combination of phi and percent data missing (e.g., phi $=.80$ and 108 data missing) to compare mean estimates of error variance that resulted from the use of each technique, as well as from the complete data set. With alpha set at .05 , mean estimates of variance were significantly different when they exceeded .520 .

Major findings: The severe negative autocorrelation condition $($ phi $=-.80)$ presents special problems for the deletion and mean of the adjacent observations techniques in terms of estimating variance than the other levels of phi. This finding is illustrated in Figure 2. When phi $=-.80$, these techniques substantially overestimate error variance, with mean of the adjacent observations significantly less accurate than deletion.

At every other level of phi, deletion and mean of the adjacent observations yielded accurate variance estimates. (See Figure 3). This finding probably accounts for the shortcomings in these techniques that were found in the follow up tests of the technique by percent missing by slope interaction, described above. 
Table 1

Means and standard Deviationg of Estimate of Error Variance for $10 \%$

Misging Data. Criterion $=1$.

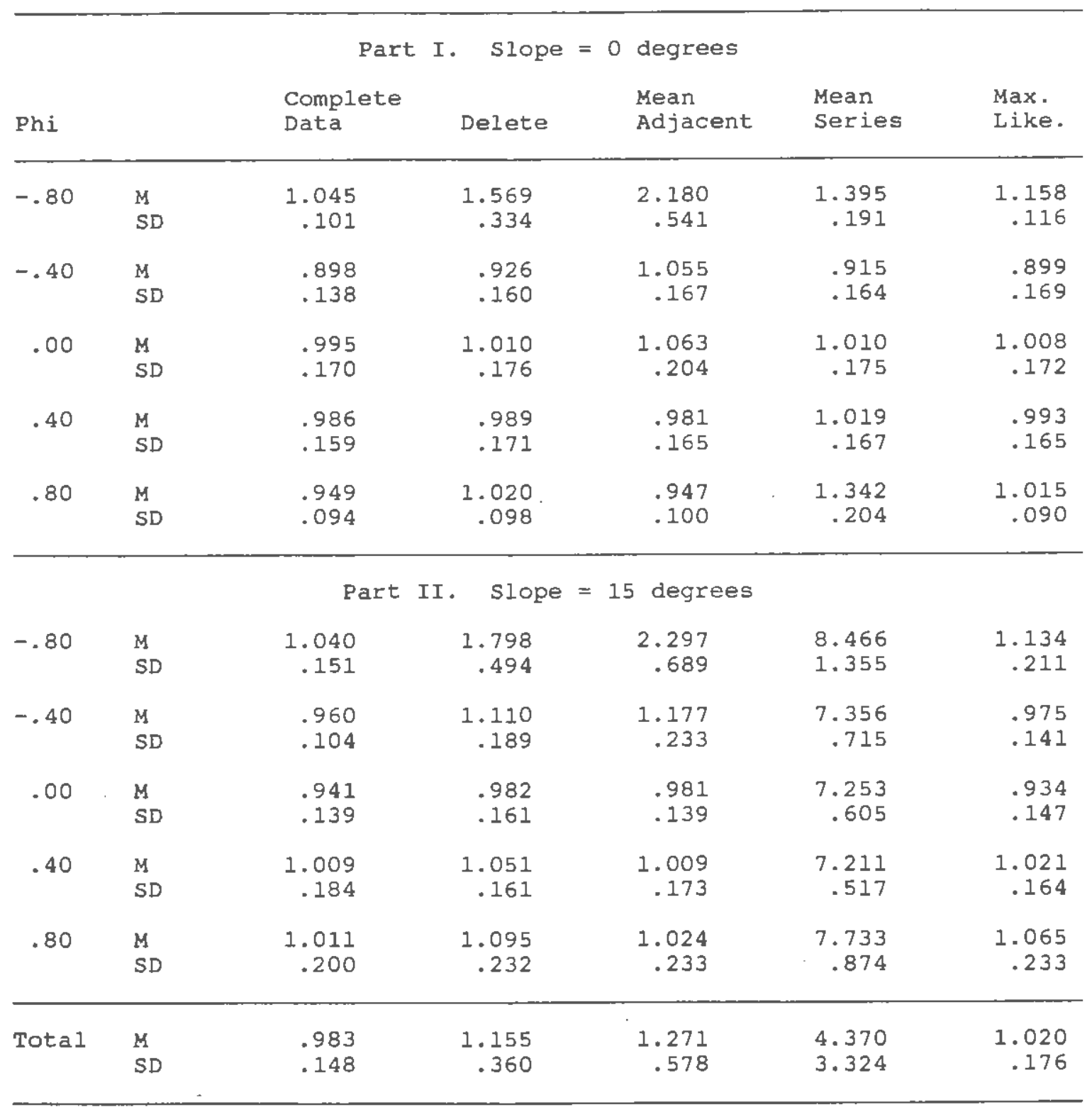


Table 2

Means and Standard Deviations of Estimate of Error Variance for $20 \%$ Missing Data. Criterion $=1$.

\begin{tabular}{|c|c|c|c|c|c|c|}
\hline Phi & & $\begin{array}{l}\text { Part } \\
\text { Complete } \\
\text { Data }\end{array}$ & $\begin{array}{l}\text { Slope } \\
\text { Delete }\end{array}$ & $\begin{array}{l}\text { O degrees } \\
\text { Mean } \\
\text { Adjacent }\end{array}$ & $\begin{array}{l}\text { Mean } \\
\text { Series }\end{array}$ & $\begin{array}{l}\text { Max. } \\
\text { Like. }\end{array}$ \\
\hline-.80 & $\begin{array}{l}M \\
S D\end{array}$ & $\begin{array}{r}1.045 \\
.101\end{array}$ & $\begin{array}{r}1.846 \\
.448\end{array}$ & $\begin{array}{r}2.828 \\
.646\end{array}$ & $\begin{array}{r}1.621 \\
.286\end{array}$ & $\begin{array}{r}1.148 \\
.150\end{array}$ \\
\hline-.40 & $\begin{array}{l}\mathrm{M} \\
\mathrm{SD}\end{array}$ & $\begin{array}{l}.898 \\
.138\end{array}$ & $\begin{array}{l}.986 \\
.200\end{array}$ & $\begin{array}{r}1.209 \\
.284\end{array}$ & $\begin{array}{l}.970 \\
.184\end{array}$ & $\begin{array}{l}.934 \\
.183\end{array}$ \\
\hline .00 & $\begin{array}{l}\mathrm{M} \\
\mathrm{SD}\end{array}$ & $\begin{array}{l}.995 \\
.170\end{array}$ & $\begin{array}{l}.964 \\
.142\end{array}$ & $\begin{array}{r}1.070 \\
.180\end{array}$ & $\begin{array}{l}.966 \\
.141\end{array}$ & $\begin{array}{l}.961 \\
.137\end{array}$ \\
\hline .40 & $\begin{array}{l}M \\
S D\end{array}$ & $\begin{array}{l}.986 \\
.159\end{array}$ & $\begin{array}{r}1.010 \\
.187\end{array}$ & $\begin{array}{l}.994 \\
.188\end{array}$ & $\begin{array}{r}1.031 \\
.185\end{array}$ & $\begin{array}{r}1.004 \\
.183\end{array}$ \\
\hline .80 & $\begin{array}{l}M \\
S D\end{array}$ & $\begin{array}{l}.949 \\
.094\end{array}$ & $\begin{array}{r}1.139 \\
.150\end{array}$ & $\begin{array}{l}.968 \\
.146\end{array}$ & $\begin{array}{r}1.620 \\
.177\end{array}$ & $\begin{array}{r}1.114 \\
.146\end{array}$ \\
\hline \multicolumn{7}{|c|}{ Part II. Slope $=15$ degrees } \\
\hline-.80 & $\begin{array}{l}M \\
S D\end{array}$ & $\begin{array}{r}1.040 \\
.151\end{array}$ & $\begin{array}{r}2.292 \\
.912\end{array}$ & $\begin{array}{l}3.163 \\
1.241\end{array}$ & $\begin{array}{r}14.719 \\
1.756\end{array}$ & $\begin{array}{r}1.200 \\
.262\end{array}$ \\
\hline-.40 & $\begin{array}{l}M \\
S D\end{array}$ & $\begin{array}{l}.960 \\
.104\end{array}$ & $\begin{array}{r}1.266 \\
.273\end{array}$ & $\begin{array}{r}1.309 \\
.235\end{array}$ & $\begin{array}{r}13.364 \\
1.549\end{array}$ & $\begin{array}{r}.964 \\
.118\end{array}$ \\
\hline .00 & $\begin{array}{l}M \\
S D\end{array}$ & $\begin{array}{l}.941 \\
.139\end{array}$ & $\begin{array}{r}1.002 \\
.136\end{array}$ & $\begin{array}{l}.973 \\
.136\end{array}$ & $\begin{array}{r}13.115 \\
1.621\end{array}$ & $\begin{array}{l}.881 \\
.122\end{array}$ \\
\hline .40 & $\begin{array}{l}\mathrm{M} \\
\mathrm{SD}\end{array}$ & $\begin{array}{r}1.009 \\
.184\end{array}$ & $\begin{array}{r}1.104 \\
.240\end{array}$ & $\begin{array}{r}1.207 \\
.203\end{array}$ & $\begin{array}{r}12.916 \\
1.732\end{array}$ & $\begin{array}{r}1.038 \\
.214\end{array}$ \\
\hline .80 & $\begin{array}{l}\mathrm{M} \\
\mathrm{SD}\end{array}$ & $\begin{array}{r}1.011 \\
.200\end{array}$ & $\begin{array}{r}1.146 \\
.281\end{array}$ & $\begin{array}{l}.997 \\
.243\end{array}$ & $\begin{array}{r}13.490 \\
2.391\end{array}$ & $\begin{array}{r}1.108 \\
.273\end{array}$ \\
\hline Total & $\begin{array}{l}\mathrm{M} \\
\mathrm{SD}\end{array}$ & $\begin{array}{r}.983 \\
.148\end{array}$ & $\begin{array}{r}1.276 \\
.550\end{array}$ & $\begin{array}{r}1.454 \\
.909\end{array}$ & $\begin{array}{l}7.381 \\
6.315\end{array}$ & $\begin{array}{r}1.035 \\
.203\end{array}$ \\
\hline
\end{tabular}


Table 3

Means and Standard Deviations of Estimate of Error Variance for $30 \%$

Missing Data.... Criterion $=1$.

\begin{tabular}{|c|c|c|c|c|c|c|}
\hline Phi & & $\begin{array}{l}\text { Part } \\
\text { Complete } \\
\text { Data }\end{array}$ & $\begin{array}{l}\text { Slope } \\
\text { Delete }\end{array}$ & $\begin{array}{l}\text { O degrees } \\
\text { Mean } \\
\text { Adjacent }\end{array}$ & $\begin{array}{l}\text { Mean } \\
\text { Series }\end{array}$ & $\begin{array}{l}\text { Max. } \\
\text { Like. }\end{array}$ \\
\hline-.80 & $\begin{array}{l}M \\
S D\end{array}$ & $\begin{array}{r}1.045 \\
.101\end{array}$ & $\begin{array}{r}2.057 \\
.588\end{array}$ & $\begin{array}{r}3.388 \\
.721\end{array}$ & $\begin{array}{r}1.861 \\
.332\end{array}$ & $\begin{array}{r}1.282 \\
.176\end{array}$ \\
\hline-.40 & $\begin{array}{l}\mathrm{M} \\
\mathrm{SD}\end{array}$ & $\begin{array}{l}.898 \\
.138\end{array}$ & $\begin{array}{l}.966 \\
.184\end{array}$ & $\begin{array}{r}1.239 \\
.247\end{array}$ & $\begin{array}{l}.948 \\
.183\end{array}$ & $\begin{array}{l}.910 \\
.179\end{array}$ \\
\hline .00 & SD & $\begin{array}{l}.995 \\
.170\end{array}$ & $\begin{array}{l}.981 \\
.220\end{array}$ & $\begin{array}{r}1.150 \\
.266\end{array}$ & $\begin{array}{l}.990 \\
.222\end{array}$ & $\begin{array}{l}.982 \\
.220\end{array}$ \\
\hline .40 & $\begin{array}{l}M \\
S D\end{array}$ & $\begin{array}{l}.986 \\
.159\end{array}$ & $\begin{array}{r}1.059 \\
.175\end{array}$ & $\begin{array}{r}1.017 \\
.176\end{array}$ & $\begin{array}{r}1.073 \\
.171\end{array}$ & $\begin{array}{r}1.042 \\
.167\end{array}$ \\
\hline .80 & $\begin{array}{l}M \\
S D\end{array}$ & $\begin{array}{l}.949 \\
.094\end{array}$ & $\begin{array}{r}1.219 \\
.186\end{array}$ & $\begin{array}{l}.911 \\
.119\end{array}$ & $\begin{array}{r}1.874 \\
+329\end{array}$ & $\begin{array}{r}1.171 \\
.162\end{array}$ \\
\hline \multicolumn{7}{|c|}{ Part II. Slope $=15$ degrees } \\
\hline-.80 & $\begin{array}{l}M \\
S D\end{array}$ & $\begin{array}{r}1.040 \\
.151\end{array}$ & $\begin{array}{r}2.549 \\
.679\end{array}$ & $\begin{array}{l}3.593 \\
1.234\end{array}$ & $\begin{array}{r}19.756 \\
1.927\end{array}$ & $\begin{array}{r}1.300 \\
.207\end{array}$ \\
\hline-.40 & $\begin{array}{l}M \\
S D\end{array}$ & $\begin{array}{l}.960 \\
.104\end{array}$ & $\begin{array}{r}1.324 \\
.196\end{array}$ & $\begin{array}{l}1.796 \\
1.190\end{array}$ & $\begin{array}{r}18.457 \\
1.601\end{array}$ & $\begin{array}{r}1.027 \\
.118\end{array}$ \\
\hline .00 & $\begin{array}{l}M \\
S D\end{array}$ & $\begin{array}{l}.941 \\
.139\end{array}$ & $\begin{array}{r}1.104 \\
.277\end{array}$ & $\begin{array}{r}1.043 \\
.238\end{array}$ & $\begin{array}{r}18.211 \\
1.619\end{array}$ & $\begin{array}{l}.920 \\
.170\end{array}$ \\
\hline .40 & $\begin{array}{l}M \\
S D\end{array}$ & $\begin{array}{r}1.009 \\
.184\end{array}$ & $\begin{array}{r}1.148 \\
.201\end{array}$ & $\begin{array}{r}1.261 \\
.668\end{array}$ & $\begin{array}{r}17.776 \\
1.663\end{array}$ & $\begin{array}{r}1.052 \\
.236\end{array}$ \\
\hline .80 & $\begin{array}{l}M \\
S D\end{array}$ & $\begin{array}{r}1.011 \\
.200\end{array}$ & $\begin{array}{r}1.278 \\
.348\end{array}$ & $\begin{array}{r}1.003 \\
.243\end{array}$ & $\begin{array}{r}18.320 \\
3.221\end{array}$ & $\begin{array}{r}1.183 \\
.284\end{array}$ \\
\hline Total & $\begin{array}{l}M \\
S D\end{array}$ & $\begin{array}{l}.983 \\
.148\end{array}$ & $\begin{array}{r}1.369 \\
.598\end{array}$ & $\begin{array}{l}1.640 \\
1.141\end{array}$ & $\begin{array}{l}9.927 \\
8.756\end{array}$ & $\begin{array}{r}1.087 \\
.230\end{array}$ \\
\hline
\end{tabular}


Table 4

Means and Standard Deviations of Estimate of Error Variance for $40 \%$

Missing Data. Criterion $=1$.

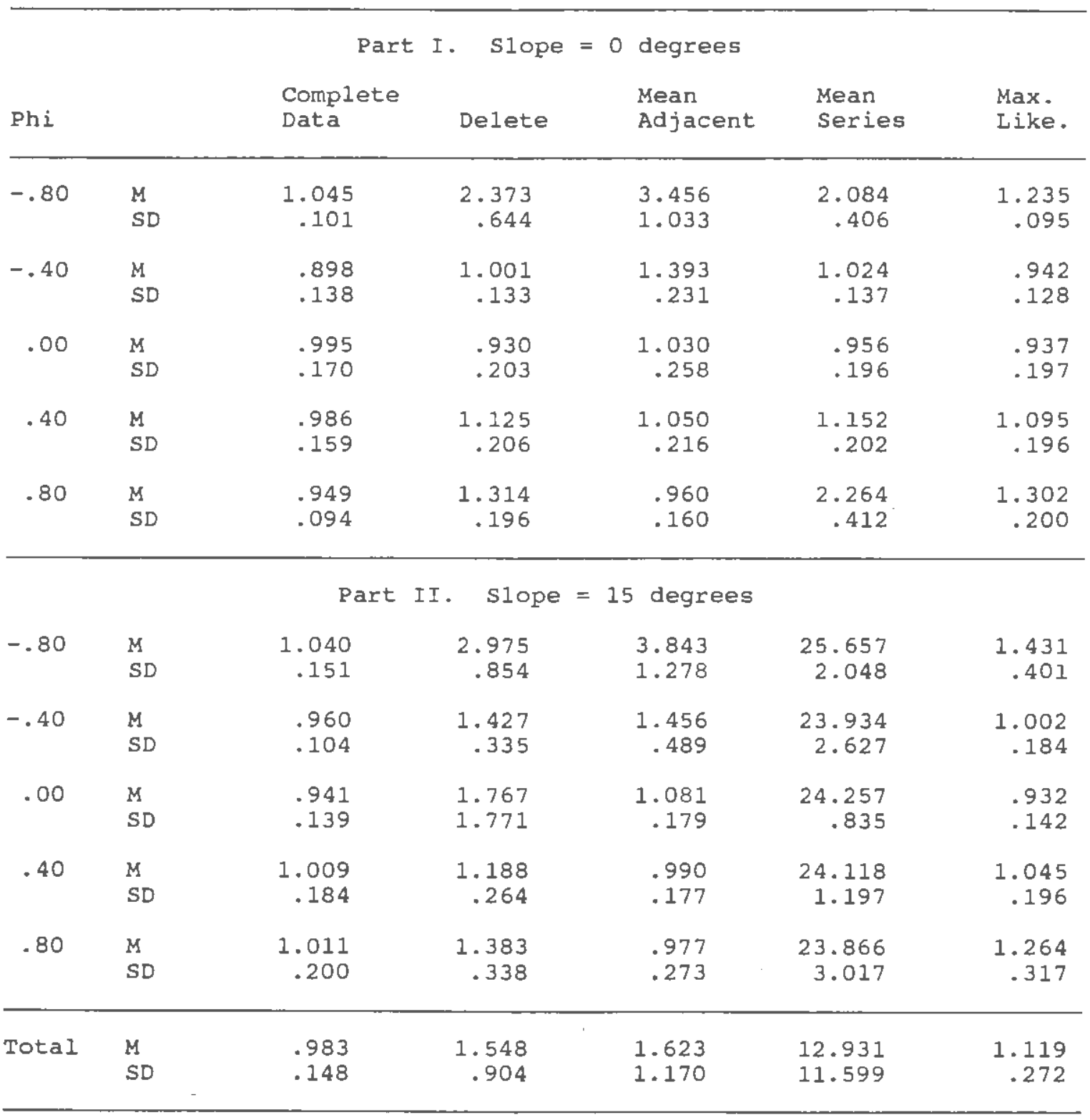




\section{Phi: Overview.}

Because phi was an independent variable in this study, five separate $2 \times 5 \times 4$ (slope by percent missing by technique) analysis of variance was done for each level of phi $(-.80,-.40,0, .40, .80)$. In this design, slope is a between-groups factor; percent missing and technique are both repeated measures (i.e., within-groups) factors. A. Phi $=-.80$.

Significant overall effects. All of the effects in the analysis of variance were significant. The main effects were: slope (F (1, 18) $=19.52, \mathrm{E}<.001)$ percent missing $(\underline{\mathrm{E}}(4,72)=192.11, \mathrm{Q}<.001)$ and technique $(\underline{E}(3,54)=601.37, \mathrm{P}<.001)$. The 2-way interactions were: slope by percent missing ( $\mathrm{E}(4,72)=6.65, \mathrm{E}<.001)$ and slope by technique $(\underline{E}(3,54)=92.50, \underline{D}<.001)$.

The 3-way interaction, technique by percent missing by slope (F $(12,216)=8.73, \mathrm{p}<.001)$ is presented in Figure 4. Simple effects tests found that the technique by percent missing interaction was significant at both levels of slope: 0 degrees $(\underline{F}(12,216)=519.30, \mathrm{p}$ $<.001)$ and 15 degrees $(\underline{F}(12,216)=691.23, \underline{p}<.001)$. Simple simple effects tests were significant at the $\underline{p}<.001$ level for technique at every combination of percent missing and slope. The results of these tests are presented in Appendix L (Part I).

Follow up tests of significance: Technigue by percent missing by slope interaction. Tukey tests were done to follow up the simple simple effects tests; mean differences had to exceed .095 to be significant at the $\mathrm{p}<.05$ level. 


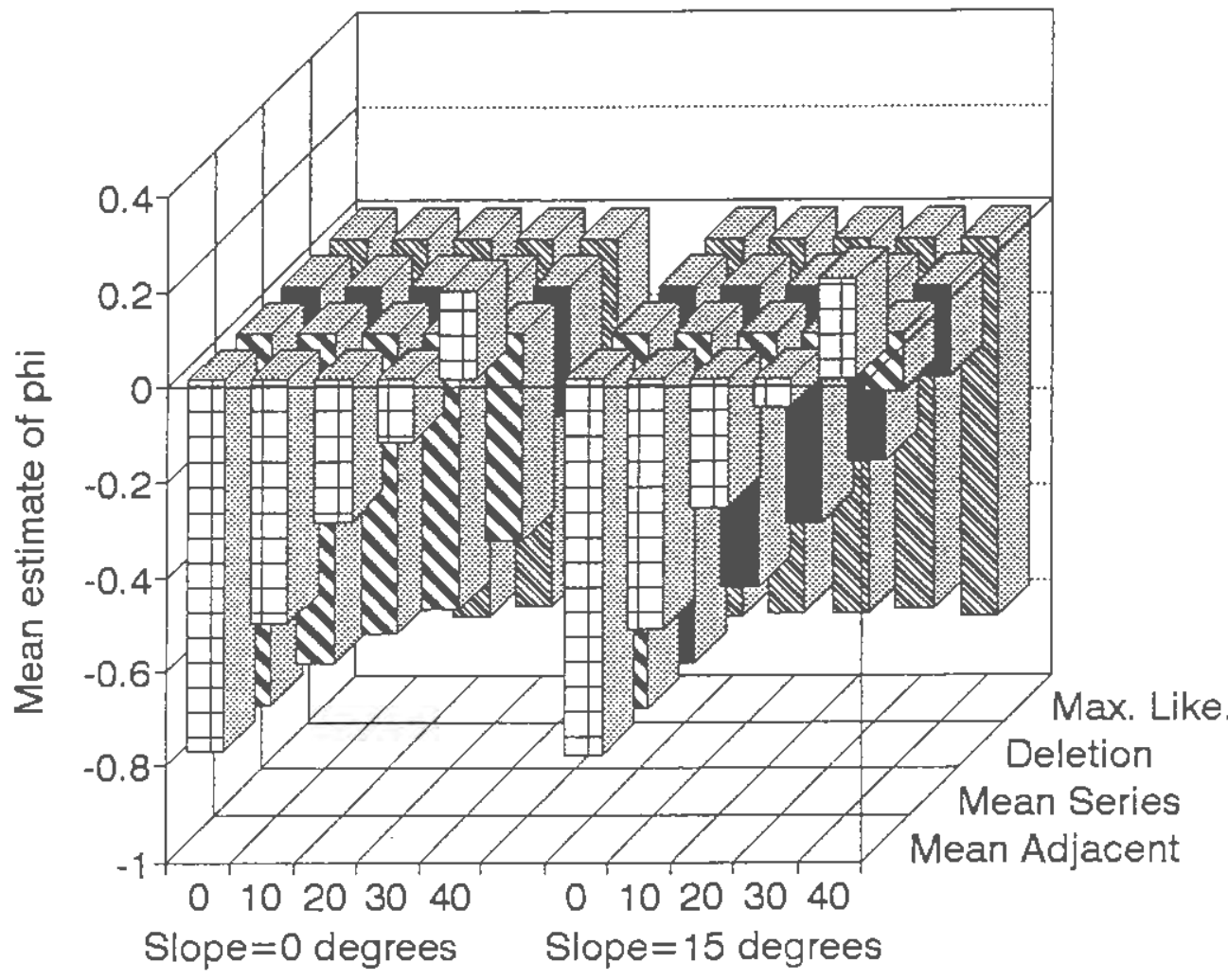

Percentage of data points missing

Figure 4. Mean estimates of phi as a function of missing data technique, percent data missing, and slope of series. Criterion $=-.80$. 
Major findings: As demonstrated in Figure 4 , use of the maximum likelihood approach yielded accurate estimates of phi under all conditions. All of the other techniques generally underestimated phi, and estimation was slightly less accurate when slope $=15$ degrees as opposed to o degrees. Using mean of the adjacent observations produced the least accurate estimates of phi; these estimates got substantially worse at each increasing level of missing data. At 408 missing data, this approach estimated phi to be moderately positive, at approximately .20 (see Table 5, Part I, for means and standard deviations).

Minor findings. Deletion underestimated phi, and was significantly less accurate than mean of the series, under all conditions. When slope $=0$ degrees and only 10 of of the data were missing, mean of the series was accurate; otherwise mean of the series underestimated phi.

B. $\quad$ Phi $=-.40$.

Significant overall effects. All of the effects in this analysis were significant, except the main effect for slope. significant effects included: main effects for percent missing $(\underline{F}(4,72)=68.30, \underline{p}<.001)$ and technique $(\underline{F}(3,54)=176.37, \underline{p}<.001) ; 2$-way interaction effects for percent missing by slope $(\mathrm{F}(4,72)=7.20, \mathrm{p}<.001)$, technique by slope $(\underline{F}(3,54)=18.02, \underline{p}<.001)$, and percent missing by technique $(\underline{F}$ $(12,216)=38.36, \mathrm{p}<.001)$; and the 3 -way interaction for technique by percent missing by slope $(\underline{\mathrm{F}}(12,216)=5.20, \mathrm{p}<.001)$. Simple effects tests showed the 3-way interaction to be significant at both levels of slope: O degrees $(\underline{F}(12,216)=205.29, \mathrm{p}$ 
Table 5

Means and Standard Deviations of Estimate of Phi.

\begin{tabular}{|c|c|c|c|c|c|c|c|}
\hline \multirow[b]{2}{*}{$\begin{array}{l}\text { Percent } \\
\text { Missing }\end{array}$} & \multirow[b]{2}{*}{ slope } & & \multirow{2}{*}{$\begin{array}{l}\text { Part I. } \\
\text { Complete }\end{array}$} & \multicolumn{2}{|c|}{ Eriterion $=-.80$} & \multirow[b]{2}{*}{$\begin{array}{l}\text { Mean } \\
\text { Series }\end{array}$} & \multirow[b]{2}{*}{$\begin{array}{l}\text { Max. } \\
\text { Iike. }\end{array}$} \\
\hline & & & & Delete & $\begin{array}{l}\text { Mean } \\
\text { Adjacent }\end{array}$ & & \\
\hline \multirow[t]{2}{*}{$10 \%$} & 0 & $\begin{array}{l}M \\
S D\end{array}$ & $\begin{array}{r}-.783 \\
.053\end{array}$ & $\begin{array}{r}-.658 \\
.051\end{array}$ & $\begin{array}{r}-.513 \\
.093\end{array}$ & $\begin{array}{r}-.696 \\
.071\end{array}$ & $\begin{array}{r}-.781 \\
.052\end{array}$ \\
\hline & 15 & $\begin{array}{l}\text { M } \\
\text { SD }\end{array}$ & $\begin{array}{r}-.792 \\
.064\end{array}$ & $\begin{array}{r}-.632 \\
.052\end{array}$ & $\begin{array}{r}-.526 \\
.056\end{array}$ & $\begin{array}{r}-.295 \\
.128\end{array}$ & $\begin{array}{r}-.788 \\
.073\end{array}$ \\
\hline \multirow[t]{2}{*}{$20 \%$} & 0 & $\begin{array}{l}M \\
\text { SD }\end{array}$ & $\begin{array}{r}-.783 \\
.053\end{array}$ & $\begin{array}{r}-.563 \\
.123\end{array}$ & $\begin{array}{r}-.295 \\
.160\end{array}$ & $\begin{array}{r}-.632 \\
.086\end{array}$ & $\begin{array}{r}-.793 \\
.058\end{array}$ \\
\hline & 15 & $\begin{array}{l}M \\
S D\end{array}$ & $\begin{array}{r}-.792 \\
.064\end{array}$ & $\begin{array}{r}-.459 \\
.123\end{array}$ & $\begin{array}{r}-.266 \\
.144\end{array}$ & $\begin{array}{r}-.106 \\
.117\end{array}$ & $\begin{array}{r}-.786 \\
.060\end{array}$ \\
\hline \multirow[t]{2}{*}{308} & 0 & $\begin{array}{l}M \\
S D\end{array}$ & $\begin{array}{r}-.783 \\
.053\end{array}$ & $\begin{array}{r}-.519 \\
.127\end{array}$ & $\begin{array}{r}-.132 \\
+120\end{array}$ & $\begin{array}{r}-.580 \\
.071\end{array}$ & $\begin{array}{r}-.770 \\
.081\end{array}$ \\
\hline & 15 & $\begin{array}{l}M \\
S D\end{array}$ & $\begin{array}{r}-.792 \\
.064\end{array}$ & $\begin{array}{r}-.368 \\
.190\end{array}$ & $\begin{array}{r}-.059 \\
+164\end{array}$ & $\begin{array}{r}-.093 \\
.162\end{array}$ & $\begin{array}{r}-.779 \\
.056\end{array}$ \\
\hline \multirow[t]{3}{*}{40 安 } & 0 & $\begin{array}{l}M \\
\text { SD }\end{array}$ & $\begin{array}{r}-.783 \\
.053\end{array}$ & $\begin{array}{r}-.271 \\
.162\end{array}$ & $\begin{array}{l}.188 \\
.151\end{array}$ & $\begin{array}{r}-.437 \\
.097\end{array}$ & $\begin{array}{r}-.807 \\
.064\end{array}$ \\
\hline & 15 & $\begin{array}{l}M \\
S D\end{array}$ & $\begin{array}{r}-.792 \\
.064\end{array}$ & $\begin{array}{r}-.191 \\
.091\end{array}$ & $\begin{array}{l}.210 \\
.113\end{array}$ & $\begin{array}{r}-.123 \\
.145\end{array}$ & $\begin{array}{r}-.792 \\
.053\end{array}$ \\
\hline & & & Part II. & Criterion & $=-.40$ & & \\
\hline \multirow[t]{2}{*}{$10 \%$} & 0 & $\begin{array}{l}\mathrm{M} \\
\mathrm{SD}\end{array}$ & $\begin{array}{r}-.376 \\
.139\end{array}$ & $\begin{array}{r}-.346 \\
.137\end{array}$ & $\begin{array}{r}-.222 \\
.165\end{array}$ & $\begin{array}{r}-.358 \\
.147\end{array}$ & $\begin{array}{r}-.389 \\
.154\end{array}$ \\
\hline & 15 & $\begin{array}{l}M \\
S D\end{array}$ & $\begin{array}{r}-.424 \\
.098\end{array}$ & $\begin{array}{r}-.287 \\
.129\end{array}$ & $\begin{array}{r}-.221 \\
.107\end{array}$ & $\begin{array}{r}-.083 \\
.139\end{array}$ & $\begin{array}{r}-.410 \\
.108\end{array}$ \\
\hline
\end{tabular}


$<.001)$, and 15 degrees $(\underline{F}(12,216)=317.99, \underline{P}<.001)$. Simple simple effects tests were done to follow up these interactions, and were significant for technique at every combination of percent missing and slope. The results of these tests are presented in Appendix L (Part II).

Follow up tests of significance: Technique by percent missing by slope interaction. Tukey tests were done to follow up the simple simple effects tests; estimates of phi had to be different by more than .111 to be significantly different at the $\mathrm{D}<.05$ level.

Major findings. Again, the maximum likelihood technique resulted in accurate estimates of phi under every set of conditions, all other techniques generally underestimated phi, and estimation was slightly worse when slope $=15$ degrees rather than 0 degrees. Mean of the adjacent observations was the most inaccurate approach.

As Figure 5 demonstrates, mean of the adjacent observations significantly underestimated the negative autocorrelation under every condition. By $20 \%$ missing data, this approach was estimating phi to be between 0 and -0.1 . At $30 \%$ and $40 \%$ missing data, moderately positive autocorrelation was estimated, ranging from .13 to .22 when slope $=0$, and from .21 to .32 when slope $=15$ degrees. See Tables 5 and 6 for means and standard deviations.

Minor findings, When slope $=0$, deletion was accurate at all levels of missing data, except 308, when it underestimated phi. Mean of the series was accurate until 408 of the data were missing, when it 


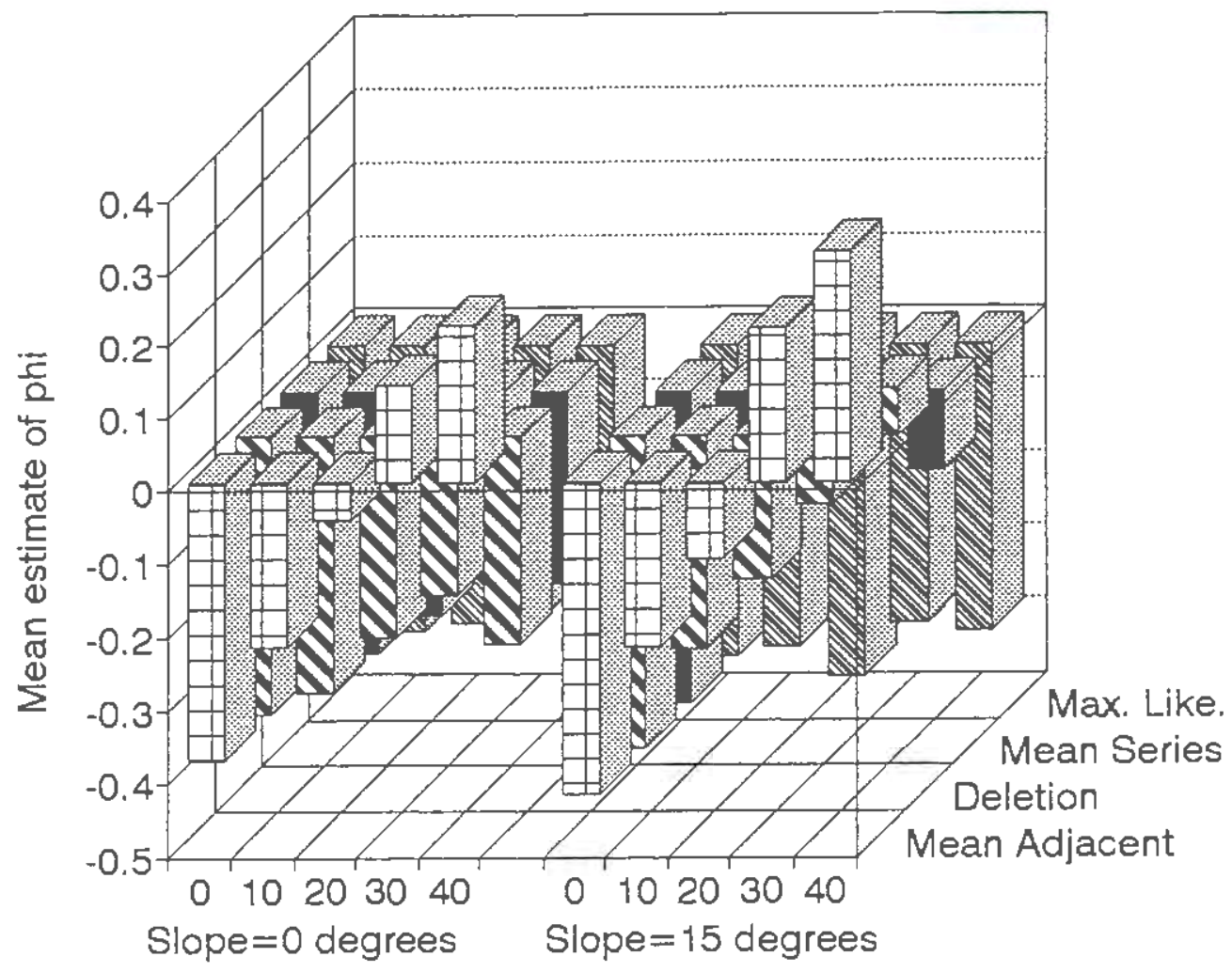

Percentage of data points missing

Figure 5. Mean estimates of phi as a function of missing data technique, percent data missing, and slope of series. Criterion $=-.40$. 
Table 6

Means and Standard Deviations of Estimate of Phi.

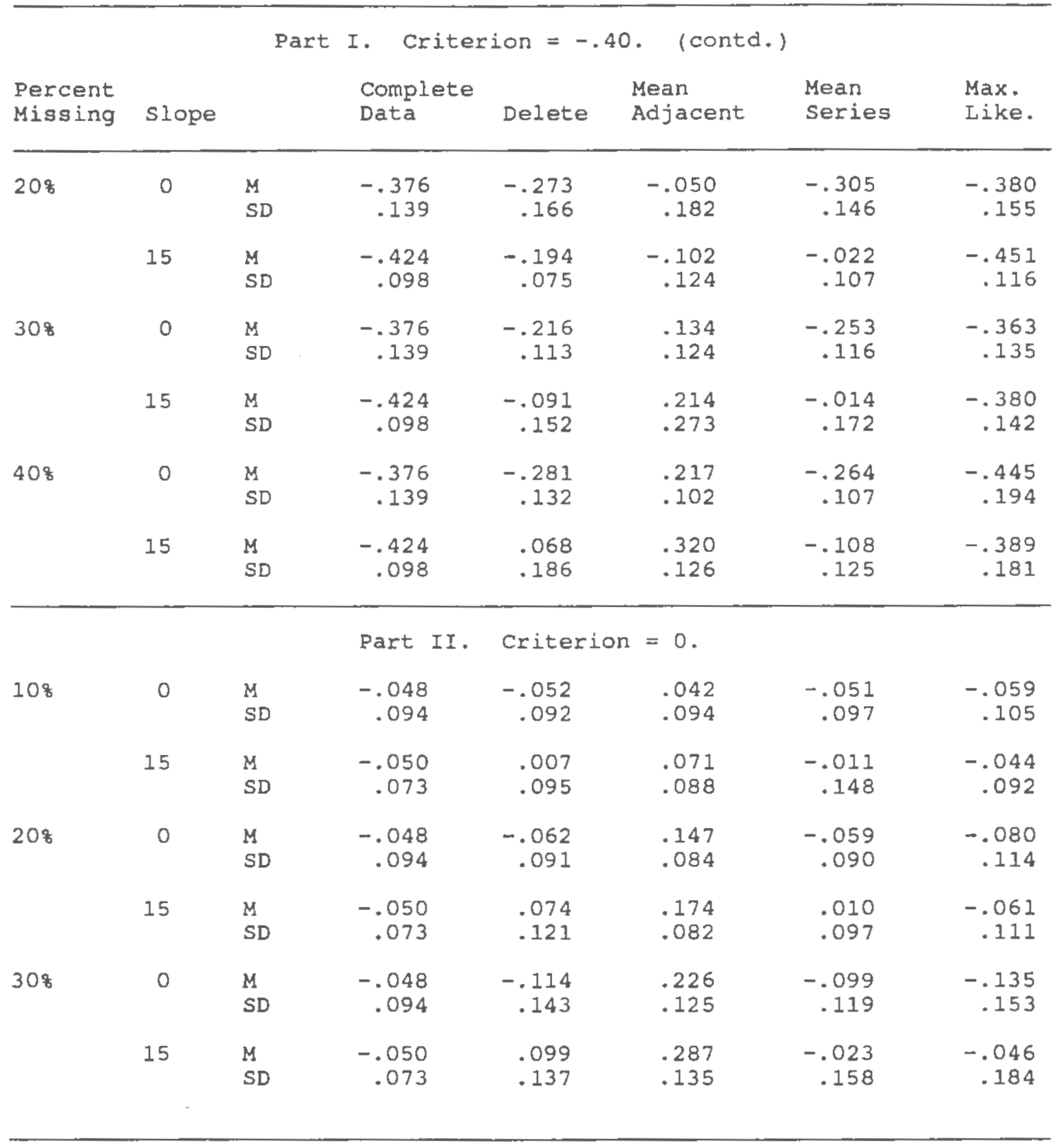


underestimated phi. When slope $=15$ degrees, both of these techniques significantly underestimated phi at every level of missing data.

C. $\operatorname{Ph} i=0$.

Significant overall effects. In this analysis, significant main effects were found for percent missing $(\underline{E}(4,72)=8.89, \mathrm{p}<.001)$ and technique $(\underline{F}(3,54)=161.38, \underline{p}<.001)$. As in the moderate negative autocorrelation (phi $=-.40$ ) condition, the main effect for slope was not significant. All 2-way interactions were significant: percent missing by slope $(\underline{F}(4,72)=3.03, \underline{p}<.05)$, technique by slope (E $(3$, $54)=8.62, \underline{\underline{p}}<.001)$, and percent missing by technique $(\underline{\underline{F}}(12,216)=$ $29.96, \underline{\mathrm{p}}<.001)$. The 3 -way interaction, technique by percent missing by slope, was also significant $(\underline{F}(12,216)=2.11, \underline{p}<.05)$ and is presented in Figure 6.

Simple effects tests demonstrated that the technique by percent missing interaction was significant at slope $=0$ degrees $(\underline{F}(12,216)=$ $192.80, \underline{p}<.001)$ and at slope $=15$ degrees $(\underline{F}(12,216)=192.80, \underline{p}$ <.001). Simple simple effects tests were done as a follow up to these tests, and were significant for technique at every combination of percent missing and slope. The results of these tests are presented in Appendix $M$ (Part I).

Follow up tests of significance: Technique by percent missing by slope. Tukey tests were done with alpha set at .05; group mean differences had to be greater than .087 to be significant.

Major findings. As Figure 6 demonstrates, using the mean of the adjacent observations led to severe overestimates of phi. This approach 


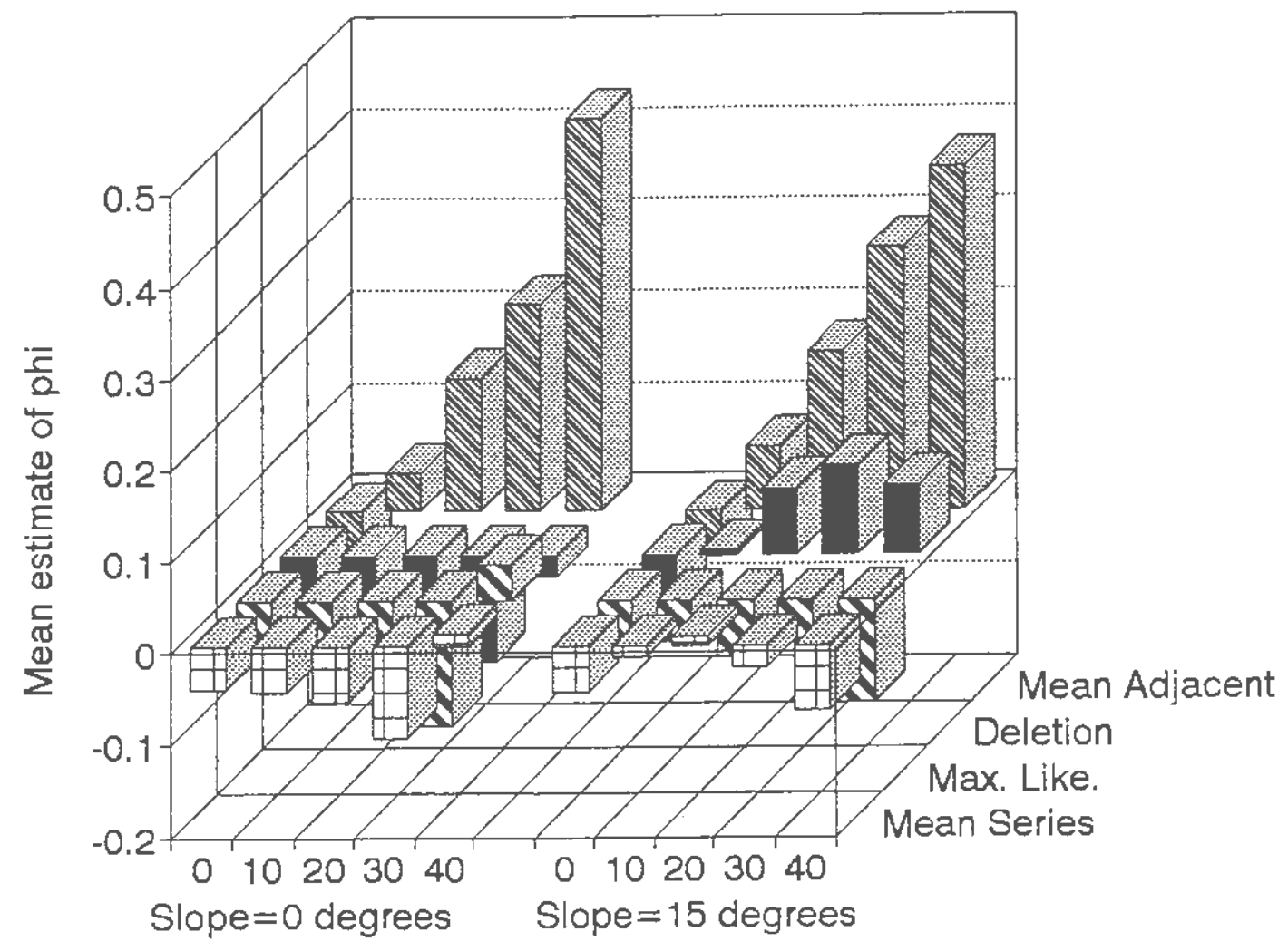

Percentage of data points missing

Figure 6. Mean estimates of phi as a function of missing data technique, percent data missing, and slope of series. Criterion $=0$. 
Table 7

Means and Standard Deviations of Estimate of Phi.

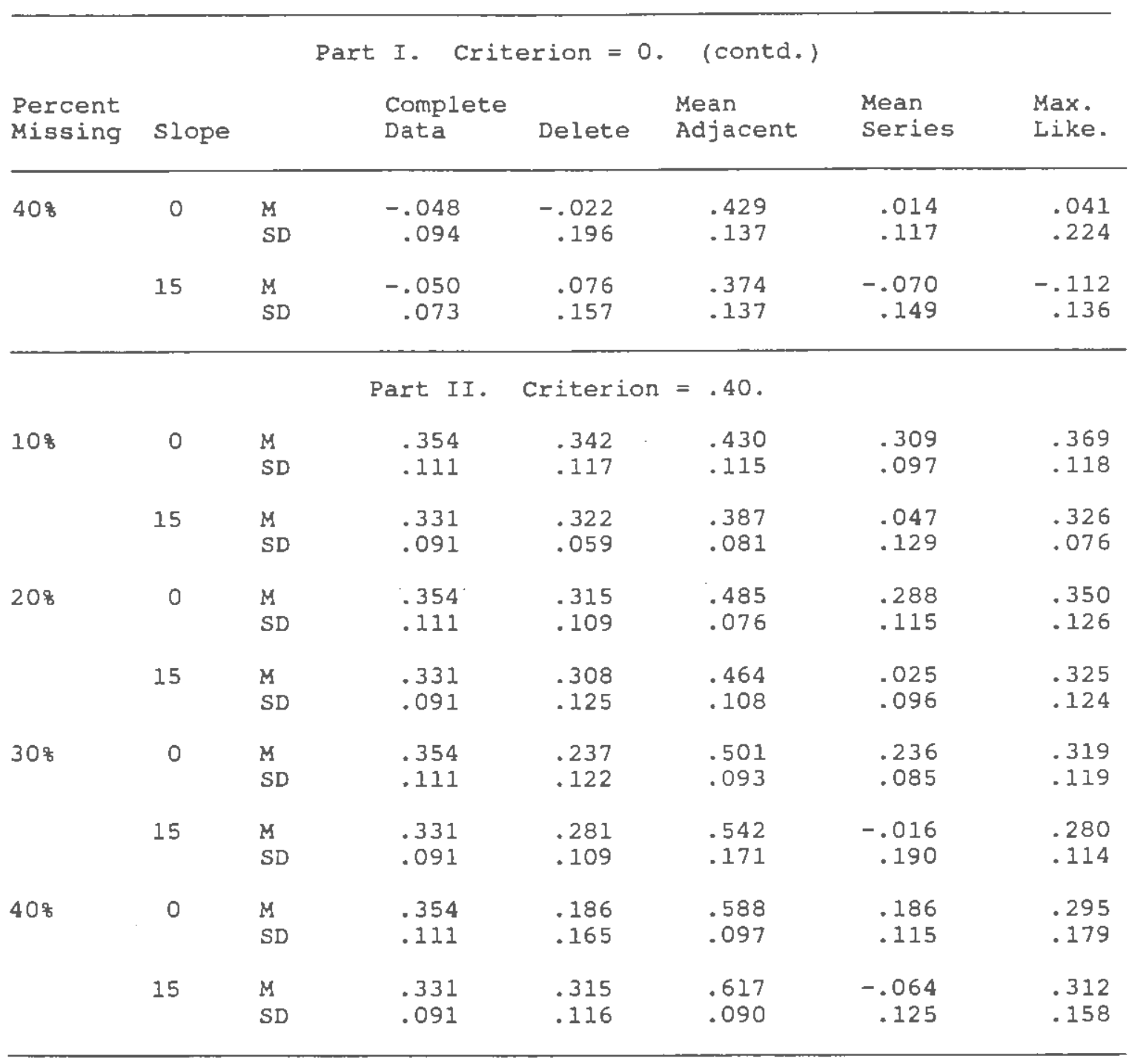


significantly overestimated phi in every condition, and its estimation got substantially worse as percent missing data increased.

Minor findings. Except for one minor exception, all other techniques led to accurate estimates of phi when slope $=0$ degrees, regardless of the percent of data missing.

When slope $=0$ degrees and $40 \%$ of the data were missing, maximum likelihood overestimated phi. The mean difference between maximum likelihood and the complete data set was .089 (i.e., exceeded the critical value for the Tukey test by .002). This is the only condition in this study under which the maximum likelihood approach was inaccurate.

When slope $=15$ degrees, maximum likelihood and mean of the series resulted in accurate phi estimates at all levels of missing data. Deletion was accurate when $10 \%$ of the data were missing, but at higher levels of missing data, deletion resulted in significant overestimates of phi. See Tables 6 and 7 for means and standard deviations. D. Phi $=.40$.

Sicnificant overall effects. This analysis of the moderate positive autocorrelation condition showed less significant effects than the other levels of phi. There was a significant main effect for technique $(\underline{F}(3,54)=188.54, \underline{p}<.001)$; and technique significantly interacted with slope $(\underline{F}(3,54)=35.41, \underline{\underline{Q}}<.001)$ and with percent missing $(\underline{F}(12,216)=32.64, \underline{\mathrm{p}}<.001)$. The 3 -way interaction between technique, percent missing, and slope was also significant $(F(12,216)$ $=4.61, \underline{\mathrm{p}}(.001)$. No other effects were significant. 
Simple effects tests showed the technique by percent missing interaction to be significant at both levels of slope: 0 degrees ( $\underline{F}$ ( 12 , $216)=139.74, \underline{\mathrm{p}<.001)}$ and 15 degrees $(\underline{E}(12,216)=310.04, \mathrm{p}<.001)$. Simple simple effects tests were significant for technique at every level of missing data and slope. The results of these tests are presented in Appendix $M$, Part II.

Follow up tests of significance: Technique by percent missing by slope. Tukey tests were done with alpha set at .05 and the critical value for group mean differences $=.089$.

Major findings. Figure 7 demonstrates that when autocorrelation was moderately positive (i.e., .40), mean of the adjacent observations and mean of the series were both inaccurate. Mean of the adjacent observations overestimated phi when more than $10 \%$ of the data were missing. At 40 o missing data, this approach led to average estimater of phi ranging from .59 to .62 (see Table 7 ).

Using mean of the series resulted in underestimates of phi. This approach was less accurate when slope $=15$ degrees, when its phi estimates ranged between .1 and -.1 . When slope $=0$ degrees, mean of the series moderately underestimated phi after 308 of the data were missing.

Use of the maximum likelihood approach resulted in accurate estimates of phi under all conditions.

Minor findings. Deletion was generally accurate in this condition. When slope $=15$ degrees, deletion estimated phi accurately at every level of missing data. When slope = 0 degrees, deletion only 


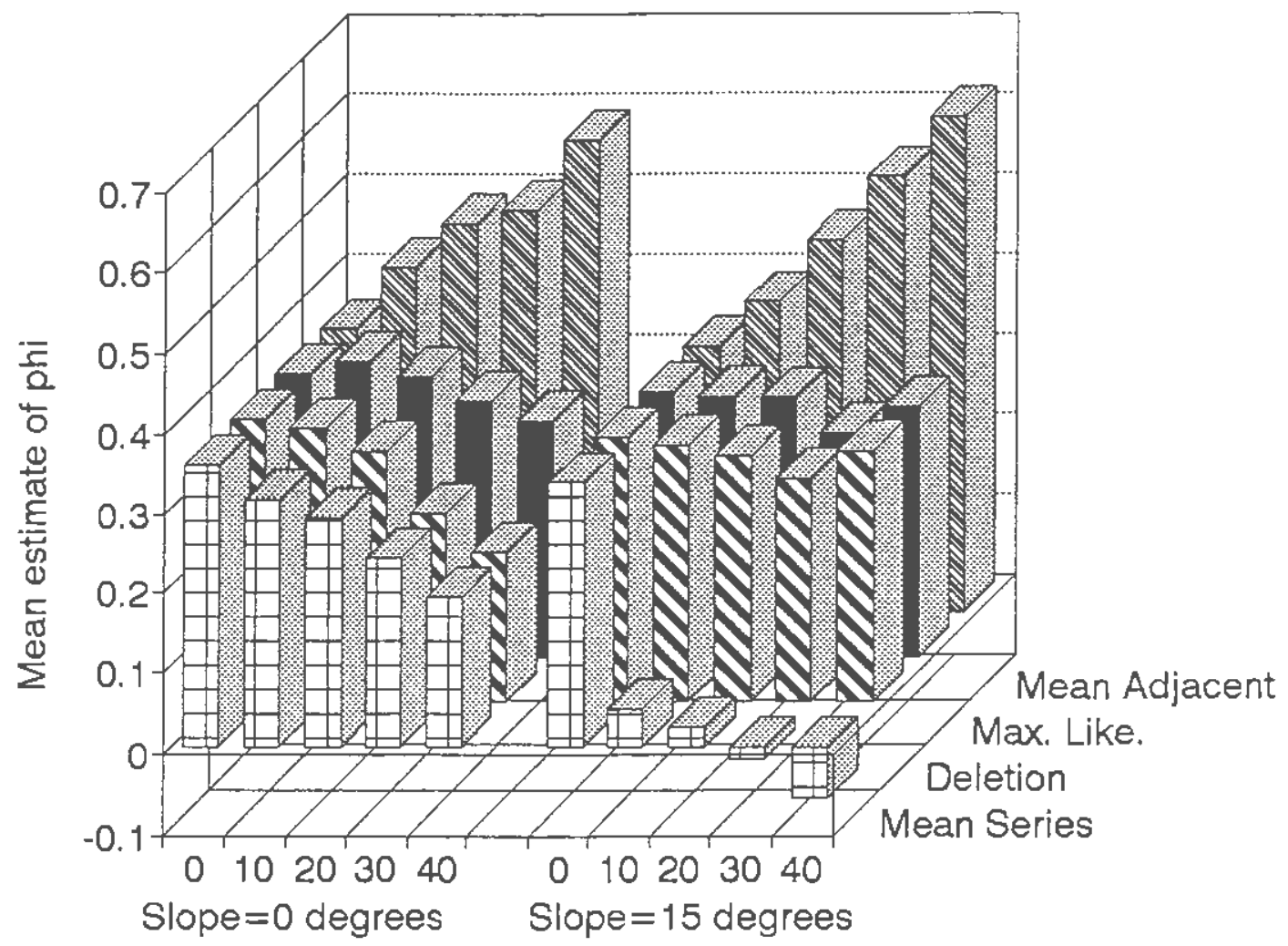

Percentage of data points missing

Figure 7. Mean estimates of phi as a function of missing data technique, percent data missing, and slope of series. Criterion $=.40$. 
underestimated phi when 30 or more of the data were missing. The means and standard deviations are presented in Table 7 Part II. E. Phi $=.80$.

Significant overall effects. As in the analysis of the severe negative autocorrelation condition, all of the effects were significant in the severe positive autocorrelation condition. The main effects were: slope $(\underline{F}(1,18)=18.33, \underline{\underline{p}}<.001)$; percent $\operatorname{missing}(\underline{F}(4,72)=$ $41.50, \underline{\mathrm{p}}<.001)$; and technique $(\underline{\underline{F}}(3,54)=693.21, \underline{\mathrm{p}}<.001)$. The 2way interactions were: percent missing by slope $(\underline{F}(4,72)=6.51$, $\underline{p}$ <.001): technique by slope $(\underline{F}(3,54)=149.46, \underline{p}<.001)$; and percent missing by technique $(\underline{E}(12,216)=78.35$, p $<.001)$.

The 3-way interaction between technique, percent missing and slope ( F $(12,216)=14.43, \underline{D}<.001)$ is presented in Figure 8 . Simple effects tests showed the technique by percent missing interaction to be significant at slope $=0$ degrees $(\underline{\underline{F}}(12,216)=255.62, \underline{p}<.001)$ and slope $=15$ degrees $(\underline{F}(12,216)=856.74, \underline{p}<.001)$. Simple simple effects tests were significant for technique at every combination of percent missing and slope. The results of these tests are presented in Appendix N.

Follow up tests of significance: Technique by percent missing by slope interaction. As a follow up to the simple simple effects tests, Tukey tests were run, with alpha level set at .05. Mean differences had to exceed .076 to be significant.

Major findings. Regardless of whether slope was 0 or 15 degrees, and regardless of the percentage of data missing from the series, use of 


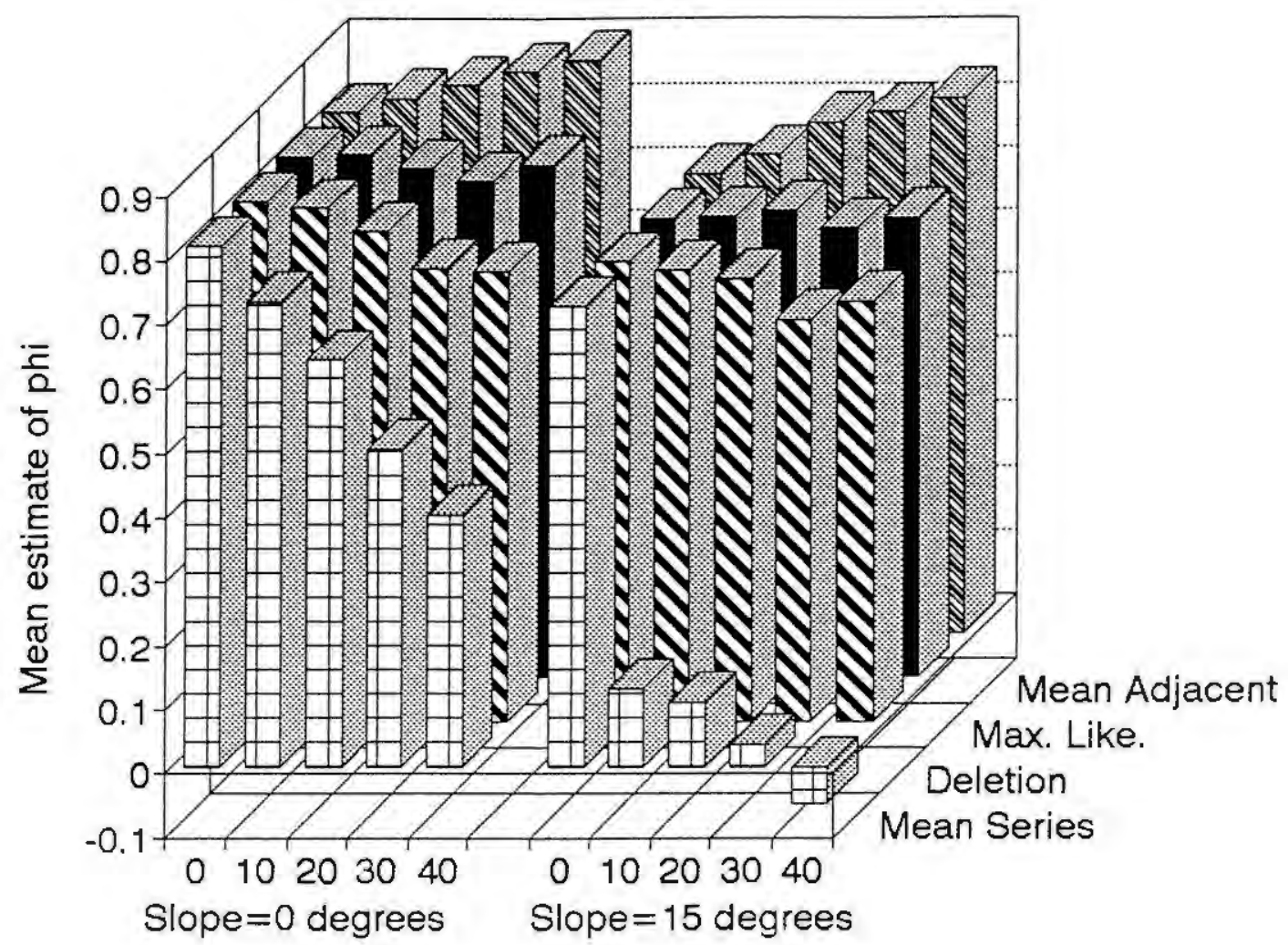

Percentage of data points missing

Figure 8. Mean estimates of phi as a function of missing data technique, percent data missing, and slope of series. Criterion $=.80$. 
maximum likelihood always resulted in accurate estimates of phi, and use of the mean of the series always led to underestimates of phi (see Figure 8). Estimates of phi when using mean of the series were substantially worse when slope = 15 degrees, with estimates ranging from .12 when $10 \%$ of the data were missing, to -.06 at 408 missing data.

Minor findings. Deletion and mean of the adjacent observations were moderately acceptable. In the 0 slope conditions, deletion began to underestimate phi when $30 \%$ of the data were missing. When $40 \%$ of the data were missing, mean of the adjacent observations overestimated phi. Otherwise, these techniques were accurate.

When slope = 15 degrees, deletion resulted in accurate estimates of phi at all levels of missing data except $30 \%$, when it underestimated phi. Mean of the adjacent observations was accurate when only 10 of the data were missing; after that, phi was significantly overestimated. While these differences are statistically significant, the actual magnitude of mean differences is moderate.

Level.

A $2 \times 5 \times 5 \times 4$ (slope $\times$ phi $x$ percent missing $x$ technique) analysis of variance was used to compare the estimates of level associated with using each of the four techniques for handing missing data, under all of the experimental conditions. Slope and phi were between-groups factors, and percent missing and technique were withingroups factors in this analysis. The means and standard deviations for each condition are presented in Tables 9 through 12. 
Table 8

Means and Standard Deviations of Estimates of Phi.

\begin{tabular}{|c|c|c|c|c|c|c|c|}
\hline \multirow{3}{*}{$\begin{array}{l}\text { Percent } \\
\text { Missing } \\
108\end{array}$} & \multicolumn{5}{|c|}{ Criterion $=.80$} & \multirow[b]{2}{*}{$\begin{array}{l}\text { Mean } \\
\text { Series }\end{array}$} & \multirow[b]{2}{*}{$\begin{array}{l}\text { Max. } \\
\text { Like. }\end{array}$} \\
\hline & \multicolumn{2}{|l|}{ Slope } & \multirow{2}{*}{$\begin{array}{l}\begin{array}{l}\text { Complete } \\
\text { Data }\end{array} \\
.811 \\
.088\end{array}$} & \multirow{2}{*}{$\begin{array}{c}\text { Delete } \\
.801 \\
.090\end{array}$} & \multirow{2}{*}{$\begin{array}{l}\begin{array}{l}\text { Mean } \\
\text { Adjacent }\end{array} \\
.835 \\
.082\end{array}$} & & \\
\hline & 0 & $\begin{array}{l}M \\
S D\end{array}$ & & & & $\begin{array}{l}.725 \\
.064\end{array}$ & $\begin{array}{l}.816 \\
.092\end{array}$ \\
\hline & 15 & $\begin{array}{l}M \\
S D\end{array}$ & $\begin{array}{l}.715 \\
.117\end{array}$ & $\begin{array}{l}.704 \\
.121\end{array}$ & $\begin{array}{l}.746 \\
.112\end{array}$ & $\begin{array}{l}.122 \\
.153\end{array}$ & $\begin{array}{r}.718 \\
.128\end{array}$ \\
\hline 208 & 0 & $\begin{array}{l}\mathrm{M} \\
\mathrm{SD}\end{array}$ & $\begin{array}{l}.811 \\
.088\end{array}$ & $\begin{array}{l}.764 \\
.100\end{array}$ & $\begin{array}{l}.855 \\
.069\end{array}$ & $\begin{array}{l}.633 \\
.087\end{array}$ & $\begin{array}{l}.794 \\
.083\end{array}$ \\
\hline & 15 & $\begin{array}{l}M \\
S D\end{array}$ & $\begin{array}{l}.715 \\
.117\end{array}$ & $\begin{array}{l}.689 \\
.156\end{array}$ & $\begin{array}{l}.796 \\
.115\end{array}$ & $\begin{array}{l}.101 \\
.086\end{array}$ & $\begin{array}{l}.726 \\
.136\end{array}$ \\
\hline 308 & 0 & $\begin{array}{l}M \\
S D\end{array}$ & $\begin{array}{l}.811 \\
.088\end{array}$ & $\begin{array}{l}.706 \\
.126\end{array}$ & $\begin{array}{l}.876 \\
.059\end{array}$ & $\begin{array}{l}.494 \\
.151\end{array}$ & $\begin{array}{l}.775 \\
.083\end{array}$ \\
\hline & 15 & $\begin{array}{l}M \\
S D\end{array}$ & $\begin{array}{l}.715 \\
.117\end{array}$ & $\begin{array}{l}.624 \\
.065\end{array}$ & $\begin{array}{l}.812 \\
.095\end{array}$ & $\begin{array}{l}.035 \\
.184\end{array}$ & $\begin{array}{l}.698 \\
.080\end{array}$ \\
\hline 408 & 0 & $\begin{array}{l}M \\
S D\end{array}$ & $\begin{array}{l}.811 \\
.088\end{array}$ & $\begin{array}{l}.702 \\
.123\end{array}$ & $\begin{array}{l}.892 \\
.051\end{array}$ & $\begin{array}{l}.392 \\
.066\end{array}$ & $\begin{array}{l}.802 \\
.090\end{array}$ \\
\hline & 15 & $\begin{array}{l}\mathrm{M} \\
\mathrm{SD}\end{array}$ & $\begin{array}{l}.715 \\
.117\end{array}$ & $\begin{array}{l}.654 \\
.146\end{array}$ & $\begin{array}{l}.835 \\
.088\end{array}$ & $\begin{array}{r}-.059 \\
.133\end{array}$ & $\begin{array}{l}.717 \\
.132\end{array}$ \\
\hline
\end{tabular}


Table 9

Means and Standard Deviations of Estimate of Level (L) for 108 Missing Data. Criterion $=0$.

Part I. Slope $=0$ degrees

\begin{tabular}{|c|c|c|c|c|c|c|}
\hline \multicolumn{2}{|l|}{ Phi } & $\begin{array}{l}\text { Complete } \\
\text { Data }\end{array}$ & Delete & $\begin{array}{l}\text { Mean } \\
\text { Adjacent }\end{array}$ & $\begin{array}{l}\text { Mean } \\
\text { Series }\end{array}$ & $\begin{array}{l}\text { Max. } \\
\text { Like. }\end{array}$ \\
\hline-.80 & $\begin{array}{l}\mathrm{M} \\
\mathrm{SD}\end{array}$ & $\begin{array}{l}.015 \\
.131\end{array}$ & $\begin{array}{l}.023 \\
.168\end{array}$ & $\begin{array}{l}.025 \\
.216\end{array}$ & $\begin{array}{l}.020 \\
.153\end{array}$ & $\begin{array}{l}.014 \\
.152\end{array}$ \\
\hline-.40 & $\begin{array}{l}M \\
\text { SD }\end{array}$ & $\begin{array}{r}-.043 \\
.130\end{array}$ & $\begin{array}{r}-.014 \\
.161\end{array}$ & $\begin{array}{l}.001 \\
.186\end{array}$ & $\begin{array}{r}-.011 \\
.149\end{array}$ & $\begin{array}{r}-.021 \\
.155\end{array}$ \\
\hline .00 & $\begin{array}{l}M \\
S D\end{array}$ & $\begin{array}{r}-.029 \\
.155\end{array}$ & $\begin{array}{r}-.044 \\
.153\end{array}$ & $\begin{array}{r}-.045 \\
.152\end{array}$ & $\begin{array}{r}-.043 \\
.137\end{array}$ & $\begin{array}{r}-.036 \\
.155\end{array}$ \\
\hline .40 & $\begin{array}{l}M \\
S D\end{array}$ & $\begin{array}{l}.001 \\
.223\end{array}$ & $\begin{array}{r}-.026 \\
.230\end{array}$ & $\begin{array}{r}-.027 \\
.238\end{array}$ & $\begin{array}{r}-.012 \\
.231\end{array}$ & $\begin{array}{r}-.008 \\
.248\end{array}$ \\
\hline .80 & $\begin{array}{l}M \\
S D\end{array}$ & $\begin{array}{l}-.472 \\
1.944\end{array}$ & $\begin{array}{l}-.516 \\
1.949\end{array}$ & $\begin{array}{l}-.505 \\
2.080\end{array}$ & $\begin{array}{l}-.450 \\
1.331\end{array}$ & $\begin{array}{l}-.609 \\
1.978\end{array}$ \\
\hline
\end{tabular}

Part II. Slope $=15$ degrees

\begin{tabular}{|c|c|c|c|c|c|c|}
\hline-.80 & $\begin{array}{l}M \\
\text { SD }\end{array}$ & $\begin{array}{l}.148 \\
.097\end{array}$ & $\begin{array}{l}.010 \\
.325\end{array}$ & $\begin{array}{l}.110 \\
.228\end{array}$ & $\begin{array}{r}1.412 \\
.345\end{array}$ & $\begin{array}{r}.117 \\
.116\end{array}$ \\
\hline-.40 & $\begin{array}{l}\text { M } \\
\text { SD }\end{array}$ & $\begin{array}{l}.043 \\
.136\end{array}$ & $\begin{array}{r}-.035 \\
.303\end{array}$ & $\begin{array}{l}.080 \\
.160\end{array}$ & $\begin{array}{r}1.370 \\
.310\end{array}$ & $\begin{array}{l}.063 \\
.128\end{array}$ \\
\hline .00 & $\begin{array}{l}M \\
S D\end{array}$ & $\begin{array}{r}-.064 \\
.258\end{array}$ & $\begin{array}{r}-.092 \\
.259\end{array}$ & $\begin{array}{r}-.022 \\
.269\end{array}$ & $\begin{array}{r}1.328 \\
.255\end{array}$ & $\begin{array}{r}-.046 \\
.274\end{array}$ \\
\hline .40 & $\begin{array}{l}M \\
S D\end{array}$ & $\begin{array}{r}-.027 \\
.383\end{array}$ & $\begin{array}{r}-.168 \\
.494\end{array}$ & $\begin{array}{r}-.065 \\
.383\end{array}$ & $\begin{array}{r}1.255 \\
.498\end{array}$ & $\begin{array}{r}-.060 \\
.377\end{array}$ \\
\hline .80 & $\begin{array}{l}M \\
S D\end{array}$ & $\begin{array}{l}-.118 \\
1.729\end{array}$ & $\begin{array}{l}-.248 \\
1.541\end{array}$ & $\begin{array}{l}-.051 \\
1.732\end{array}$ & $\begin{array}{r}.547 \\
.928\end{array}$ & $\begin{array}{l}-.149 \\
1.642\end{array}$ \\
\hline Total & $\begin{array}{l}M \\
S D\end{array}$ & $\begin{array}{r}-.055 \\
.819\end{array}$ & $\begin{array}{r}-.111 \\
.803\end{array}$ & $\begin{array}{r}-.050 \\
.857\end{array}$ & $\begin{array}{l}.542 \\
.884\end{array}$ & $\begin{array}{r}-.073 \\
.820\end{array}$ \\
\hline
\end{tabular}


Table 10

Means and Standard Deviations of Estimate of Level (L) for 20 s Missing

Data. Criterion $=0$.

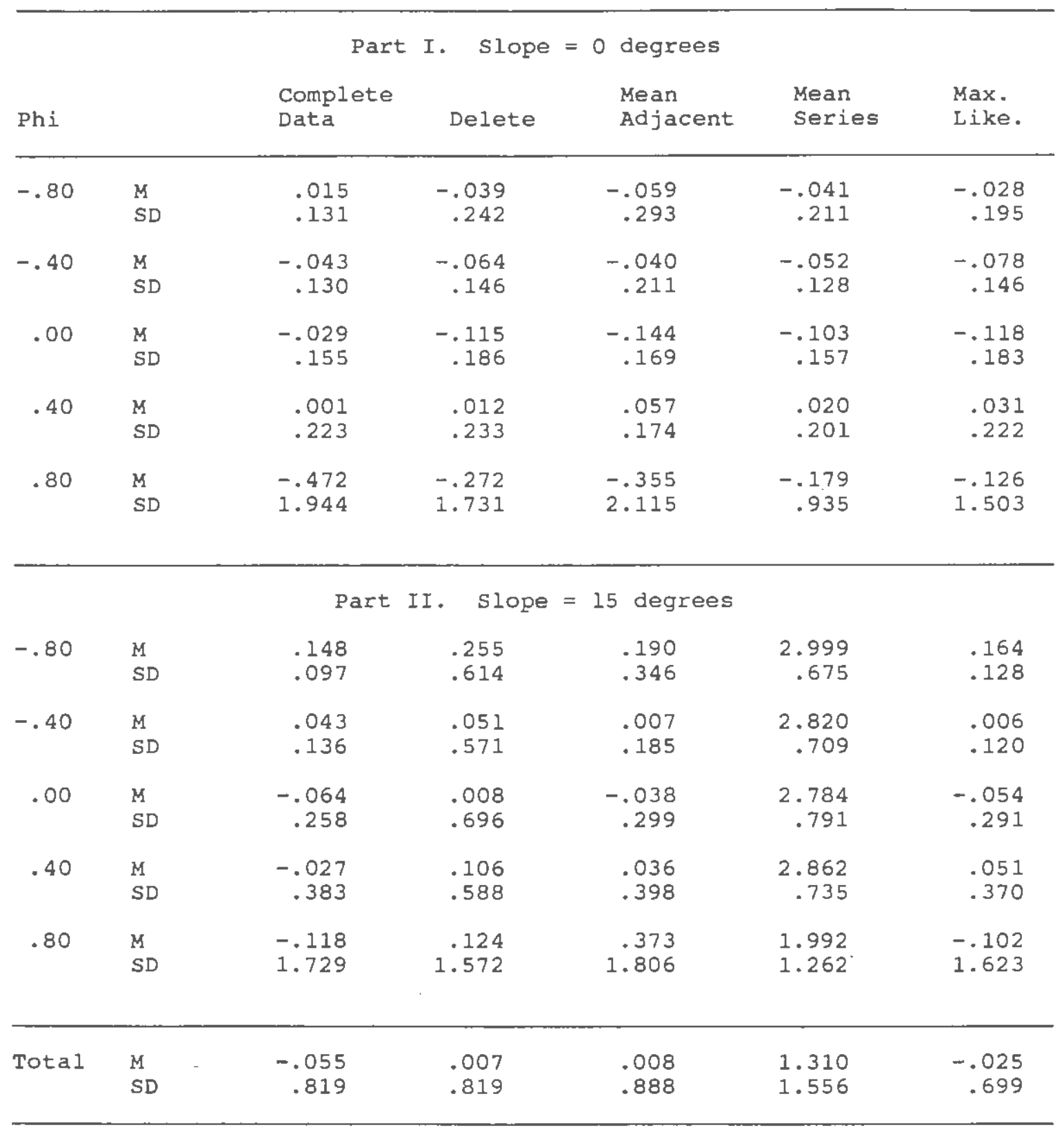


Table 11

Means and Standard Deviations of Estimate of Level (L) for $30 \%$ Missing Data. Criterion $=0$.

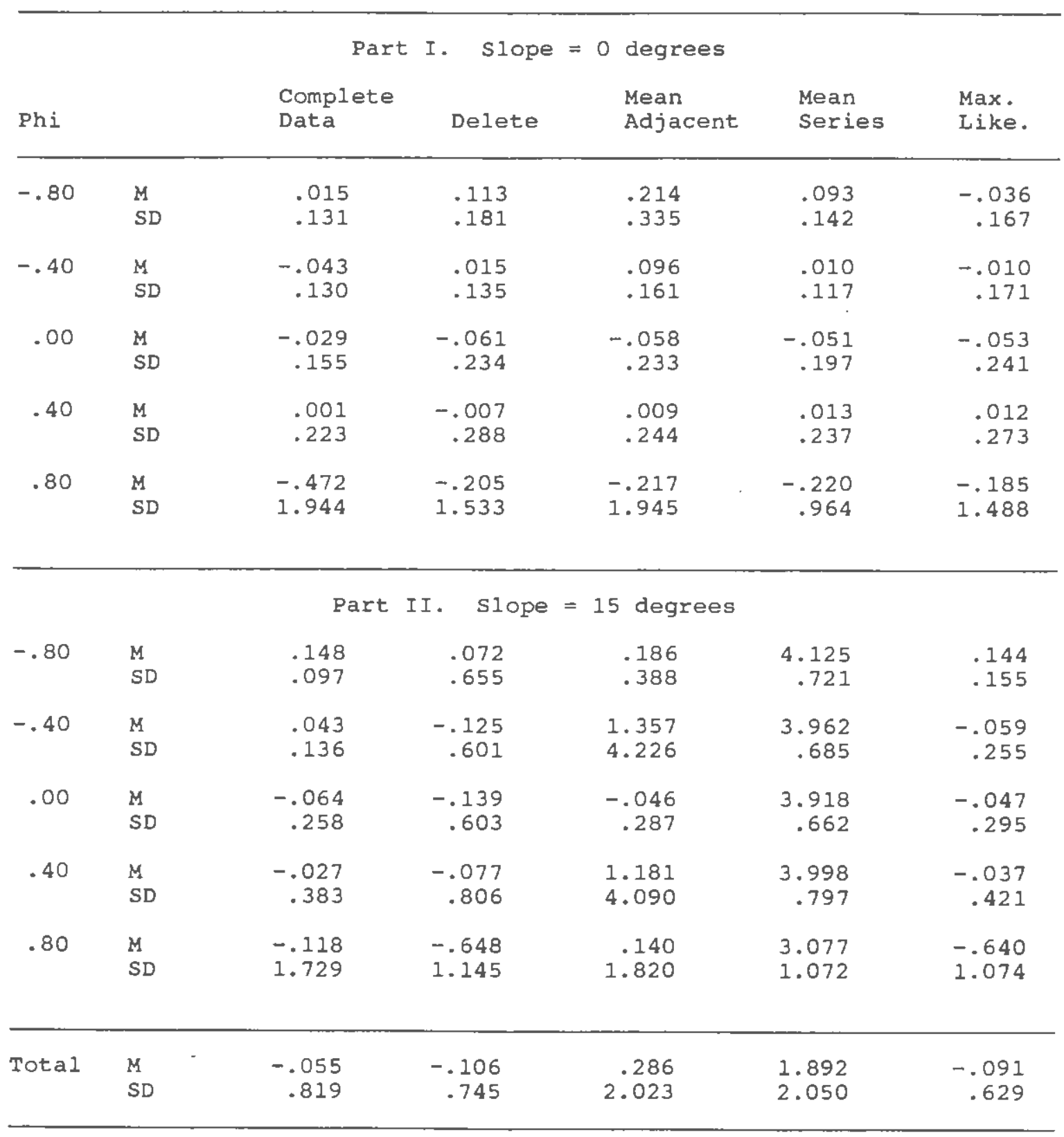


Table 12

Means and standard Deviations of Estimate of Level (L) for 408 Missing Data. Criterion $=0$.

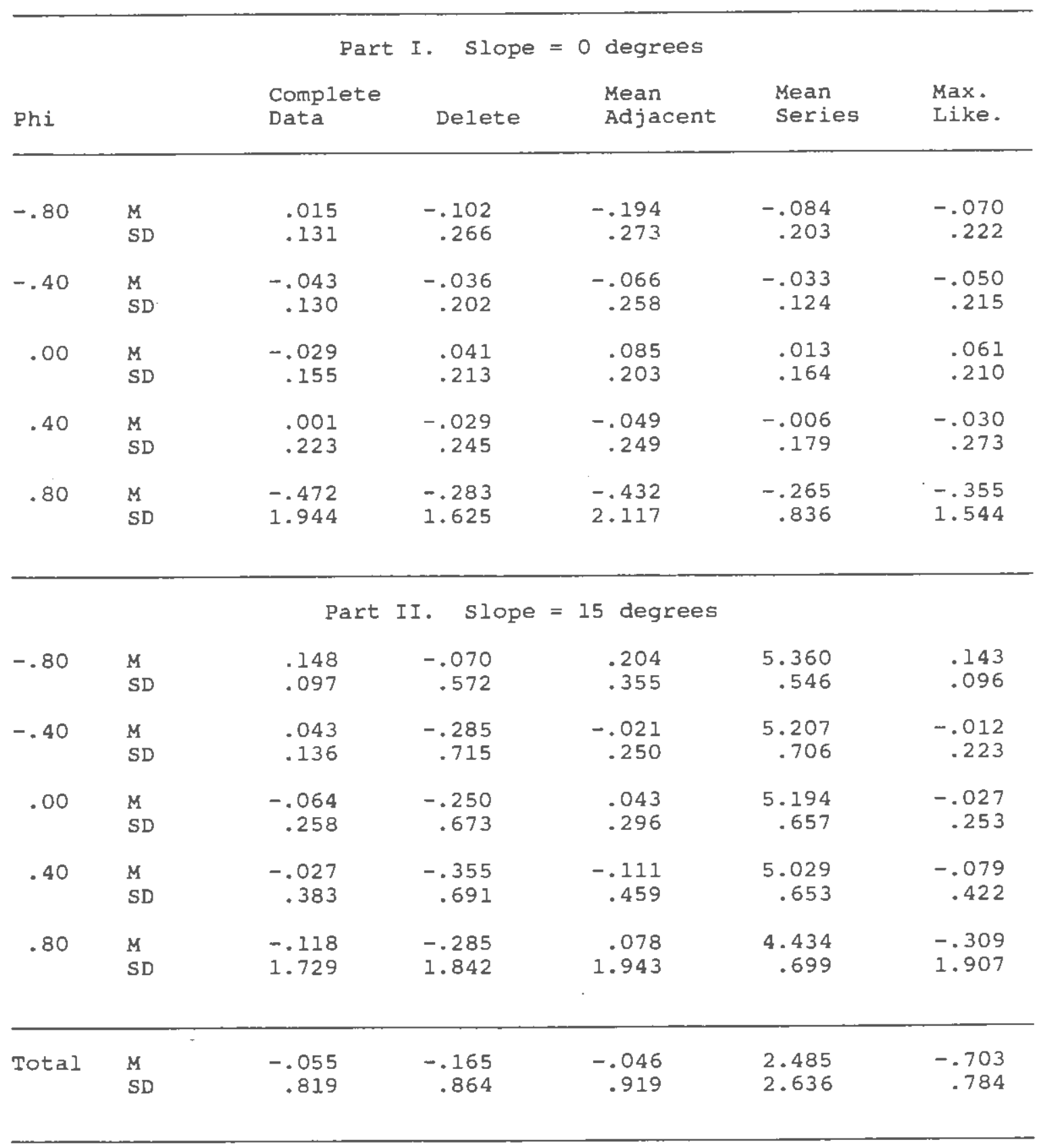


Significant overall effects. There were significant main effects for slope $(\underline{\underline{F}}(1,90)=25.93, \underline{\mathrm{p}}<.001)$, percent missing $(\underline{\underline{F}}(4,360)=$ $66.47, \underline{P}<.001)$, and technique $(\underline{F}(3,270)=488.04, \mathrm{P}<.001)$. The main effect for phi was not significant. There were three significant 2-way interactions: slope interacted with percent missing $(\underline{F}(4,360)=$ $56.48, \mathrm{P}<.001)$, and with technique $(\underline{E}(3,270)=479.82, \mathrm{P}<.001)$, and technique interacted with percent missing $(\underline{F}(12,1080)=102.88, \mathrm{p}$ $<.001$ ).

There was one significant 3-way interaction: technique by percent missing by slope $(\underline{E}(12,1080)=101.56, \underline{P}<.001)$. Simple effects tests found the interaction between technique and percent missing was only significant when slope $=15$ degrees $(\underline{\mathrm{F}}(12,1080)=200.59, \underline{\mathrm{p}}<.001)$. When slope was zero degrees, all of the missing data techniques performed equally well, and none of their level estimates were significantly different from those based on complete data. See Figure 9 for the graph of this 3-way interaction.

To examine the nature of the 3-way interaction when slope $=15$ degrees, simple simple effects tests were performed. These tests found significant mean differences for technique at each level of missing data: at 108 missing, $(\underline{F}(3,1350)=194.90, \underline{p}<.001)$; at 208 missing, $(\underline{F}(3,1350)=890.14, \underline{p}<.001) ;$ at 308 missing, $(\underline{F}(3,1350)=$ $1873.23, \underline{p}<.001) ;$ and at $40 \%$ missing, $(\underline{F}(3,1350)=3439.48, \underline{p}<$ $.001)$

Follow up tests of significance: Technique by percent missing by slope. Tukey tests were used to determine which group mean differences 


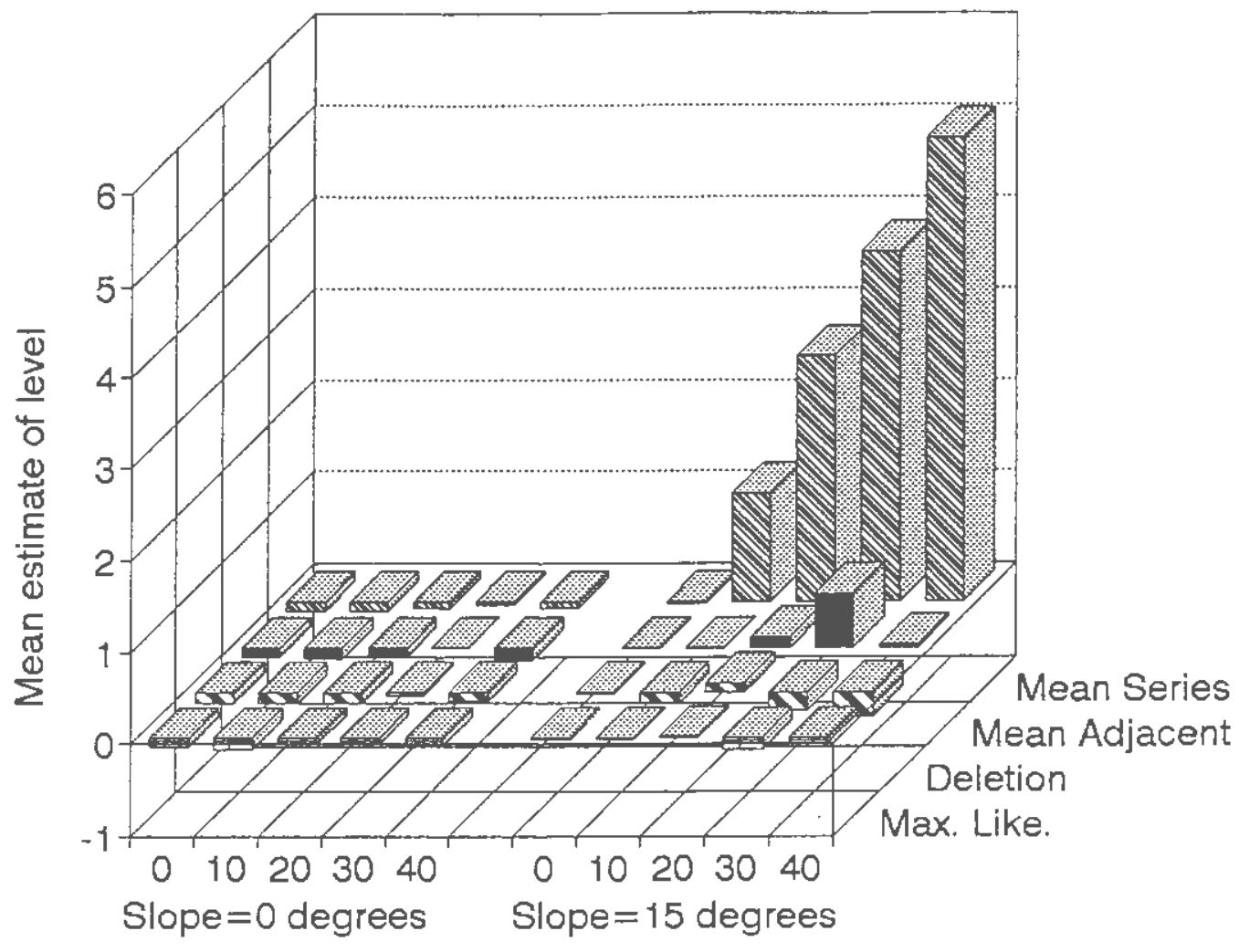

Percentage of data points missing

Figure 9. Mean estimates of level as a function of missing data technique, percent data missing, and slope of series. Criterion $=0$. 
accounted for the significant effects. The alpha level was set at .05, which resulted in a critical value of mean difference equal to .293 .

Major findings. As Figure 9 and the simple effects tests show, there were no significant effects when slope $=0$ degrees. When slope $=$ 15 degrees, using the mean of the series to handle missing data resulted in significantly inflated estimates of level. This approach produced inaccurate level estimates when only 108 of the data were missing (mean $=1.21$, and got worse as more data were missing. When 408 of the data were missing, mean of the series estimated level to be 5.0 . See Tables 9 through 12 for al1 means and standard deviations.

The other major finding was that both maximum likelihood and deletion resulted in accurate estimates of level under all conditions. Minor findings. When slope $=15$ degrees and $30 \%$ of the data were missing, using the mean of the adjacent observations yielded a significantly inflated estimate of level. This technique estimated level to be 56 (the criterion value was 0). However, at every other level of missing data, use of this technique resulted in accurate estimates of level.

Slope: Overview.

Separate $5 \times 5 \times 4$ (phi by percent missing by technique) analyses of variance were conducted for each value of slope used in the study (i.e., O and 15 degrees). Phi was a between-groups factor, percent missing and technique were within-groups factors. 


\section{A. Slope $=0$ degrees.}

Significant overall effects. When slope $=0$ degrees, there were no significant effects in the analysis. All techniques accurately estimated slope to be 0 degrees, regardless of the level of phi, or the percent of missing data. Means and standard deviations are presented in Tables 13 and 14 for slope $=0$.

\section{B. Slope $=15$ degrees.}

Significant overall effects. When slope $=15$ degrees, all main effects were significant: phi $(\underline{F}(4,45)=2.63, \mathrm{p}<.05)$; percent missing $(\underline{F}(4,180)=89.29, \underline{p}<.001) ;$ and technique $(\underline{F}(4,135)=$ 6153.54, ㄴ.001). There were also two significant 2-way interactions: technique by phi $(\underline{F}(12,135)=1.94, \underline{p}<.05)$, and technique by percent missing $(\underline{F}(12,540)=1339.06, \underline{p}<.001)$, which are presented in Figures 10 and 11 respectively. The 3 -way interaction (technique by percent missing by phi) was not significant.

Simple effects tests were done to follow up the interactions between technique and phi. These tests were significant for technique at every level of phi: $-.80(\underline{\underline{F}}(3,135)=2972.97, \mathrm{p}<.001) ;-.40$ ( $\underline{\mathrm{F}}$ (3, $135)=3040.54, \underline{\underline{a}}<.001) ; 0(\underline{F}(3,135)=2972.97, \underline{\underline{L}}<.001) ; .40(\underline{F}(3$, $135)=2972.97, \underline{p}<.001) ; .80(\underline{\underline{F}}(3,135)=2567.57, \underline{\underline{p}}<.001)$.

To follow up the technique by percent missing interaction, simple effects tests were performed. Significant effects were found at every level of missing data: $108(\underline{F}(3,675)=40, \underline{p}<.001) ; 208(\underline{F}(3,675)=$ $175, \underline{\underline{p}}<.001) ; 308(\underline{F}(3,675)=480, \underline{\underline{g}}<.001) ;$ and $408(\underline{F}(3,675)=$ $1020, \mathrm{p}<.001)$. 
Table 13

Means and Standard Deviations of Tangent of Slope, when slope $=0$

Degrees. Criterion $=0$.

108 Missing Data

$\begin{array}{llll} & \text { Complete } & \text { Mean } & \text { Mean Max. } \\ \text { Phi Data } & \text { Delete } & \text { Adjacent } & \text { Series }\end{array}$

\begin{tabular}{|c|c|c|c|c|c|c|}
\hline-.80 & $\begin{array}{l}\mathrm{M} \\
\mathrm{SD}\end{array}$ & $\begin{array}{l}.000 \\
.002\end{array}$ & $\begin{array}{r}-.001 \\
.003\end{array}$ & $\begin{array}{r}-.001 \\
.003\end{array}$ & $\begin{array}{r}-.001 \\
.002\end{array}$ & $\begin{array}{r}.000 \\
.002\end{array}$ \\
\hline-.40 & $\begin{array}{l}M \\
S D\end{array}$ & $\begin{array}{l}.001 \\
.002\end{array}$ & $\begin{array}{r}-.004 \\
.014\end{array}$ & $\begin{array}{l}.001 \\
.003\end{array}$ & $\begin{array}{l}.001 \\
.002\end{array}$ & $\begin{array}{l}.001 \\
.002\end{array}$ \\
\hline .00 & $\begin{array}{l}\mathrm{M} \\
\mathrm{SD}\end{array}$ & $\begin{array}{l}.000 \\
.003\end{array}$ & $\begin{array}{l}.000 \\
.004\end{array}$ & $\begin{array}{l}.000 \\
.003\end{array}$ & $\begin{array}{l}.000 \\
.003\end{array}$ & $\begin{array}{l}.000 \\
.003\end{array}$ \\
\hline .40 & $\begin{array}{l}M \\
S D\end{array}$ & $\begin{array}{l}.001 \\
.004\end{array}$ & $\begin{array}{l}.001 \\
.004\end{array}$ & $\begin{array}{l}.001 \\
.004\end{array}$ & $\begin{array}{l}.001 \\
.003\end{array}$ & $\begin{array}{l}.001 \\
.004\end{array}$ \\
\hline .80 & $\begin{array}{l}M \\
\text { SD }\end{array}$ & $\begin{array}{l}.008 \\
.029\end{array}$ & $\begin{array}{r}-.037 \\
.130\end{array}$ & $\begin{array}{l}.009 \\
.030\end{array}$ & $\begin{array}{l}.007 \\
.023\end{array}$ & $\begin{array}{r}.010 \\
.030\end{array}$ \\
\hline
\end{tabular}

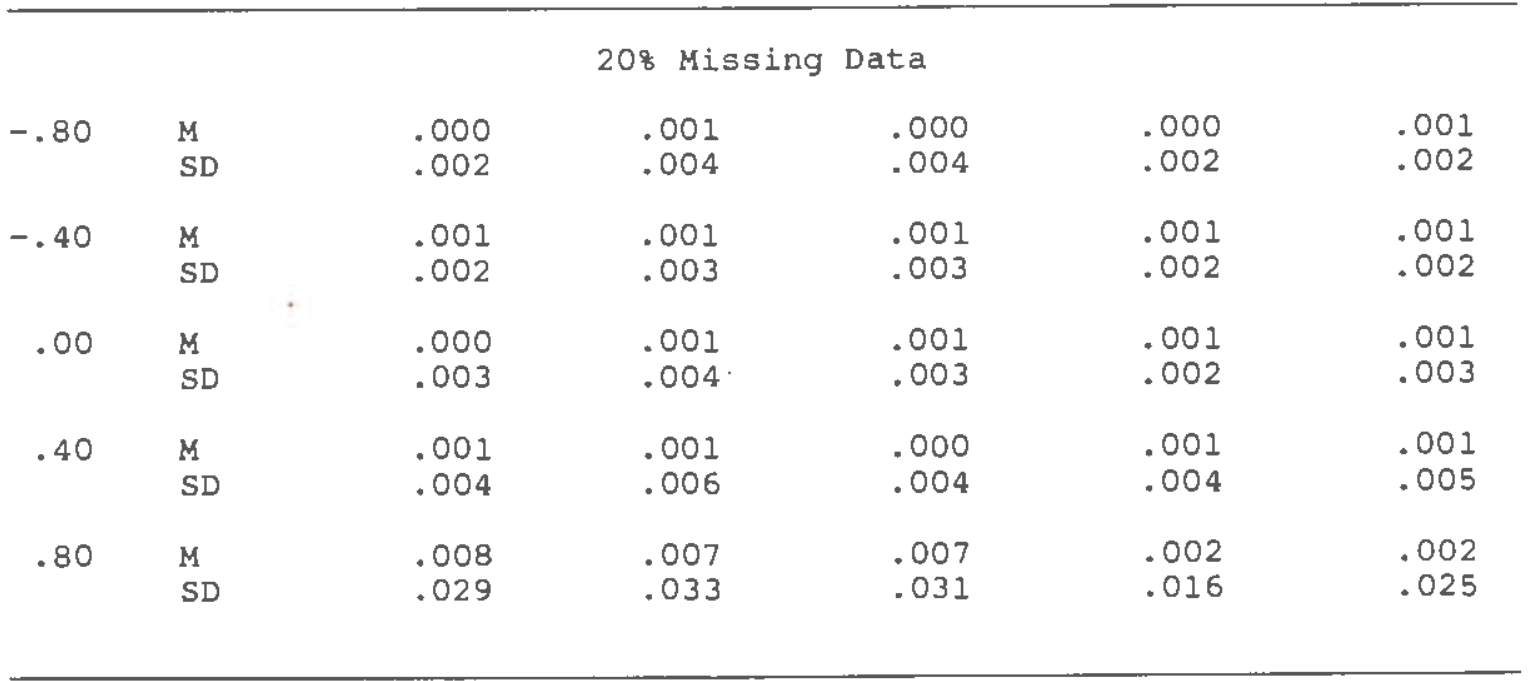


Table 14

Means and Standard Deviations of Tangent of Slope, when Slope $=0$

Degrees. Criterion $=0$.

308 Missing Data

\begin{tabular}{|c|c|c|c|c|c|c|}
\hline Phi & & $\begin{array}{l}\text { Complete } \\
\text { Data }\end{array}$ & Delete & $\begin{array}{l}\text { Mean } \\
\text { Adjacent }\end{array}$ & $\begin{array}{l}\text { Mean } \\
\text { Series }\end{array}$ & $\begin{array}{l}\text { Max. } \\
\text { Like. }\end{array}$ \\
\hline-.80 & $\begin{array}{l}\mathrm{M} \\
\mathrm{SD}\end{array}$ & $\begin{array}{l}.000 \\
.002\end{array}$ & $\begin{array}{r}-.002 \\
.004\end{array}$ & $\begin{array}{r}-.003 \\
.005\end{array}$ & $\begin{array}{r}-.001 \\
.002\end{array}$ & $\begin{array}{l}.001 \\
.003\end{array}$ \\
\hline-.40 & $\begin{array}{l}M \\
S D\end{array}$ & $\begin{array}{l}.001 \\
.002\end{array}$ & $\begin{array}{r}-.001 \\
.003\end{array}$ & $\begin{array}{r}-.002 \\
.003\end{array}$ & $\begin{array}{l}.000 \\
.001\end{array}$ & $\begin{array}{l}.000 \\
.002\end{array}$ \\
\hline .00 & $\begin{array}{l}M \\
S D\end{array}$ & $\begin{array}{l}.000 \\
.003\end{array}$ & $\begin{array}{l}.001 \\
.004\end{array}$ & $\begin{array}{l}.001 \\
.003\end{array}$ & $\begin{array}{l}.001 \\
.002\end{array}$ & $\begin{array}{l}.001 \\
.003\end{array}$ \\
\hline .40 & $\begin{array}{l}M \\
S D\end{array}$ & $\begin{array}{l}.001 \\
.004\end{array}$ & $\begin{array}{l}.001 \\
.008\end{array}$ & $\begin{array}{l}.001 \\
.004\end{array}$ & $\begin{array}{l}.000 \\
.003\end{array}$ & $\begin{array}{l}.001 \\
.005\end{array}$ \\
\hline .80 & $\begin{array}{l}M \\
S D\end{array}$ & $\begin{array}{l}.008 \\
.029\end{array}$ & $\begin{array}{l}.009 \\
.032\end{array}$ & $\begin{array}{l}.007 \\
.026\end{array}$ & $\begin{array}{l}.003 \\
.016\end{array}$ & $\begin{array}{l}.005 \\
.022\end{array}$ \\
\hline
\end{tabular}

\begin{tabular}{|c|c|c|c|c|c|c|}
\hline & & & 40\% Mis & Data & & \\
\hline-.80 & $\begin{array}{l}M \\
S D\end{array}$ & $\begin{array}{l}.000 \\
.002\end{array}$ & $\begin{array}{l}.002 \\
.007\end{array}$ & $\begin{array}{l}.002 \\
.005\end{array}$ & $\begin{array}{l}.001 \\
.003\end{array}$ & $\begin{array}{l}.002 \\
.003\end{array}$ \\
\hline-.40 & $\begin{array}{l}M \\
S D\end{array}$ & $\begin{array}{l}.001 \\
.002\end{array}$ & $\begin{array}{l}.001 \\
.007\end{array}$ & $\begin{array}{l}.000 \\
.005\end{array}$ & $\begin{array}{l}.000 \\
.002\end{array}$ & $\begin{array}{r}.000 \\
.004\end{array}$ \\
\hline .00 & $\begin{array}{l}M \\
S D\end{array}$ & $\begin{array}{l}.000 \\
.003\end{array}$ & $\begin{array}{r}-.003 \\
.006\end{array}$ & $\begin{array}{r}-.002 \\
.003\end{array}$ & $\begin{array}{r}-.001 \\
.002\end{array}$ & $\begin{array}{r}-.002 \\
.004\end{array}$ \\
\hline .40 & $\begin{array}{l}M \\
S D\end{array}$ & $\begin{array}{l}.001 \\
.004\end{array}$ & $\begin{array}{l}.001 \\
.010\end{array}$ & $\begin{array}{l}.001 \\
.005\end{array}$ & $\begin{array}{l}.000 \\
.003\end{array}$ & $\begin{array}{l}.001 \\
.006\end{array}$ \\
\hline .80 & $\begin{array}{l}\mathrm{M} \\
\mathrm{SD}\end{array}$ & $\begin{array}{l}.008 \\
.029\end{array}$ & $\begin{array}{l}.010 \\
.042\end{array}$ & $\begin{array}{l}.009 \\
.029\end{array}$ & $\begin{array}{l}.003 \\
.012\end{array}$ & $\begin{array}{l}.006 \\
.025\end{array}$ \\
\hline
\end{tabular}




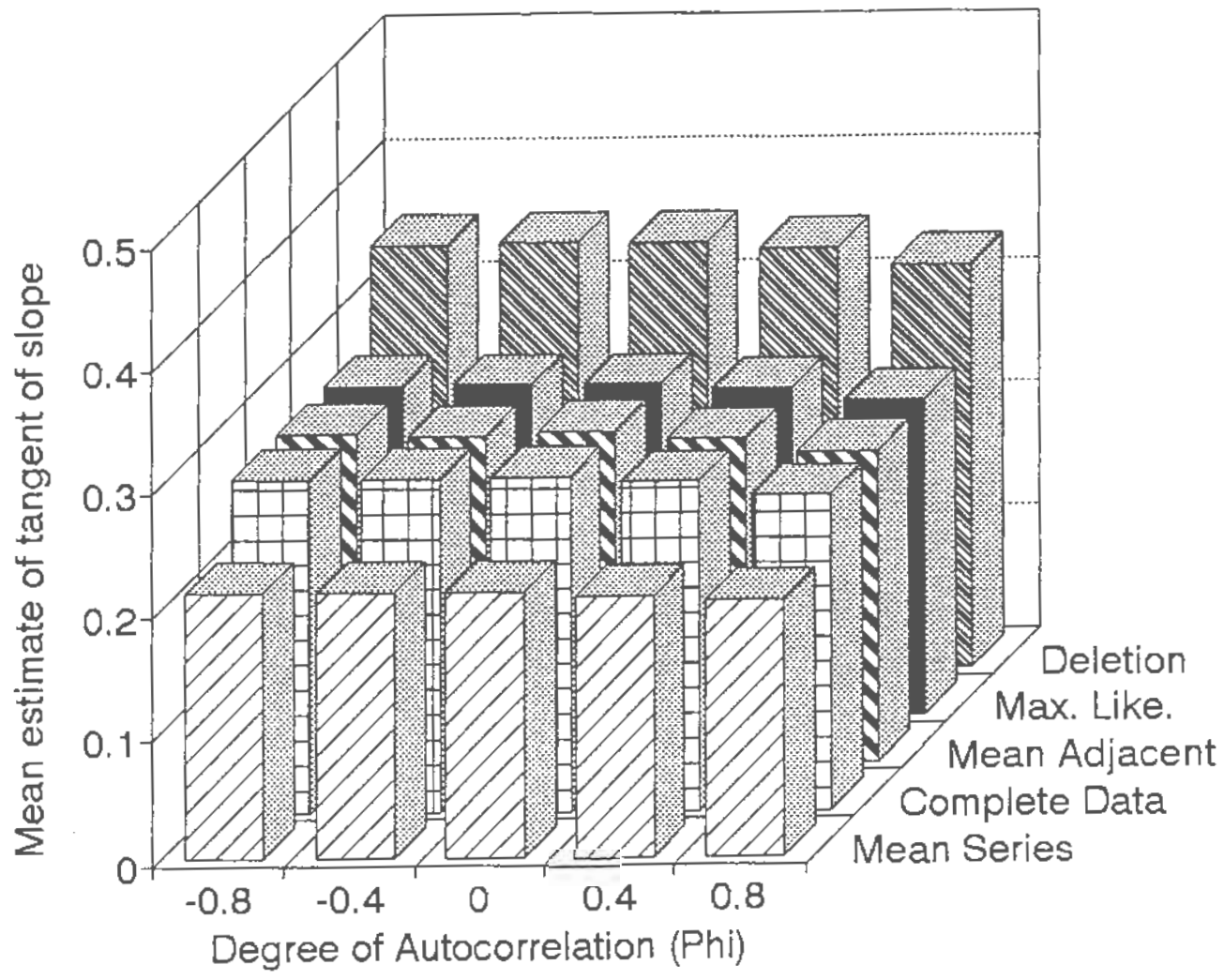

Figure 10. Mean tangent of slope as a function of missing data technique and phi. Criterion $=.27$. 


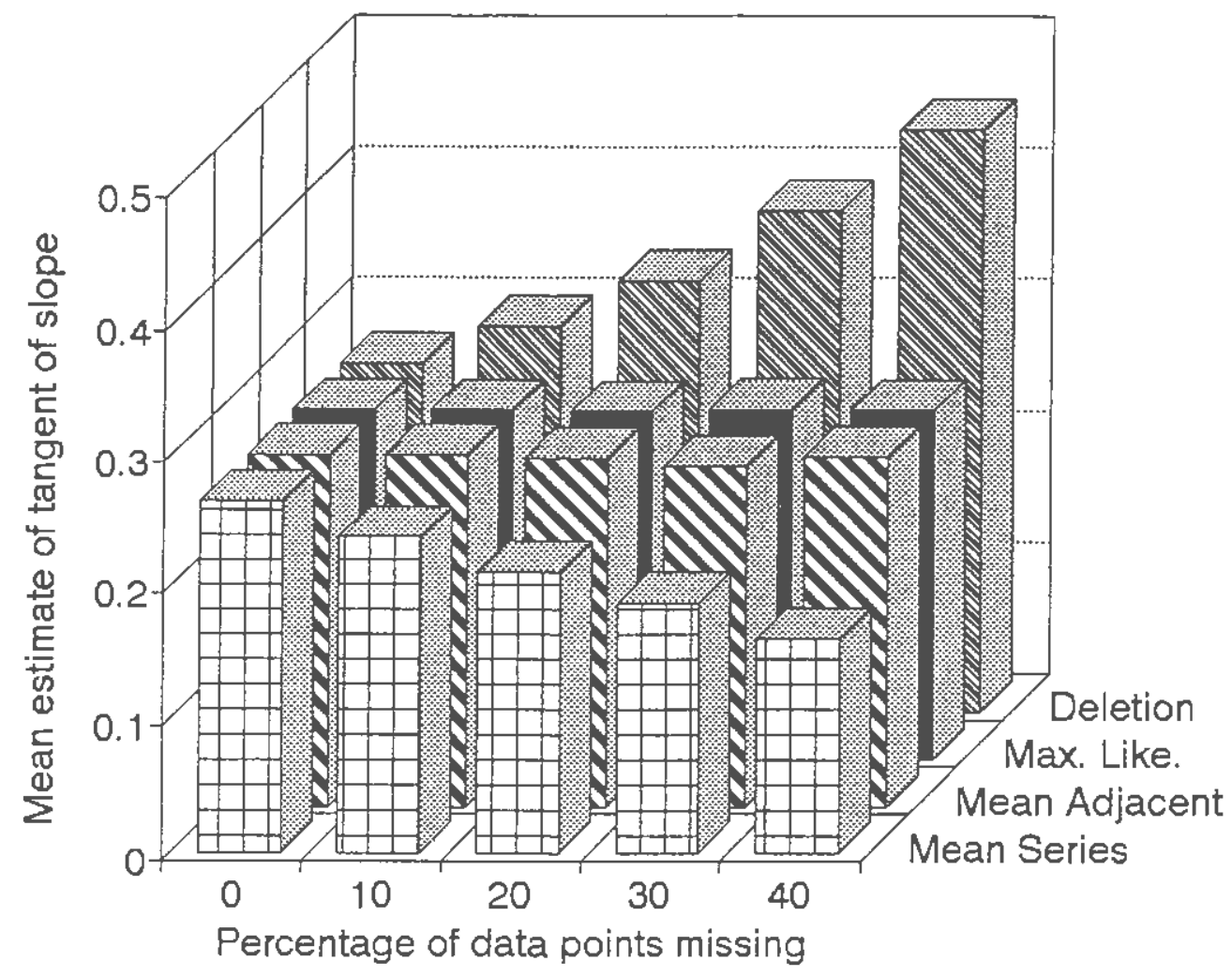

Figure 11. Mean tangent of slope as a function of missing data technique and percent data missing. Criterion $=.27$. 
Tables 15 and 16 present the means and standard deviations for slope $=15$ degrees. The criterion value for these means is .27 , which represents the tangent that corresponds to a 15 degree angle. It is the tangent of the slope that the time series program actually estimates. However, results will be discussed in terms of slope, because degrees are more meaningful in general than tangents.

Follow up tests of significance: Technique by phi interaction. Tukey tests were done as a follow up to the simple effects tests. With alpha set at .05 , group mean differences had to exceed .007 to be significant.

Major findings: At all levels of phi: (1) using mean of the series significantly underestimated slope; (2) using deletion significantly overestimated slope; and (3) using the maximum likelihood algorithm and mean of the adjacent observations resulted in accurate estimates of slope. As Figure 10 demonstrates, estimation of slope was consistent at all levels of phi for these techniques.

Follow up tests of significance: Technique by percent migsing interaction. The alpha level for the Tukey tests was set at .05; the critical value for mean differences was .024 .

Major findings. At every level of missing data, maximum likelihood and mean of the adjacent observations both resulted in accurate estimates of slope. Use of deletion led to significant overestimates of slope, and using mean of the series significantly underestimated slope. As Figure 11 shows, both of these problems in 
Table 15

Means and Standard Deviations of Tangent of Slope, when slope $=15$ Degrees. Criterion $=.27$.

10\% Missing Data

\begin{tabular}{|c|c|c|c|c|c|c|}
\hline Phi & & $\begin{array}{l}\text { Complete } \\
\text { Data }\end{array}$ & Delete & $\begin{array}{l}\text { Mean } \\
\text { Adjacent }\end{array}$ & $\begin{array}{l}\text { Mean } \\
\text { Series }\end{array}$ & $\begin{array}{l}\text { Max. } \\
\text { Like. }\end{array}$ \\
\hline-.80 & $\begin{array}{l}M \\
S D\end{array}$ & $\begin{array}{r}.268 \\
.002\end{array}$ & $\begin{array}{l}.297 \\
.004\end{array}$ & $\begin{array}{l}.269 \\
.004\end{array}$ & $\begin{array}{l}.240 \\
.005\end{array}$ & $\begin{array}{r}.268 \\
.003\end{array}$ \\
\hline-.40 & $\begin{array}{l}M \\
S D\end{array}$ & $\begin{array}{l}.268 \\
.002\end{array}$ & $\begin{array}{l}.297 \\
.002\end{array}$ & $\begin{array}{l}.268 \\
.002\end{array}$ & $\begin{array}{l}.239 \\
.003\end{array}$ & $\begin{array}{l}.268 \\
.001\end{array}$ \\
\hline .00 & $\begin{array}{l}M \\
S D\end{array}$ & $\begin{array}{l}.269 \\
.003\end{array}$ & $\begin{array}{l}.297 \\
.005\end{array}$ & $\begin{array}{l}.268 \\
.004\end{array}$ & $\begin{array}{l}.240 \\
.005\end{array}$ & $\begin{array}{l}.269 \\
.004\end{array}$ \\
\hline .40 & $\begin{array}{l}\mathrm{M} \\
\mathrm{SD}\end{array}$ & $\begin{array}{l}.265 \\
.007\end{array}$ & $\begin{array}{l}.294 \\
.009\end{array}$ & $\begin{array}{l}.266 \\
.007\end{array}$ & $\begin{array}{l}.237 \\
.008\end{array}$ & $\begin{array}{l}.266 \\
.007\end{array}$ \\
\hline .80 & $\begin{array}{l}M \\
S D\end{array}$ & $\begin{array}{l}.253 \\
.027\end{array}$ & $\begin{array}{l}.280 \\
.027\end{array}$ & $\begin{array}{l}.252 \\
.027\end{array}$ & $\begin{array}{r}.232 \\
.017\end{array}$ & $\begin{array}{l}.254 \\
.024\end{array}$ \\
\hline
\end{tabular}

208 Missing Data

\begin{tabular}{|c|c|c|c|c|c|c|}
\hline-.80 & $\begin{array}{l}M \\
S D\end{array}$ & $\begin{array}{r}.268 \\
.002\end{array}$ & $\begin{array}{l}.332 \\
.008\end{array}$ & $\begin{array}{l}.267 \\
.006\end{array}$ & $\begin{array}{r}.212 \\
.010\end{array}$ & $\begin{array}{r}.267 \\
.003\end{array}$ \\
\hline-.40 & $\begin{array}{l}M \\
S D\end{array}$ & $\begin{array}{r}.268 \\
.002\end{array}$ & $\begin{array}{l}.334 \\
.008\end{array}$ & $\begin{array}{l}.269 \\
.003\end{array}$ & $\begin{array}{l}.213 \\
.009\end{array}$ & $\begin{array}{l}.268 \\
.002\end{array}$ \\
\hline .00 & $\begin{array}{l}M \\
S D\end{array}$ & $\begin{array}{l}.269 \\
.003\end{array}$ & $\begin{array}{l}.334 \\
.010\end{array}$ & $\begin{array}{l}.269 \\
.005\end{array}$ & $\begin{array}{l}.213 \\
.011\end{array}$ & $\begin{array}{l}.269 \\
.004\end{array}$ \\
\hline .40 & $\begin{array}{l}M \\
S D\end{array}$ & $\begin{array}{l}.265 \\
.007\end{array}$ & $\begin{array}{r}.328 \\
.011\end{array}$ & $\begin{array}{l}.264 \\
.007\end{array}$ & $\begin{array}{l}.209 \\
.011\end{array}$ & $\begin{array}{r}.264 \\
.007\end{array}$ \\
\hline .80 & $\begin{array}{l}M \\
S D\end{array}$ & $\begin{array}{l}.253 \\
.027\end{array}$ & $\begin{array}{l}.311 \\
.029\end{array}$ & $\begin{array}{l}.247 \\
.027\end{array}$ & $\begin{array}{l}.207 \\
.015\end{array}$ & $\begin{array}{l}.252 \\
.028\end{array}$ \\
\hline
\end{tabular}


Table 16

Means and Standard Deviations of Tangent of Slope, when Slope $=15$

Deqrees. Criterion $=.27$.

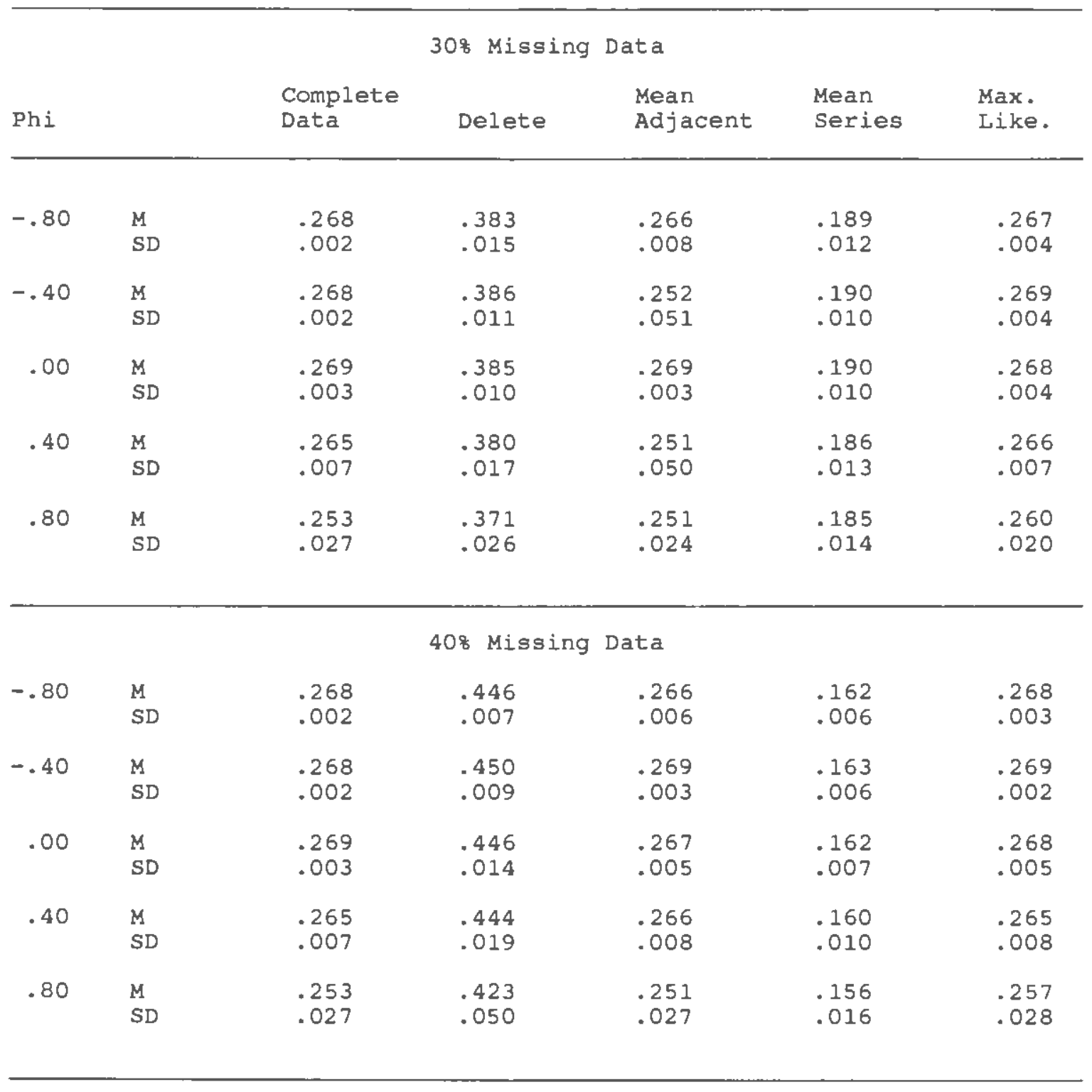


slope estimation got increasingly worse at each higher level of missing data.

\section{Discussion}

This study compared the accuracy of four widely used methods for handling missing data in time series analysis. Accuracy was measured in terms of resulting parameter estimates for the time series model: level, slope, error variance, and phi. In order to evaluate the strengths and the limitations of these methods, they were tested using computer-generated time series that represented different levels of slope, autocorrelation and percent of data missing in the series.

The major findings in this study involve: (1) the accuracy of the Jones (1980) maximum likelihood algorithm which is available in sAS/ETS, Version 6.0 ; and (2) the inaccuracy of using the mean of the series to handle missing data, especially when the slope of the series is not zero.

The maximum likelihood procedure for handling missing data outperformed all others, remaining accurate in parameter estimation even when forty percent of the data had been randomly eliminated. These results contradict statistical "rules of thumb" that suggest that data can only be used if they have less than 10 or 20 percent missing data points. The fact that using maximum likelihood to handle missing data results in accurate estimates of level, slope, and error variance indicates that it is a suitable technique to use for time series analysis, including interrupted time series designs, in which various interventions are tested. 
A minor limitation of the maximum likelihood technique is that estimates of the actual missing data points can not be obtained in the current version of SAS/ETS. This would be important to the researcher who prefers a visual presentation of the data.

Imputing the mean of the series is an unacceptable method for handling missing time series data, based on the results of this study. When the slope of the time series was 15 degrees, use of this method led to severe overestimates of error variance and level, as well as moderate underestimates of slope. (Note that if the slope of the series had been negative, using the mean of the series would have underestimated level). Phi was moderately underestimated regardless of the slope of the series. These findings indicate that this method of handling missing data should not be used for time series designs, even when as few as $10 \%$ of the observations are missing.

Minor findings in this study involve the specific sets of circumstances under which imputing the mean of the adjacent observations and deletion prove acceptable methods for handing missing data. These will be explored in terms of the objective of the time series analysis. For the researcher interested in testing interventions, baseline measures of level, slope, and error variance are critical. When the true slope of the baseline series was zero, both of these techniques accurately estimated of level and slope, even when forty percent of the data were missing. This was unexpected, given the lack of mathematical sophistication of these approaches. The implication of this finding is that if the baseline series is stable (i.e., the behavior in question is 
not increasing or decreasing prior to an intervention) either of these two approaches would generally provide accurate estimates of these parameters.

When the baseline series is not stable (in the case of this study, the slope of the series was 15 degrees) use of deletion led to an overestimate of slope, but estimates of level (often the more interesting intervention parameter) were accurate. The mean of the adjacent observations led to accurate estimates of slope and level. However, one shortcoming of using the mean of the adjacent observations to replace missing data was illustrated when 30 percent of data were eliminated. By chance, the pattern of random elimination at 308 missing data included several missing data points at the beginning of the series. Since this approach substitutes the mean of the adjacent observations, data points missing at the beginning (or end) of a series cannot be estimated, and therefore, the series begins at the first nonmissing observation. Thus, a series with a non-zero slope and data points missing at the beginning of the series will result in an inaccurate estimate of level.

Estimation of error variance is also important to significance tests of intervention effects. Deletion and mean of the adjacent observations both performed consistently well in terms of error variance estimation, except in cases of severe negative autocorrelation when both techniques yielded inflated estimates of variance. This finding is especially relevant to applied researchers in areas such as weight loss or smoking cessation, where conditions of severe negative 
autocorrelation are likely to exist. For example, patients who binge eat on one day may make up for it the following day by following their diet closely. Overestimating error variance for this type of data could result in failing to detect a significant intervention effect.

Estimation of phi is not as important to testing the significance of changes due to interventions, but it is still important to social scientists as a means of better understanding the nature of a behavior of interest. Also, since the main advantage of time series analysis is that it accounts for dependency in the data, and transforms the data to correct for it, an accurate estimate of phi is important to time series analysis. It is also important for forecasting purposes, more commonly used by economists and engineers.

Use of the mean of the adjacent observations underestimated negative autocorrelation and overestimated positive autocorrelation and zero autocorrelation. This had been predicted, since imputing the mean of the adjacent observations artificially smooths the series. Deletion had mixed results in estimating phi; its accuracy varied depending on the particular combination of phi, slope, and percent of data missing in the series.

Future directions for research. Given the exceptional performance of the maximum likelihood algorithm available in SAS/ETS, future directions in this area of research should include testing the limitations of this approach. For example, it would be interesting to test how much data could be missing from a series before the estimates became inaccurate. A related issue is the length of the series: how 
short could a series be and still benefit from this approach to handing missing data? Another area of interest would be the model specification required by SAS/ETS. In this study, the proper model was always specified. However, even though the AR (1, 0, 0) model sufficiently fits many data sets, the maximum likelihood algorithm is likely to not be as accurate when the model is incorrectly specified.

Other areas of future research should include: (1) the effects of various methods of handling missing data in series that fit other types of ARIMA models (e.g., series with a moving averages component, or a seasonality component); (2) a comparison of missing data techniques using interrupted time series data, to test differences in the ability to detect intervention effects; and (3) the effects of missing data techniques on systematically missing data.

This study has examined the consequences of using four different methods of handling missing data on time series analysis. The results demonstrate that the choice of a method to handle missing data is a critical one. Used under inappropriate circumstances, some methods will lead one to incorrectly conclude that an intervention had been ineffective. For example, when the mean of the series was substituted for missing observations and the slope of the series was moderate (15 degrees), error variance was estimated as 8 to 25 times greater than it actually was, depending on the percentage of data that had been missing from the series (i.e., 10 to $40 \%$ ). Such high estimates of error variance could easily preclude finding a true (even robust) intervention effect. Under similar conditions, mean of the series resulted in level 
estimates as high as 5.4, when the true value of level was zero. The amount of inaccuracy increases as the slope of the series increases. This could prove disastrous for testing interventions for alcohol or drug problems, since it is common for alcohol or drug use to be sharply increasing just before treatment is sought.

Use of an inappropriate method could also lead to an incorrect assumption of the model that underlies the data. When the mean of the adjacent observations is imputed for missing observations, a series with severe negative autocorrelation would likely be determined to have a moderate positive autocorrelation; a conclusion with very different implications for intervention and general understanding of the behavior of interest.

Because using the wrong method to handle missing data can result in parameter estimates that are so severely inaccurate, we recommend that published studies which use time series analysis include details in the method section about the amount of missing data in the series, and the method used to handle it. Results of this study provide an empirical basis upon which researchers may choose which method of handling missing data best meets their needs, given the characteristics of their data.

In summary, the major conclusions of this study are listed below: 1. The choice of which technique to use to estimate missing data for time series analysis has potentially severe consequences. 2. For estimating missing time series data, maximum likelihood estimation (available in SAS/ETS) is the method of choice. 
3. At lower levels of missing data (i.e., less than $20 \%$ missing), deletion and mean of the adjacent observations are adequate for intervention tests.

4. For studies involving model identification, maximum likelihood estimation must be used; all other methods tested in this study were inaccurate.

5. Mean of the series is an unacceptable technique and should never be used for estimating time series data. 


\section{References}

Baum, L. E., Petrie, T., Soules, G., \& Weiss, N. (1970). A maximization technique occurring in the statistical analygis of probabilistic functions of Markov chains. Annals of Mathematical statistics, 41, $164-171$

Beale, E. M. L., \& Little, R. J. A. (1975). Missing values in multivariate analysis. Journal of the Royal statistical society, Series $B, 37,129-145$.

Bollen, K. A. (1989). Structural equations with Iatent variables. New York: John wiley \& Sons.

Box, G. E. P., \& Jenkins, G. M. (1970) Time-series analysis: Forecasting and control. San Francisco: Holden-Day.

Brown, C. H. (1983). Asymptotic comparison of missing data procedures for estimating factor loadings. Psychometrika, 48, 269-291.

Busk, P. L. \& Marascuilo, I. A. (1988). Autocorrelation in singlesubject research: A counterargument to the myth of no autocorrelation. Behavioral Assessment, 10, $229-242$.

Dempster, A. P., Laird, N. M., \& Rubin, D. B. (1977). Maximum likelihood estimation from incomplete data via the EM algorithm. Journal of the Royal statistical society, Series $B, 39,1-38$.

Dixon, W. J. (1988). BMDP statistical software. [Computer program manual]. Berkeley: University of California Press. Dixon, W. J. (1990). BMDP statistical software. [Computer program manual]. Berkeley: University of California Press. 
Glass, G. V., Willson, V. L., \& Gottman, J. M. (1975). Design and Analysis of Time Series Experiments. Boulder: Colorado Assoc. Univ. Press.

Gottman, J. M. (1981). Time series analysis: A comprehensive introduction for social scientists. New York: Cambridge University Press,

Harrop, J. W., \& Velicer, W. F. (1990). Computer programs for interrupted time series analysis: II. A quantitative evaluation. Multivariate Behavioral Research, 25,233-248.

Hartley, H. O. (1958). Maximum likelihood estimation from incomplete data. Biometrics, 14, 174-194.

Harvey, A. C., \& Pierse, R. G. (1984). Estimating missing observations in economic time series. Journal of the American statistical Association, 79, 125-131.

Jones, R. H. (1980). Maximum likelihood fitting of ARMA models to time series with missing observations. Technometrics, 22, 389-396. Kalman, R. E. (1960). A new approach to linear filtering and prediction problems. JournaI of Basic Engineering, $82,34-35$.

Kohn, R., Ansley, C. F. (1986). Estimation, prediction, and interpolation for ARIMA models with missing data. Journal of the American Statistical Association, 81, 751-761.

Laird, N. M. (1988). Missing data in longitudinal studies. Statistics in Medicine, $7,305-315$. 
Little, R. J. A. (1988). A test of missing completely at random for multivariate data with missing values. Journal of the American Statistical Society, $83,404,1198-1202$.

Little, R. J. A., Rubin, D. B. (1987). Statistical analysis with missing data. New York: Wiley.

Little, R. J. A., \& Rubin, D. B. (1990). The analysis of social science data with missing values. In J, Fox and J. S. Long (Eds.), Modern methods of data analysis (pp. 374-409). Newbury Park, California: Sage Publications.

Marsh, J. C., \& Shibano, M. (1984). Issues in the statistical analysis of clinical time-series data. Social Work Research and Abstracts, 20 , $7-12$.

Mccleary, R., \& Hay, R. A. Jr. (1980). Applied time series analysis for the social sciences. Beverly Hills, CA: Sage.

Padia, W. L. (1975). The consequences of model misidentification in the interrupted time-series experiment. Dissertation Abstracts International, 36,4875A. (University Microfilms No. 76-3938).

Rankin, E. D., \& Marsh, J. C. (1985). Effects of missing data on the statistical analysis of clinical time series. Social Hork Research and Abstracts, 21, 13-16. 
Revenstorf, D., Kessler, A., Schindler, L., Hahlweg, K., \& Bluemner E. (1980). Time series analysis: Clinical applications evaluating intervention effects in diaries. In O. D. Anderson (Ed.), Analyzing Time Series: Proceedings of the International conference held on Guernsey, Channel Islands, October, 1979 (pp. 291-312). Amsterdam: North-Holland.

Rubin, D. B. (1976). Inference and missing data. Biometrika, 63, 581592.

SAS Institute Inc. (1988). SAS/ETS user's guide, version 6, first edition. Cary, NC: SAS Institute Inc.

Simonton, D. K. (1977). Cross-sectional time-series experiments: Some suggested statistical analyses. Psychological Bulletin, 84, 489-502. SPSS, Inc. (1988). SPSS-X Trends. [Computer program manual]. Chicago, IL: SPSS, Inc.

suen, H. K. (1987). On the epistemology of autocorrelation in applied behavior analysis. Behavioral Assessment, 9,113-124.

Swaminathan, H., \& Algina, J. (1977). Analysis of quasi-experimental time-series designs. Multivariate Behavioral Research, 12, 111-131.

Tabachnick B. G., \& Fidell, L. S. (1989). Using multivariate statistics: New York, NY: Harper \& Row.

Velicer, W. F., \& Harrop, J. W. (1983). The reliability and accuracy of time series model identification. Evaluation Review, 7, 551-560. Velicer, W. F*, \& McDonald, R. P. (1984). Time series analysis without model identification. Multivariate Behavioral Research, 19, 33-47. 
Appendix A: ANOVA Summary Table for Error Variance.

\begin{tabular}{|c|c|c|c|c|}
\hline & $d f$ & SS & $F$ & $p$ \\
\hline$s$ & 1 & 4535.67 & 2623.51 & .000 \\
\hline$P$ & 4 & 245.28 & 35.47 & .000 \\
\hline$S \times P$ & 4 & 9.30 & 1.35 & ns \\
\hline Sub $(S \times P)$ & 90 & 155.60 & $(M S=1.73)$ & \\
\hline PM & 4 & 2694.61 & 1721.68 & .000 \\
\hline PM $x \mathrm{~S}$ & 4 & 2078.09 & 1327.76 & .000 \\
\hline$P M \times P$ & 16 & 68.58 & 10.95 & .000 \\
\hline$P M \times S \times P$ & 16 & 7.30 & 1.17 & ns \\
\hline Sub $x$ PM $(S \times P)$ & 360 & 140.86 & $(M S=.39)$ & \\
\hline T & 3 & $13004 \cdot 18$ & 6062.99 & .000 \\
\hline$T \times S$ & 3 & 12751.13 & 5944.72 & .000 \\
\hline$T \times P$ & 12 & 94.68 & 11.03 & .000 \\
\hline$T \times S \times P$ & 12 & 8.97 & 1.05 & ns \\
\hline Sub $\times T(S \times P)$ & 270 & 193.05 & $(M S=.71)$ & \\
\hline $\mathrm{PM} \times \mathrm{T}$ & 12 & 6048.44 & 1845.24 & .000 \\
\hline PM $\times T \times S$ & 12 & 5892.09 & 1797.54 & .000 \\
\hline$P M \times T \times P$ & 48 & 33.84 & 2.58 & .000 \\
\hline PM $\times T \times S \times P$ & 48 & 7.39 & .56 & ns \\
\hline Sub $x$ PM $x T(S \times P)$ & 1080 & 295.01 & $(M S=.27)$ & \\
\hline
\end{tabular}

S = slope

$\mathbf{P}=\mathrm{Phi}$

PM = Percent Missing

$\mathrm{T}=$ Technique 
Appendix B: ANOVA Summary Table for Phi when Phi $=-.80$.

S

Sub (S)

PM

$P M \times S$

Sub (PM $\times$ s)

T

$\mathrm{T} \times \mathrm{S}$

Sub ( $T \times s)$

PM $x \quad T$

$\mathrm{PM} \times \mathrm{T} \times \mathrm{S}$

Sub $x P M(T \times S)$

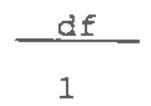

18

4

4

72

3

3

54

12

12

216

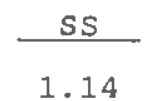

1.05

12.05

.42

1.13

12.56

1.93

.38

192.11

6.65

$(\mathrm{MS}=.02)$

601.37

$92+50$

$(\mathrm{MS}=.01)$

6.30

.60

1.23

92.03
.000

.000
.000

8.73

.000

.000

.000

$(\mathrm{MS}=.01)$

$S$ = Slope

PM = Percent Missing

$\mathrm{T}=$ Technique 
Appendix C: ANova Summary Table for Phi when Phi $=-.40$.

$S$

Sub (S)

PM

$\mathrm{PM} \times \mathrm{S}$

Sub (PM $\times$ S)

$\mathrm{T}$

$\mathrm{T} \times \mathrm{S}$

Sub $(T \times S)$

$P M \times T$

PM $\times \mathrm{T} \times \mathrm{S}$

Sub $x$ PM (T $x$ S)

S = slope

PM = Percent Missing

$\mathrm{T}=$ Technique
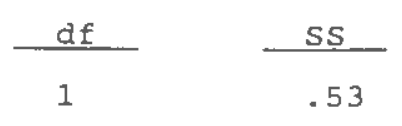

18

$$
4
$$

4

72

3

3

54

12

12

216

3.73

4. 68

.49

1.23

6.14

.63

.63

2

.46
68.30

7.20

$(\mathrm{MS}=.02)$

176.37

.000

18.02

$(\mathrm{MS}=.01)$

3. 43

38.36

.000

5.20

.000

$(\mathrm{MS}=.01)$ 
Appendix D: ANova Summary Table for Phi when Phi $=0$.

S

sub (S)

PM

$\mathrm{PM} \times \mathrm{S}$

Sub (PM $x$ S $)$

$\mathrm{T}$

$\mathrm{T} \times \mathrm{S}$

Sub (T $\times S$ )

PM $\times \mathrm{T}$

PM $\times \mathrm{T} \times \mathrm{S}$

Sub $x$ PM $(T \times S)$

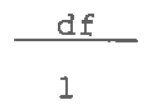

18

4

4

72

3

3

54

12

12

216

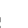

3

54

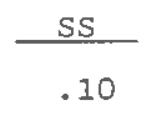

2.25

.86

.29

1.74

3.16

.17

.35

8.89

3.03

$(M S=.02)$

1.70

.12

1.02

8.52

(MS $=.01)$

9.96

2.11

$(M S=.00)$

.000

.000

.018

$\mathrm{s}=$ slope

PM = Percent Missing

$\mathrm{T}=$ Technique 
Appendix E: ANOVA Sumury Table for Phi when Phi $=.40$.

S

Sub (S)

PM

PM $\mathbf{x}$ S

Sub (PM $\times$ S )

$\mathrm{T}$

$\mathrm{T} \times \mathrm{S}$

Sub ( $T \times S)$

$P M \times T$

$\mathrm{PM} \times \mathrm{T} \times \mathrm{S}$

Sub $x \operatorname{PM}(T \times S)$

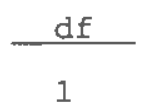

18

$$
4
$$

4

72

3

3

54

12

12

216

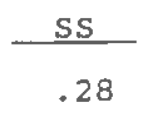

2.59

.10

.08

.87

4.54

.85

.43

1.80

.25

.99
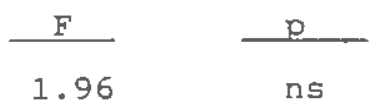

$$
1.96
$$

$(M S=.14)$

1.99

ก5

1.79

ns

$(\mathrm{MS}=.01)$

188.54

.000

35.41

.000

$(\mathrm{MS}=.01)$

32.64

.000

4.61

.000

(MS $=.00)$

\footnotetext{
$S=$ Slope

PM = Percent Missing

$\mathrm{T}=\mathrm{Technique}$
} 
Appendix F: ANova Summary Table for Phi when Phi $=.80$.

$\mathbf{S}$

Sub (S)

$\mathrm{PM}$

$\mathrm{PM} \times \mathrm{S}$

Sub (PM $\times$ S)

T

$T \times S$

Sub $(T \times S)$

PM $\times \mathrm{T}$

$\mathrm{PM} \times \mathrm{T} \times \mathrm{S}$

Sub $\times P M(T \times S)$

$\mathrm{S}=\mathrm{Slope}$

$\mathrm{PM}=$ Percent Missing

$T=$ Technique

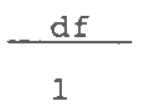

4

4

72

3

3

54

12

12

216

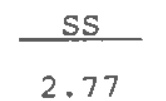

2.72

1.08

.17

.47

10.59

2.28

.28

41.50

6.51

$(\mathrm{MS}=.01)$

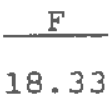

$\frac{\mathrm{p}}{.000}$

$(\mathrm{MS}=.15)$

.000

.000

47

93.21

.000

149.46

.000

$(\mathrm{MS}=.01)$

.34

78.35

.000

.62

14.43

.000

.77

$(\mathrm{MS}=.00)$ 
Appendix G: ANOVA Summary Table for Level

$$
\begin{array}{ll}
\mathrm{S} & \\
\mathrm{P} & \\
\mathrm{S} \times \mathrm{P}
\end{array}
$$

Sub (S $x$ P)

PM

PM $\times 5$

$\mathrm{PM} \times \mathrm{P}$

$P M \times S \times P$

Sub $x$ PM (S $x$ P)

$\mathrm{T}$

$T \times S$

$T \times P$

$T \times S \times P$

Sub $\times$ T $(S \times P)$

PM $\times \quad T$

$P M \times T \times S$

PM $\times$ T $\times P$

\begin{tabular}{|c|c|}
\hline $\mathrm{df}$ & SS \\
\hline 1 & 263.48 \\
\hline 4 & 35.76 \\
\hline 4 & 1.57 \\
\hline
\end{tabular}

PM $X \quad T \times S x \cdot P$

Sub $x$ PM $\times$ T (S X P) 1080
90

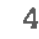

4

16

16

360

3

3

12

12

270

12

12

48

48

109.80

93.31

5.90

7.95

148.68

613.53

603.20

4.82

6.58

113.14

315.07

311.03

6.48

8.09

$275 \cdot 62$

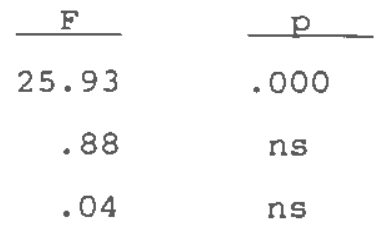

$(M S=10.16)$

914.53

66.47

.000

56.48

.000

.89

I)

1.20

$\mathrm{ns}$

$(M S=.41)$

488.04

.000

479.82

.000

.96

ns

1.31

ns

$(\mathrm{MS}=.42)$

102.88

.000

101.56

.000

.53

ns

.66

ns

$S=$ slope

$\mathrm{P}=\mathrm{Phi}$

$\mathrm{PM}=$ Percent Missing

$T$ = Technique

$(\mathrm{MS}=.26)$ 
Appendix H: ANOVA Summary Table for slope when Slope $=0$ degrees.

$\mathrm{P}$

Sub (P)

PM

PM $\times \mathrm{P}$

Sub (PM $\times$ P)

$\mathrm{T}$

T $\times P$

Sub $\left(\begin{array}{lll}T & \mathrm{P}\end{array}\right)$

PM $\times \mathrm{T}$

$\mathrm{PM} \times \mathrm{T} \times \mathrm{P}$

Sub $x$ PM $(T \times P)$

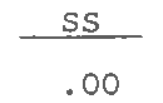

.10

.00

.00

.04

.00

.00

.03

.00

.01

.13

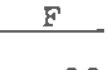

.33

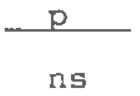

$(\mathrm{MS}=.00)$

.93

ns

.89

ns

$(M S=.00)$

.76

$\mathrm{ns}$

.72

ns

135

12

48

97

$(\mathrm{MS}=.00)$

$P=P h I$

$\mathrm{PM}=$ Percent Missing

$\mathrm{T}=$ Technique 
Appendix I: ANOVA Sumnary Table for slope when slope = 15 degrees.

$\mathrm{P}$

Sub (P)

PM

$\mathrm{PM} \times \mathrm{P}$

Sub (PM $\times$ P)

$\mathrm{T}$

$\mathrm{T} \times \mathrm{P}$

Sub ( $T \times P)$

PM $\times \mathrm{T}$

$\mathrm{PM} \times \mathrm{T} \times \mathrm{P}$

Sub $x$ PM $(T \times P)$

$\mathrm{P}=\mathrm{Phi}$

PM = Percent Missing

$\mathrm{T}=$ Technique

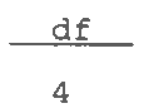

45

4

16

180

3

12

135

12

48

540

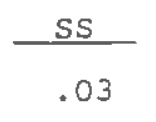

.13

.05

.00

.02
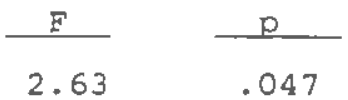

.047

$(\mathrm{MS}=.00)$

99.29

.000

.73

ns

$$
\text { (MS }=.00)
$$

$2+14$

.00

.02

6153.54

.000

1.94

.035

$(\mathrm{MS}=.00)$

1.29

1339.06

.000

.67

ns

.04 


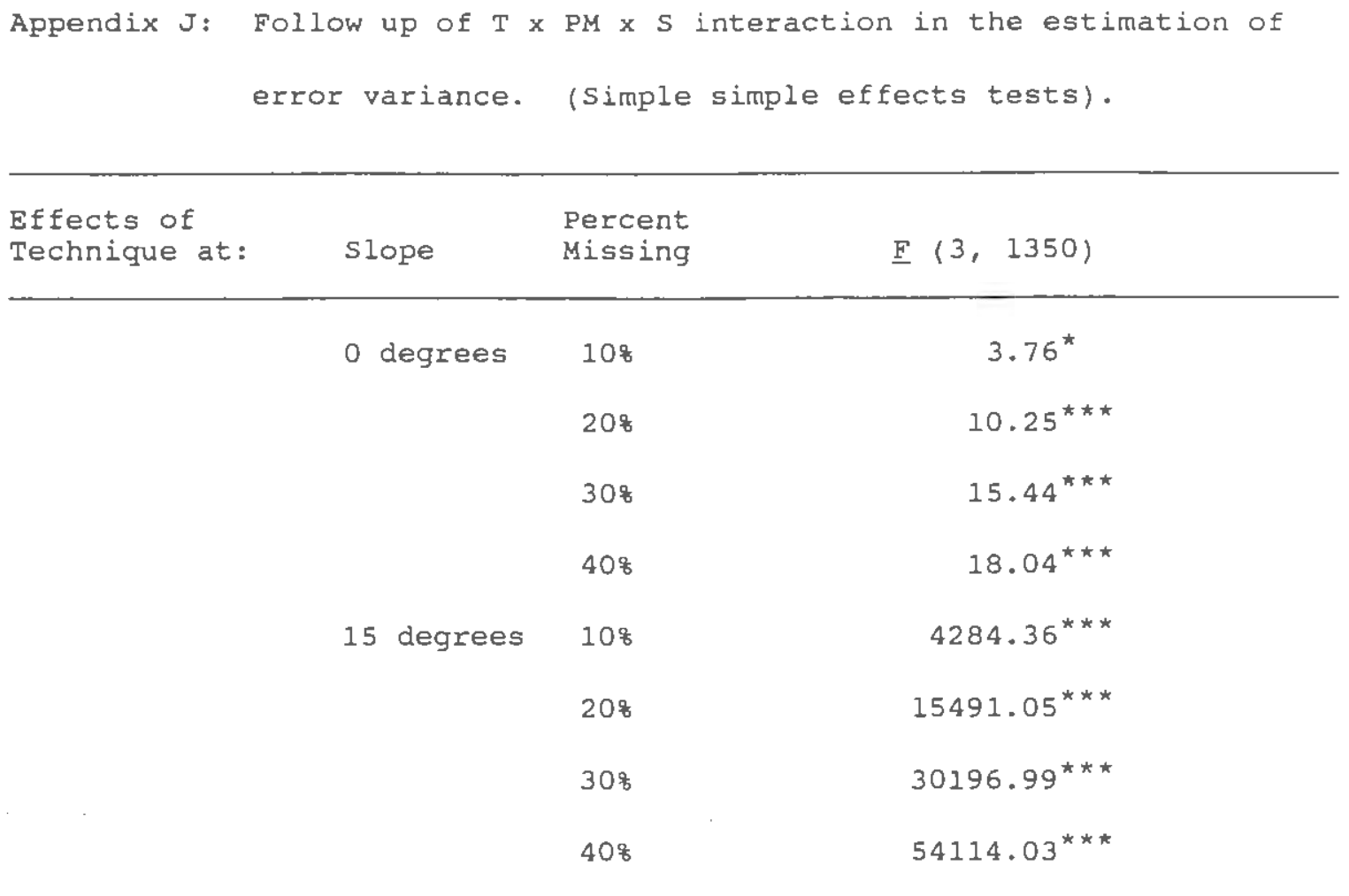

$\star p<.05 \quad$ *** $p<.001$ 
Appendix K: Follow up of T $x$ PM $\times$ P interaction in the estimation of error variance. (Simple simple effects tests).

\begin{tabular}{|c|c|c|c|}
\hline $\begin{array}{l}\text { Effects of } \\
\text { Technique at: }\end{array}$ & $\begin{array}{l}\text { Percent } \\
\text { Missing }\end{array}$ & Phi & $E(12,1350)$ \\
\hline & 108 & -.80 & $468.32^{\star \star \star}$ \\
\hline & & -.40 & $402.16^{* * *}$ \\
\hline & & 0 & $407.46^{\star \star \star}$ \\
\hline & & .40 & $400.19^{\star \star \star}$ \\
\hline & & .80 & $510.58^{* \star \star}$ \\
\hline & $20 \%$ & -.80 & $1628.65^{\star \star \star}$ \\
\hline & & -.40 & $1522.27^{\star \star \star}$ \\
\hline & & 0 & $1524.67^{* * *}$ \\
\hline & & .40 & $1464.06^{* * *}$ \\
\hline & & .80 & $1738.45^{* \star *}$ \\
\hline & $30 \%$ & -.80 & $3090.55^{* \hbar \star}$ \\
\hline & & -.40 & $2996.77^{\star \star \star}$ \\
\hline & & 0 & $3044.12^{\star \star \star}$ \\
\hline & & .40 & $2874.25^{\star * *}$ \\
\hline & & .80 & $3336.27^{\star \star \star}$ \\
\hline & $40 \%$ & -.80 & $5458.01^{\star \star *}$ \\
\hline & & -.40 & $5273.70^{\star \star \star}$ \\
\hline & & 0 & $5479.17^{\star * *}$ \\
\hline & & .40 & $5530.69^{\star \star \star}$ \\
\hline & & .80 & $5837.96^{\star \star \star}$ \\
\hline
\end{tabular}

$\star \star \star \mathrm{p}<.001$ 
Appendix L: Follow up of T $x$ PM $x$ S interaction in the estimation of phi. (Simple simple effects tests).

\begin{tabular}{|c|c|c|c|}
\hline \multirow[t]{9}{*}{$\begin{array}{l}\text { Effects of } \\
\text { Technique at: }\end{array}$} & Slope & $\begin{array}{l}\text { Percent } \\
\text { Missing }\end{array}$ & $\underline{E}(3,270)$ \\
\hline & o degrees & $10 \%$ & $63.33^{* \star \star}$ \\
\hline & & $20 \%$ & $215.00^{* \star \star}$ \\
\hline & & $30 \%$ & $358 \cdot 33^{* \hbar \hbar}$ \\
\hline & & $40 \%$ & $851.67^{\star \star \star}$ \\
\hline & 15 degrees & 108 & $215.00^{* * *}$ \\
\hline & & 208 & $436.67^{\star \star \star}$ \\
\hline & & 308 & $555.00^{\star \star \star}$ \\
\hline & & 408 & $870.00^{\star \hbar \hbar}$ \\
\hline & Par & E II. Ph & \\
\hline & o degrees & $10 \%$ & $19.28^{\star \star \star}$ \\
\hline & & 208 & $72.29^{* \star *}$ \\
\hline & & 308 & $166.27^{* * *}$ \\
\hline & & 408 & $293.98^{\star \star \hbar}$ \\
\hline & 15 degrees & $10 \%$ & $67.47^{\star \star \star}$ \\
\hline & & $20 \%$ & $125 \cdot 30^{\star \star \star}$ \\
\hline & & $30 \%$ & $339.62^{\star \star \star}$ \\
\hline - & & $40 z$ & $321.69^{\star \star \star}$ \\
\hline
\end{tabular}

$\star \star * \mathrm{P}<.001$ 
Appendix M: Follow up of $\mathrm{T} x$ PM $\mathrm{x} S$ interaction in the estimation of phi. (Simple simple effects tests).

$$
\text { Part I. Phi }=0 \text {. }
$$

Effects of Technique at:
Percent

Missing $E(3,270)$

0 degrees $\quad 10 \%$

208

$30 \%$

408

15 degrees $10 \%$

208

$30 \%$

$40 \%$

Part II. Phi $=.40$

0 degrees $10 \%$

20 \%

$30 \%$

$40 \%$

15 degrees $10 \%$

20 \%

$30 \%$

40 \%

$\begin{array}{ll}20 \% & 43.40^{\star \star \star} \\ 30 \% & 88.68^{\star \star \star} \\ 40 \% & 203.77^{\star \star \star} \\ 15 \text { degrees } & 130.19^{\star \star \hbar} \\ 20 \% & 190.57^{\star \star \hbar} \\ 30 \% & 294.34^{\star \star \star} \\ 40 \% & 439.62^{\star \star \star}\end{array}$

$13.73^{\star \star \star}$

$68 \cdot 63^{\star \star \star}$

$174.51^{* \star *}$

$260.78^{* *}$

$13.72^{\star \star \star ~}$

$58.82^{\star \star \star}$

$137.26^{\star \star \star}$

284.31

$\star * * p<.001$ 


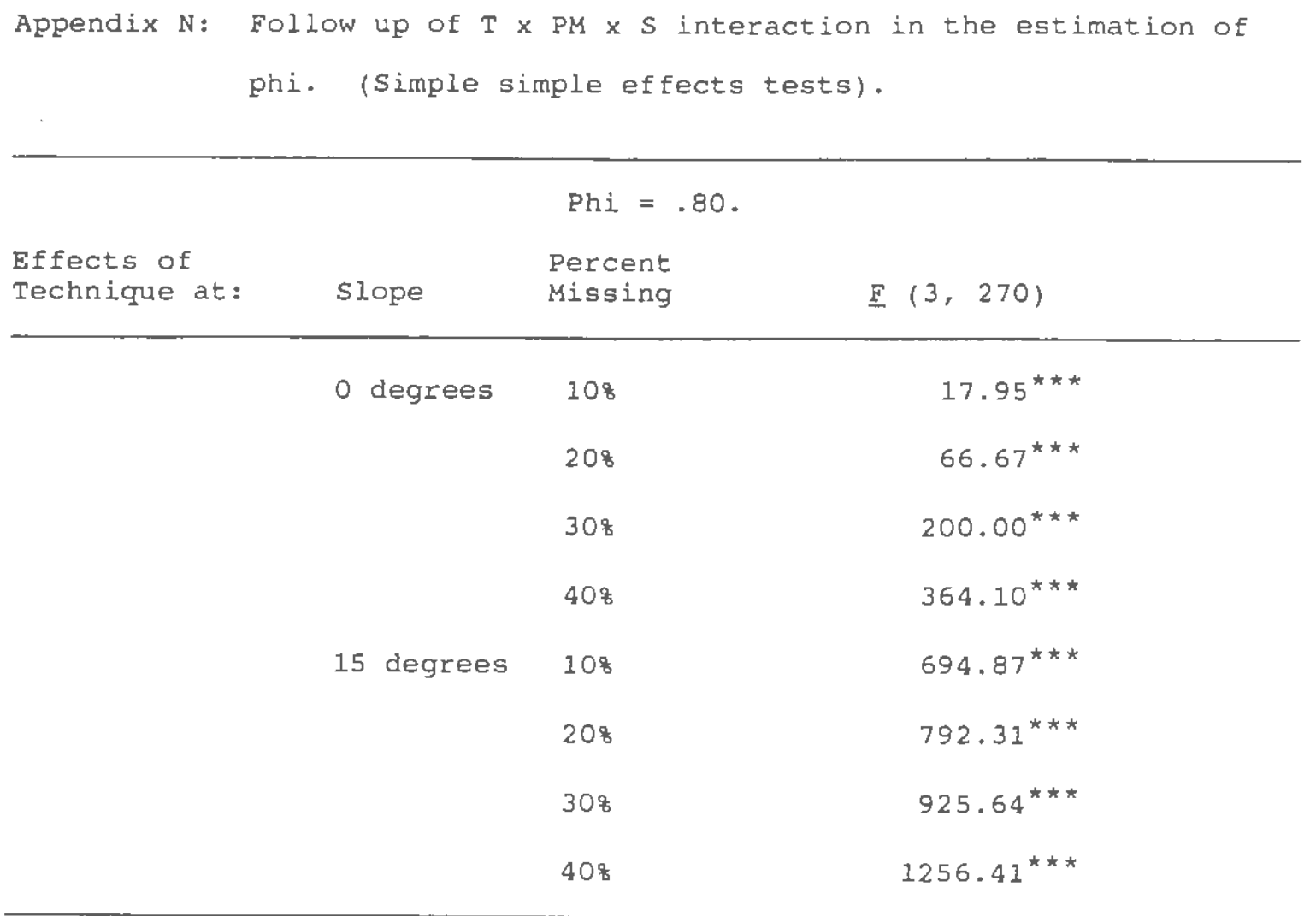

$\star \star * p<.001$ 


\section{Bibliography}

Baum, L. E., Petrie, T., Soules, G., \& Weiss, N. (1970). A maximization technique occurring in the statistical analysis of probabilistic functions of Markov chains. Annals of Mathematical Statistics, 41 , $164-171$.

Beale, E. M. I., \& Little, R. J. A. (1975). Missing values in multivariate analysis. Journal of the Royal statistical society, Series $B, 37,129-145$.

Bollen, K. A. (1989). Structural equations with latent variables. New York: John Wiley \& Sons.

Box, G. E. P., \& Jenkins, G. M. (1970) Time-series analysis: Forecasting and control. San Francisco: Holden-Day.

Brown, C. H. (1983). Asymptotic comparison of missing data procedures for estimating factor loadings. Psychometrika, 48, 269-291.

Busk, P. L. \& Marascuilo, L. A. (1988). Autocorrelation in singlesubject research: A counterargument to the myth of no autocorrelation. Behavioral Assessment, 10, 229-242.

Dempster, A. P., Laird, N. M., \& Rubin, D. B. (1977). Maximum likelihood estimation from incomplete data via the EM algorithm. Journal of the Royal statistical Society, Series $B, 39,1-38$.

Dixon, W. J. (1988). BMDP statistical software. (Computer program manual]. Berkeley: University of California Press.

Dixon, W. J. (1990). BMDP statistical software. [Computer program manual]. Berkeley: University of California press. 
Glass, G. V., Willson, V. I., G Gottman, J. M. (1975). Design and Analysis of Time Series Experiments. Boulder: colorado Assoc. Univ. Press.

Gottman, J. M. (1981). Time series analysis: A comprehensive introduction for social scientists. New York: Cambridge University Press.

Harrop, J. W., \& Velicer, W. F. (1990). Computer programs for interrupted time series analysis: II. A quantitative evaluation. Multivariate Behavioral Research, 25,233-248.

Hartley, H. O. (1958). Maximum likelihood estimation from incomplete data. Biometrics, 14, 174-194.

Harvey, A. C., E Pierse, R. G. (1984). Estimating missing observations in economic time series. Journal of the American Statistical Association, 79, 125-131.

Jones, R. H. (1980). Maximum likelihood fitting of ARMA models to time series with missing observations. Technometrics, 22, 389-396.

Kalman, R. E. (1960). A new approach to linear filtering and prediction problems. Journal of Basic Engineering, 82,34-35.

Kohn, R., \& Ansley, C. F. (1986). Estimation, prediction, and interpolation for ARIMA models with missing data. Journal of the American Statistical Association, 81, 751-761.

Laird, N. M. (1988). Missing data in longitudinal studies. Statistics in Medicine, 7, 305-315. 


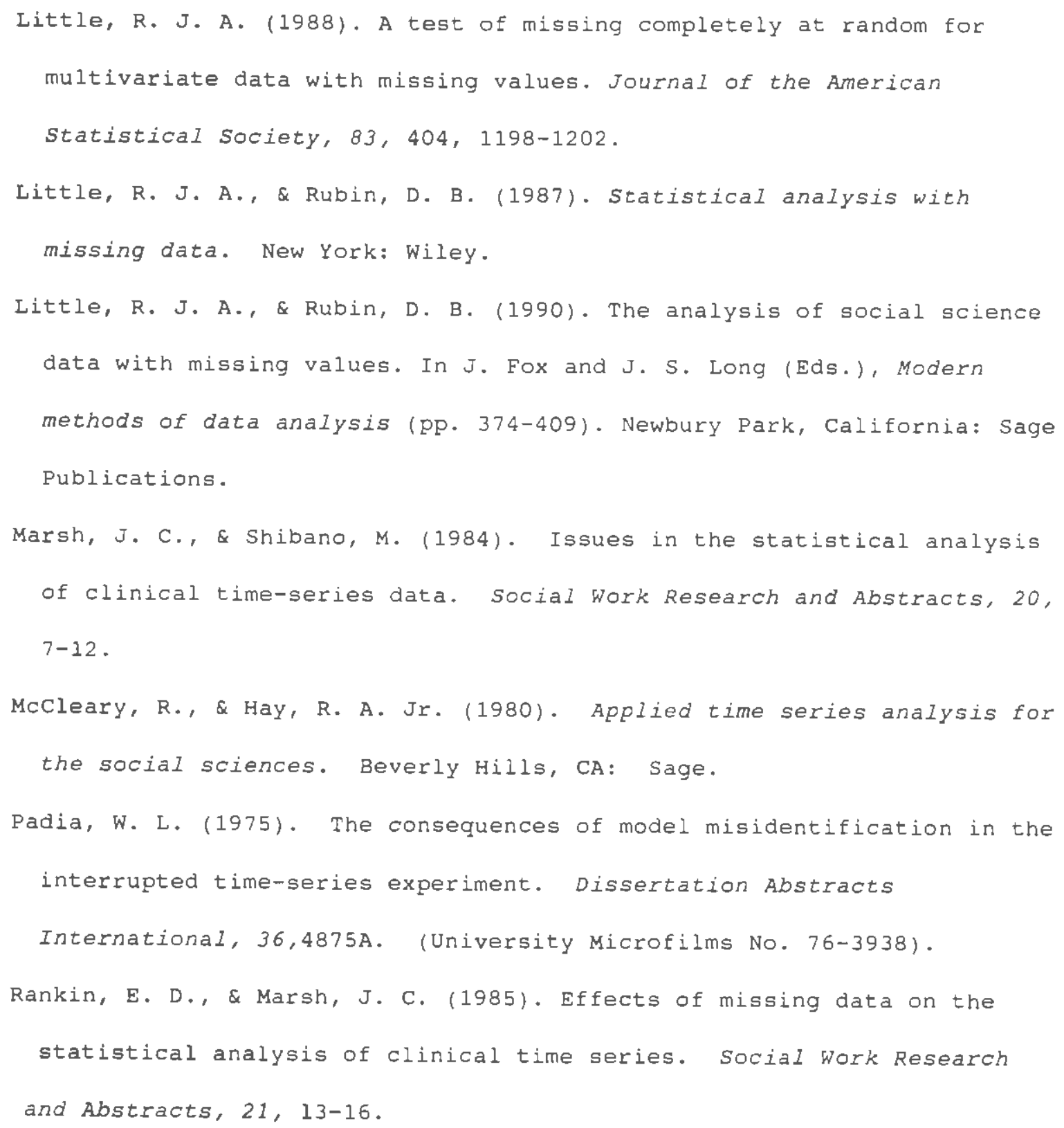


Revenstorf, D., Kessler, A., Schindler, L., Hahlweg, K., \& Bluemner E. (1980). Time series analysis: clinical applications evaluating intervention effects in diaries. In O. D. Anderson (Ed.), Analyzing Time Series: Proceedings of the International conference held on Guernsey, Channel Islands, October, 1979 (pp. 291-312). Amsterdam: North-Holland.

Rubin, D. B. (1976). Inference and missing dăta. Biometrika, 63, 581592.

SAS Institute InC. (1988). SAS/ETS user's guide, version 6, first edition. Cary, NC; SAS Institute Inc.

Simonton, D. K. (1977). Cross-sectional time-series experiments: Some suggested statistical analyses. Psychological Bulletin, 84, 489-502. SPSS, Ine. (1988). SPSS-X Trends. [Computer program manual]. Chicago, IL: SPSS, Inc.

Suen, H. K. (1987). On the epistemology of autocorrelation in applied behavior analysis. Behavioral Assessment, 9,113-124.

Swaminathan, H., \& Algina, J. (1977). Analysis of quasi-experimental time-series designs. Multivariate Behavioral Research, 12, 111-131. Tabachnick B. G., \& Fidell, L. S. (1989). Using multivariate statistics. New York, NY: Harper \& Row.

velicer, W. F., \& Harrop, J.W. (1983). The reliability and accuracy of time series model identification. Evaluation Review, 7, 551-560.

Velicer, W. F., \& McDonald, R. P. (1984). Time series analysis without model identification. Multivariate Behavioral Research, 19, 33-47. 